University of Rhode Island

DigitalCommons@URI

Open Access Master's Theses

2013

\title{
Rhode Island Aquaculturists' Perceptions of Eco-Labeling Certification Programs
}

Nicole DeAngelis

University of Rhode Island, ndeangelis89@gmail.com

Follow this and additional works at: https://digitalcommons.uri.edu/theses

\section{Recommended Citation}

DeAngelis, Nicole, "Rhode Island Aquaculturists' Perceptions of Eco-Labeling Certification Programs" (2013). Open Access Master's Theses. Paper 8.

https://digitalcommons.uri.edu/theses/8

This Thesis is brought to you for free and open access by DigitalCommons@URI. It has been accepted for inclusion in Open Access Master's Theses by an authorized administrator of DigitalCommons@URI. For more information, please contact digitalcommons-group@uri.edu. 


\title{
RHODE ISLAND AQUACULTURISTS' PERCEPTIONS OF ECO-LABELING CERTIFICATION PROGRAMS
}

\author{
BY \\ NICOLE DEANGELIS
}

A THESIS SUBMITTED IN PARTIAL FULFILLMENT OF THE REQUIREMENTS FOR THE DEGREE OF

MASTER OF ARTS

IN

MARINE AFFAIRS

UNIVERSITY OF RHODE ISLAND

2013 


\title{
MASTER OF ARTS IN MARINE AFFAIRS THESIS
}

OF

NICOLE DEANGELIS

\begin{abstract}
APPROVED:
Thesis Committee:

Major Professor: Tracey Dalton

Rick Burroughs

Graham Forrester
\end{abstract}

Nasser H. Zawia

DEAN OF THE GRADUATE SCHOOL

UNIVERSITY OF RHODE ISLAND

2013 


\begin{abstract}
Eco-labeling is a communication tool that allows producers to demonstrate to consumers that they comply with a set of environmental and social criteria by placing an eco-label on their product. Since global aquaculture production is increasing and bivalve mollusks comprise a large share of the world aquaculture production, ecolabeling certification has been suggested as a tool for creating a market for products that are produced with minimal negative environmental and social impacts. Because eco-labeling certification programs for bivalve aquaculture are currently voluntary in the United States, producers' opinions of these programs influence their current and future involvement in these programs.

Rhode Island (RI), where aquaculturists almost exclusively raise bivalves, provided a valuable case study for understanding aquaculturists' opinions of ecolabeling certification programs for shellfish aquaculture. The primary objective of this study was to investigate RI bivalve mollusk aquaculturists' perceptions of eco-labeling certification programs to explore the potential role of eco-labeling in RI aquaculture. To meet this objective, the study focused on four research areas to 1.) gather basic characteristics of RI aquaculture producers, farms and products; 2.) learn if RI aquaculturists participate or plan to participate in eco-labeling programs, and their perceptions of eco-labeling; 3.) discover perceived incentives and disincentives for participation in eco-labeling programs; and 4.) understand how RI aquaculturists feel about government regulations of aquaculture. To explore these research areas, the researcher interviewed twelve RI aquaculturists, in which participants were asked a
\end{abstract}


combination of open- and closed-ended questions. Data in this study was summarized by descriptive statistics and open-ended questions were coded by themes that emerged.

Results showed that while nearly all respondents support eco-labeling programs, none of the respondents currently participate in eco-labeling certification programs, and only one aquaculturist plans to seek eco-labeling certification within the next five to ten years. This study found that most aquaculturists were unaware of the eco-labeling programs available for aquaculture and unsure about how they would choose between certification programs. Most aquaculturists would be more likely to certify their products with an eco-label if their competitors sought certification and most aquaculturists would be more likely to seek certification if they were involved in developing the certification standards. Obtaining a price premium from certification was the strongest incentive for participation in eco-labeling programs, while certification costs and additional recordkeeping required for certification were identified as the strongest disincentives. Management recommendations were provided for eco-labeling certification programs, aquaculturists, academics, and government regulators, as well as recommendations for future studies. 


\section{ACKNOWLEDGEMENTS}

Financial support for this research was provided by the Coastal Institute Graduate Fellowship program. There are a number of people who made this research possible. I wish to thank my major professor, Dr. Tracey Dalton, for her invaluable guidance, kindness, and support throughout my graduate career. This work would not have been possible without her encouragement. I wish to thank my committee members, Dr. Rick Burroughs and Dr. Graham Forrester, for their insight and the knowledge they helped me gain throughout my graduate studies. I also wish to thank my defense chair, Dr. Carlos Garcia-Quijano for his comments and help during the defense process. Special thanks go to Dave Alves, Dave Beutel, Barry Costa-Pierce, Dale Leavitt, and Bob Rheault for their professional insight and advice. My gratitude is also expressed to the participants in my study, whose input made this research possible. I would also like to thank my fellow graduate students for their friendship and support.

I especially want to thank my parents, Frank and Donna, and my sister, Marissa, for their love and encouragement. I owe a great deal of gratitude to all of my friends, especially James, who supported me and believed in me. 


\section{TABLE OF CONTENTS}

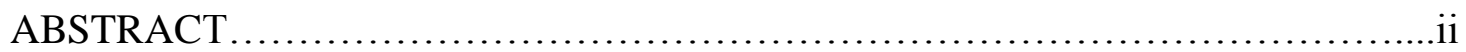

ACKNOWLEDGEMENTS.................................................. iv

TABLE OF CONTENTS ..................................................

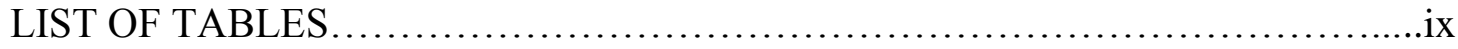

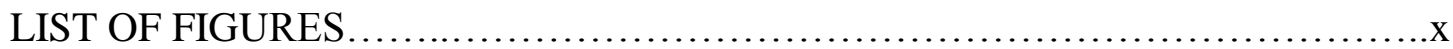

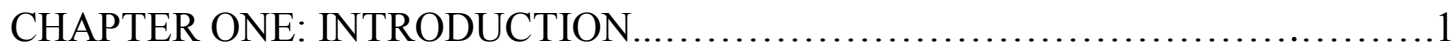

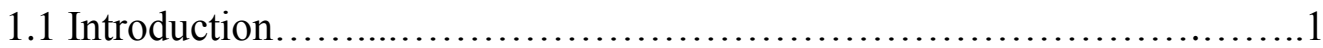

1.2 Sustainable Aquaculture and Eco-labeling..........................4

1.3 Research Questions..............................................6

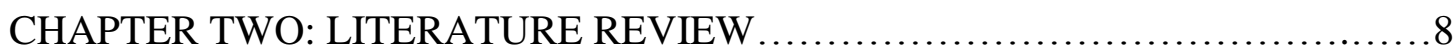

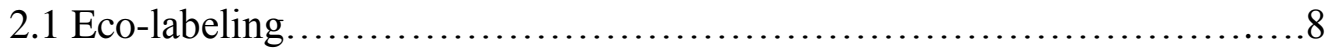

2.2 Bivalve Mollusk Aquaculture.....................................11

2.2.1 Impacts of Bivalve Aquaculture..........................12

2.3 Bivalve Mollusk Aquaculture in Rhode Island......................... 16

2.3.1 Rhode Island Aquaculture Farms............................18

2.3.2 Regulation of Bivalve Aquaculture in Rhode Island............21

2.4 Seafood Eco-labeling and Marketing Campaigns........................23

2.5 Bivalve Mollusk Aquaculture Eco-labels............................26

2.5.1 Organic Eco-labels.........................................31

2.6 Bivalve Mollusk Industry Best Management Practices..................32

2.6.1 East Coast Shellfish Growers’ Best Management Practices.......34 
2.7 Local Labels and Direct-Farm Sales...................................36

2.8 First-Party Labels and Marketing ....................................38

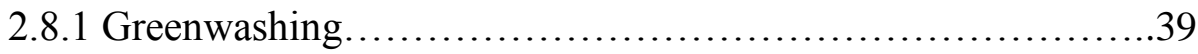

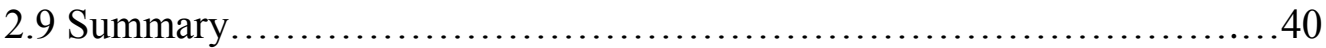

CHAPTER THREE: METHODOLOGY ....................................42

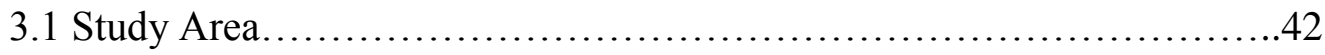

3.2 Data Collection.........................................................

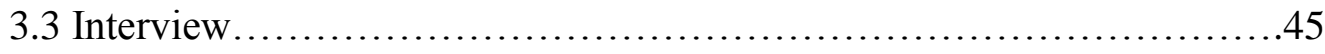

3.4 New Ecological Paradigm...........................................47

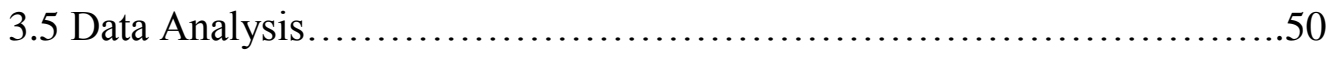

3.5.1 New Ecological Paradigm Data Analysis.........................51

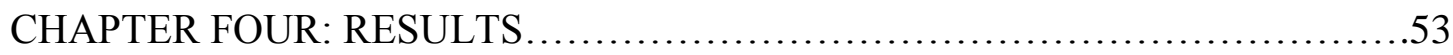

4.1 Response Rate.................................................. 53

4.2 Characteristics of RI Aquaculture Producers, Products, and Farms.........54

4.2.1 Respondents' Personal Characteristics.........................54

4.2.2 Involvement in Aquaculture Organizations.....................55

4.2.3 New Ecological Paradigm......................................56

4.2.4 RI Aquaculture Farms and Products...........................62

4.2.5 Communication with Buyers and End Users....................65

4.2.6 Product Marketing............................................66

4.2.7 Methods of Aquaculture Production...............................66

4.2.8 Perceived Aquaculture Impacts.............................67 
4.3 RI Aquaculturists' Participation in and Perceptions of Eco-labeling

Programs.

4.3.1 Basic Characteristics and Intention to Participate in Eco-labeling

Programs....................................................... 73

4.4 Perceived Incentives and Disincentives of Eco-labeling Programs...........75

4.5 RI Aquaculturists' Opinions of Government Regulations for

Aquaculture.................................................... 79

CHAPTER FIVE: DISCUSSION ......................................... 84

5.1 Relationship of Producer, Farm, and Product and Intention to Participate in

Eco-labeling............................................................ 84

5.2 Relationship of Environmental Concern with Stakeholder Characteristics

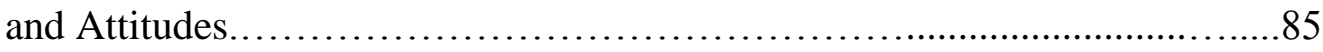

5.3 Communication with Buyers and the Local Food Movement....................89

5.4 Lack of Awareness of Eco-labeling Programs.......................................99

5.5 Perceived Incentives and Disincentives of Eco-labeling Programs............94

5.5.1 Price Premiums and Certification Cost.....................................96

5.6 Government Regulations of Aquaculture in Rhode Island.......................98

5.6.1 Government Regulations and Eco-labels...............................100

5.7 Recommendations..................................................... 101

5.7.1 Management Recommendations...............................101

5.7.2 Recommendations for Future Studies........................103

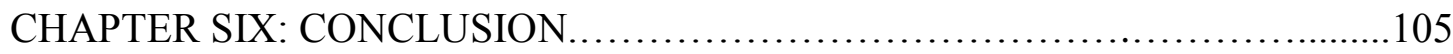

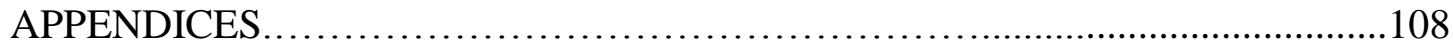


Appendix A: Methods of Bivalve Culture.

Appendix B: Standards for selected aquaculture eco-labeling certification

programs.......................................................... 111

Appendix C: Recruitment letter....................................113

Appendix D: Follow-up postcard....................................114

Appendix E: Interview questions...................................115

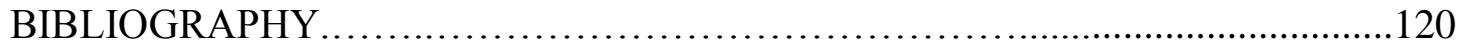




\section{LIST OF TABLES}

Table 1: Characteristics of selected aquaculture eco-labeling programs.............28

Table 2: Consumer labels of selected aquaculture eco-labeling programs............29

Table 3: Motivations for entering the aquaculture industry........................54

Table 4: Descriptive statistics of RI aquaculturists............................55

Table 5: Responses to New Ecological Paradigm statements.........................58

Table 6: Responses to five facets of New Ecological Paradigm statements.............59

Table 7: NEP Scores by education level.....................................60

Table 8: NEP Scores by intention to participate in eco-labeling programs............61

Table 9: NEP Scores by the participant's years of experience in aquaculture.........61

Table 10: Descriptive statistics of respondents' aquaculture farms..................62

Table 11: Aquaculturists' interactions with buyers..............................65

Table 12: Positive impacts of shellfish aquaculture............................67

Table 13: Negative impacts of shellfish aquaculture...........................68

Table 14: Important criteria for selection of an eco-labeling program...............73

Table 15: Intention to participate in eco-labeling programs in the next five years by annual oyster seed amount................................................ 74

Table 16: Intention to participate in eco-labeling programs in the next five years by

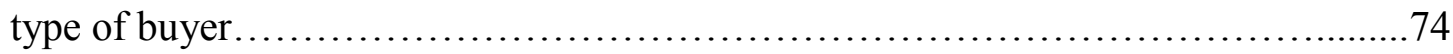

Table 17: Participants' willingness to participate in eco-labeling certification programs

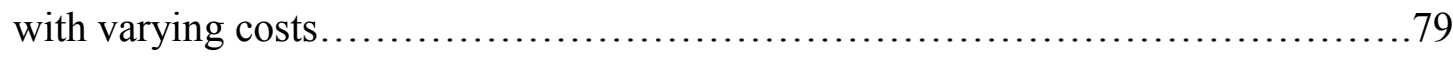




\section{LIST OF FIGURES}

Figure 1: Annual production in million tonnes of world capture fisheries and

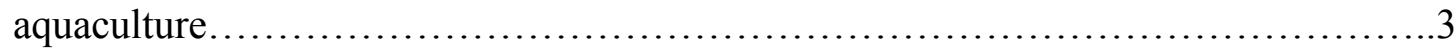

Figure 2: Location of Rhode Island in United States........................... 16

Figure 3: RI Shellfish aquaculture production.............................. 17

Figure 4: Map of RI south shore watersheds............................... 19

Figure 5: Aquaculture lease sites in Ninigret Pond, RI........................20

Figure 6: Supplemental interview form with NEP statements.....................48

Figure 7: RI Aquaculturists' involvement in aquaculture organizations.............56

Figure 8: Characteristics of cultured products in RI............................64

Figure 9: Summary of questions pertaining to participation in eco-labeling

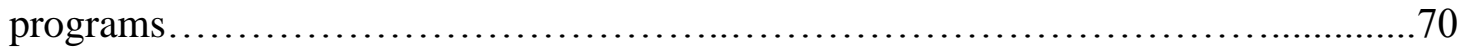

Figure 10: Summary of questions pertaining to perceptions of eco-labeling

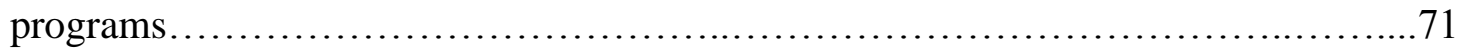

Figure 11: Summary of perceived incentives for participation in eco-labeling

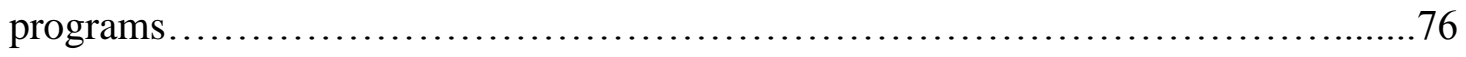

Figure 12: Summary of perceived disincentives for participation in eco-labeling

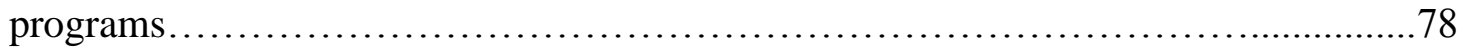

Figure 13: RI Aquaculturists' opinions of government regulations of aquaculture......81 


\section{CHAPTER ONE}

\section{INTRODUCTION}

\subsection{Introduction}

Eco-labeling is a tool that conveys to a buyer that a particular product, producer, and/or supply chain meets some environmental standard. Some eco-labeling programs also include standards with social criteria. Producers are able to demonstrate to consumers that they have met a set of environmental and social criteria by placing an eco-label on their product. Certified and eco-labeled products have been identified as one of the fastest growing food markets globally (Pelletier and Tyedmers, 2008). There are about 600 eco-labels worldwide, certifying all types of products including produce, timber, tourism, and seafood (Eilperin, 2010). Reports indicate $15 \%$ of bananas, $12 \%$ of wild fish products, $10 \%$ of timber, and $7 \%$ of coffee traded in international markets are certified with eco-labels by groups like the Marine Stewardship Council and the Forestry Stewardship Council (Eilperin, 2010). The purpose of these eco-labeling certification programs is to create a market for products that are produced with minimal negative environmental and social impacts. These products are distinguished from others in the marketplace with an eco-label readily recognized and trusted by consumers. This thesis will focus on eco-labels for cultured bivalve mollusks.

The phylum Mollusca is an important group in the animal kingdom and there are six classes of mollusks (Gosling, 2003). One class of mollusks is Bivalvia, which 
is comprised of filter-feeding animals with two shell valves (Gosling, 2003). This bivalve class elicits substantial public interest because people consume many members of the bivalve class, such as oysters, mussels, scallops, and clams (Gosling, 2003). As such, fishing and aquaculture of bivalves are important industries in the United States and around the world.

Aquaculture is defined as the "farming of aquatic organisms, including finfish, shellfish (mollusks and crustaceans) and aquatic plants," while mariculture is defined as "saltwater aquaculture, including coastal and offshore aquaculture operations as well as saltwater pond and tank systems [including] salmon and mollusk farms" (p. iii, Goldburg et al., 2001). Since bivalves are raised in saltwater, using either term is appropriate when applying these definitions, as mariculture is the saltwater subset of aquaculture. Therefore, these terms will be used interchangeably throughout this thesis. Since this thesis focuses on bivalve mollusks, the use of the word "shellfish" will pertain to bivalves in particular unless specified otherwise.

Aquaculture has been referred to as an inevitable, fast growing industry (Frankic and Hershner, 2003). Since wild fisheries are variable and some are overexploited, an increasing demand for fish products has led to a rise in aquaculture production worldwide (Costa-Pierce, 2003). While landings from wild capture fisheries have remained relatively constant in recent years, aquaculture is contributing an increasing share of the total amount of fish products worldwide (FAO, 2012)

(Figure 1). 
Figure 1: Annual production in million tonnes of world capture fisheries and aquaculture (Source: FAO, 2012)

World capture fisheries and aquaculture production

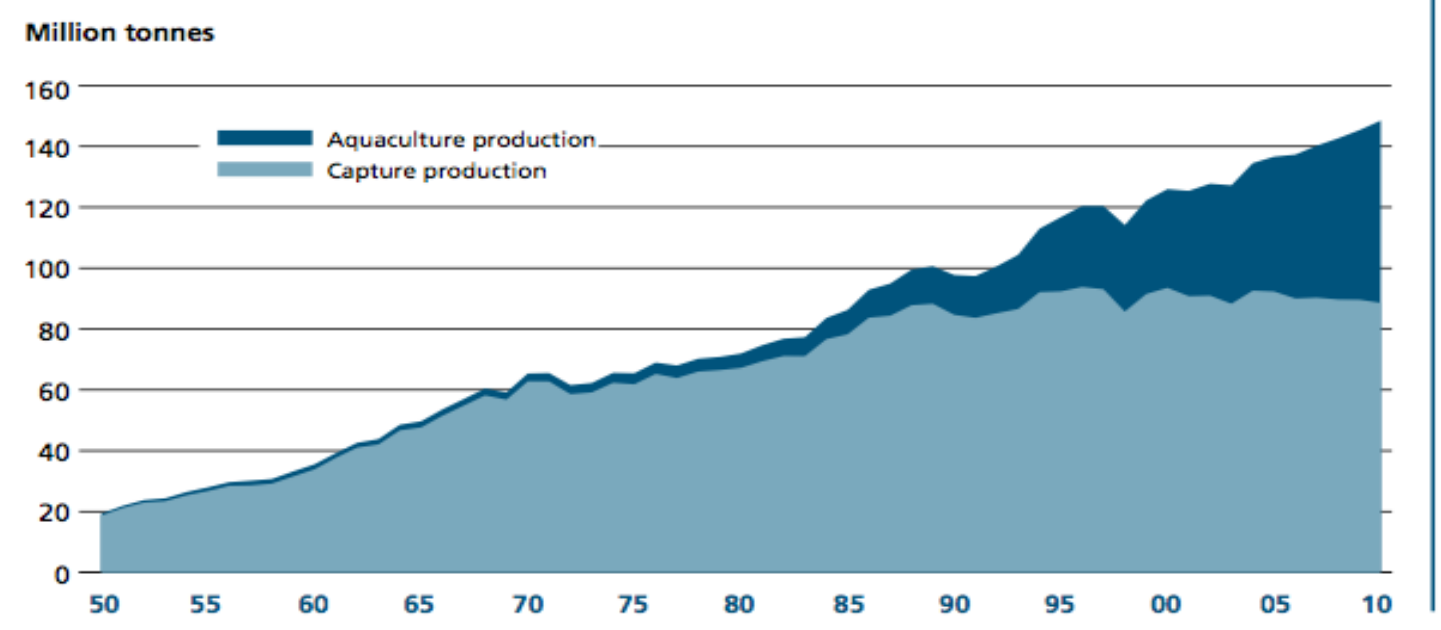

Years

In 2010, world aquaculture production (including marine and fresh water aquaculture) was comprised of 56.4 percent freshwater fishes, 23.5 percent mollusks, 9.6 percent crustaceans, 6.0 percent diadromous fishes, 3.1 percent marine fishes, and 1.4 percent other aquatic animals (FAO, 2012). Marine aquaculture production was dominated by marine mollusks in 2010, as mollusks made up 75.5 percent of cultured marine water production (FAO, 2012). Since mollusk aquaculture comprises a large share of the world and marine aquaculture production, increasing attention will likely be paid to the impacts of mollusk aquaculture as global aquaculture production grows. 


\subsection{Sustainable Aquaculture and Eco-labeling}

Bivalve aquaculture is recognized as an attractive form of aquaculture because as filter feeders, bivalves rely on natural sources of food and do not require the addition of artificial food supplements during culture (Gibbs, 2007). As such, shellfish aquaculture has been praised as a relatively sustainable type of aquaculture (Shumway et al., 2003). The National Oceanic and Atmospheric Administration (NOAA) recently emphasized the importance of sustainability in aquaculture, writing that the purpose of its Marine Aquaculture Policy is to "enable the development of sustainable marine aquaculture" (NOAA, 2011). Listed goals pertaining to sustainable aquaculture include providing domestic jobs, making aquaculture compatible with other uses, addressing the need for advanced scientific knowledge of sustainable aquaculture, advancing public understanding of sustainable aquaculture practices, and encouraging science-based best practices of sustainable aquaculture (NOAA, 2011). Unfortunately, "sustainable aquaculture" is not explicitly defined in NOAA's Marine Aquaculture Policy (NOAA, 2011).

Sustainability has been defined in many ways, including the well-known definition of "meet[ing] the needs of the present without compromising the ability of future generations to meet their own needs" (WCED, 1987). Without consensus regarding the concept of sustainability and what it should include, it is difficult to establish criteria for attaining sustainability in various industries, particularly in aquaculture (Frankic and Hershner, 2003). Since sustainability is perceived in different ways and aquaculture is a diverse industry, balanced and informed approaches are required to define and achieve sustainability in aquaculture (FAO, 
1997). Sustainable aquaculture would ideally consider spatial and temporal dimensions of environmental, economic, and social parameters (Frankic and Hershner, 2003).

Eco-labeling certification has been suggested as a strategy to assess and ensure the sustainability of a variety of products, including aquaculture products (Frankic and Hershner, 2003; Parkes et al., 2010; Bratt et al., 2011; FAO, 2012). Eco-labels are an instrument used to communicate environmental and social product information so consumers may make informed choices and producers can advertise their sustainability efforts (Bratt et al., 2011). Consumers may promote sustainable resource use by choosing to purchase eco-labeled and certified products (FAO, 2012) and producers may make their operations more sustainable in order to meet certification criteria. Reports indicate that the scope of sustainability criteria used by certification schemes is expanding (Parkes et al., 2010). Eco-labeling certifications can provide a standardized measure of sustainability, important for international trade (FAO, 2012).

As the number of eco-labeling certification programs for seafood increases (Parkes et al., 2010) and global aquaculture production increases (FAO, 2012), increasing attention will likely be paid to eco-labeling certification programs for aquaculture as a method for assessing and minimizing the negative impacts of aquaculture and as a tool for promoting the sustainability of aquaculture products. Since eco-labeling certification programs are voluntary at this time, producers' opinions of these programs influence their current and future involvement in these programs. 


\subsection{Research Questions}

Rhode Island (RI), where aquaculturists almost exclusively raise shellfish (Beutel, 2011), provides a valuable case study for understanding aquaculturists' opinions of eco-labeling certification programs for shellfish aquaculture. The primary objective of this study is to investigate RI bivalve mollusk aquaculturists' perceptions of eco-labeling certification programs to explore the potential role of eco-labeling in RI aquaculture. To meet this objective, I examined the following research questions in this study:

1. What are basic characteristics of RI aquaculture producers, farms, and products?

2. Do RI aquaculturists participate or plan to participate in eco-labeling certification programs, and what are their perceptions of eco-labeling?

3. What are the perceived incentives and disincentives to RI aquaculturists for participation in eco-labeling certification programs?

4. How do RI aquaculturists feel about government regulations of aquaculture?

This research will contribute to the knowledge of eco-labeling programs by gaining a producer perspective of eco-labeling programs for aquaculture.

Chapter two of this thesis reviews the literature on eco-labeling, bivalve mollusk aquaculture with a focus on bivalve aquaculture in Rhode Island, governance of bivalve aquaculture, cultured bivalve eco-labeling, organic eco-labeling, local labels, and industry best practices for bivalve culture. Chapter three describes the methodology used in this study. It describes the study area, methods of data collection, interview techniques, and methods of data analysis, and highlights the New Ecological Paradigm used in this study. Chapter four presents the results, in order of the four research questions. Chapter five discusses important selected findings, provides suggestions for future studies, and concludes with recommendations for eco-labeling 
certification programs, aquaculturists, academics, and government regulators. Chapter six concludes with final thoughts, highlighting the growth of the aquaculture industry worldwide and the potential role of eco-labeling certification programs to assess the impacts of aquaculture. 


\section{CHAPTER TWO}

\section{LITERATURE REVIEW}

This chapter serves as a review of selected literature on eco-labeling, bivalve mollusk aquaculture with a focus on bivalve aquaculture in Rhode Island, governance of bivalve aquaculture, cultured bivalve eco-labeling, organic eco-labeling, local labels, and industry best practices for bivalve culture.

\subsection{Eco-labeling}

Eco-labeling can rely on first-party verification, in which marketers promote social or environmental attributes of their own products, or third-party verification, in which an independent source awards labels based on determined social or environmental criteria (US EPA, 1998). Nongovernmental organizations, public agencies, buyers, marketing groups, or other interested third parties may develop certification standards (Peterson et al., 2010). Governments set mandatory standards in the form of regulations, whereas voluntary standards are created by NGOs, industry associations, and public-private partnerships and are often verified with third-party auditing (Giovannucci and Ponte, 2005). Eco-label certification criteria are typically

voluntary standards. As the world moves from national capitalism to the current age of global capitalism, new actors like NGOs and industry associations are beginning to replace or supplement the classic boundaries of governmental authority to provide new types of standards, such as sustainability standards (Giovannucci and Ponte, 2005). 
Nongovernmental entities have proposed solutions, such as eco-labeling programs, to environmental problems when nation-States have failed or have been perceived to fail to solve those environmental problems (Constance and Bonanno, 2000).

Certification has been found to promote social and environmental responsibility (Pelletier and Tyedmers, 2008). A certification from a reputable organization can help hold producers accountable for their environmental and social performance or non-performance (Gulbrandsen, 2008). Benefits of eco-labeling may include encouraging producer responsibility (Bundy, 2008), stimulating environmental accountability (Gulbrandsen, 2008), and providing incentives for best practices and innovation (Pelletier and Tyedmers, 2008). Producers of certified products can expect increased access to markets and price premiums for labeled products (Environmental Law Institute and The Ocean Foundation, 2008).

Unlike price, environmental attributes related to a product's production are difficult for the consumer to assess, so eco-labels help provide consumers with information pertaining to environmental attributes (Wessells et al., 1999). This ability to differentiate among goods and services based on environmental and social attributes facilitates price premiums and expands market access for certified products, providing financial incentives for producers to join certification programs (Blackman and Rivera, 2010). In theory, certification systems can facilitate more direct relationships between producers and consumers (Giovannucci and Ponte, 2005), providing a critical quality assurance role by communicating about sustainability (Bratt et al, 2011). Ecolabeling facilitates communication related "both to the consumers' right to know and 
to the producers' possibilities to reliably communicate their efforts" (p. 1361, Bratt et al., 2011).

Eco-labeling certification programs have received criticisms and these criticisms vary across different programs. A costly burden may be placed on the producer for the certification process and subsequent inspections, both financially and in terms of time (Gulbrandsen, 2005). A high price for certification may exclude smaller operators from marketing their sustainable practices if they cannot afford the certification. Those producers that already meet certification standards have a strong incentive to join certification programs since they do not need to make additional investments to meet the standards but can still receive benefits like a price premium once certified, meaning certification programs joined by these producers may have a limited effect on producer behavior and less intended environmental, social, and economic benefits (Blackman and Rivera, 2010).

Some certification programs have been criticized for not using holistic criteria measures, as incomplete standards would not likely meet desired sustainability objectives (Pelletier and Tyedmers, 2008; Thrane et al., 2009; Bratt et al., 2011). Similarly, inconsistencies in what is included in the labeling criteria across programs can increase consumer confusion and reduce trust in labeling programs (Bratt et al., 2011). The success of an eco-label will likely depend on a variety of factors, including consumer characteristics, trust in the labeling agency, geographic region, and the product (Wessells et al., 1999; Johnston et al., 2001). The success of an eco-label will also depend on producers, since programs are usually voluntary and would require 
buy-in from producers. This thesis focuses on producers' perceptions of eco-labeling certification programs for cultured bivalve mollusks.

\subsection{Bivalve Mollusk Aquaculture}

Main bivalve species raised in aquaculture include oysters, mussels, clams, and scallops. There are three main stages of bivalve mollusk cultivation: seed collection, nursery and grow-out, and harvest (Kaiser et al., 1998). Processing could be considered a fourth stage (Quayle and Newkirk, 1989). In the first stage, growers obtain seed from wild or hatchery stock (Quayle and Newkirk, 1989). "Wild stock" spat can be collected from wild stocks or from existing cultured stock using spat

collectors, where bivalve larvae attach themselves to a solid object or surface (Quayle and Newkirk, 1989).

The next stages are nursery and grow-out and each can be conducted in a variety of ways. The nursery stage is considered an intermediate step taken before the grow-out stage, allowing smaller, more vulnerable shellfish to grow in a more protected environment than the grow-out stage (University of Florida, 2012). Some growers like to take part in the nursery stage because purchasing smaller seeds from the hatchery costs less than purchasing larger seeds. Wellers and raceways are common types of nursery systems for raising shellfish. In a weller system, open-ended cylinders with screens to suspend the seeds are placed in a water reservoir, and seawater passes through, providing nutrients to the seeds (University of Florida, 2012). Wellers are called either downwellers or upwellers, depending on the vertical direction of water flow through the system (University of Florida, 2012). Raceway 
systems differ from weller systems in that water is pumped horizontally, rather than vertically, across shallow tanks or trays (University of Florida, 2012). Nursery systems can be built on land or in the water, commonly under docks. Once seeds grow large enough, they are moved to methods used for the grow-out stage.

The grow-out stage allows the bivalve to grow up to a harvestable size and can be performed in a number of ways (Appendix A). For example, oyster culture can be conducted on the bottom, by directly planting oysters on the seafloor, with racks and cages set above the seafloor, or with rafts or long lines that float (Quaye and Newkirk, 1989). The choice of culture method depends on the preference of the grower and features of the site, such as the presence of predators. One might choose an off-bottom method if sea stars or other benthic predators were a concern. The next stage, harvest, depends on the grow-out method selected. For instance, if the grower planted on the bottom, the grower would directly harvest by diving and collecting the mollusk, or with a rake/dredge like wild harvesters, while those growers who use racks would harvest by grading their mollusks by size and selecting appropriately sized mollusks for sale. Processing of the mollusks occurs after harvest, where the grower cleans, prepares, stores, and ships the product.

\subsubsection{Impacts of Bivalve Aquaculture}

The impacts of shellfish aquaculture, which occur at a wide range of spatial and temporal scales, can be determined by the extent of the development relative to the carrying capacity of the ecosystem (Hargreaves, 2011). As it applies to bivalve mariculture, carrying capacity can be defined as: 
"the maximum population of biomass that an area will support sustainably, as set by available space, food, and other potentially limiting resources but within the limits set by the capacity of the ecosystem to process biological wastes and by social tolerance for the change in environmental attributes" (p.12, Peterson et al. 2010).

Both social and environmental carrying capacity models can be applied to mariculture to identify and determine acceptable and unacceptable impacts.

Negative environmental impacts from shellfish aquaculture may include: excessive localized organic loading, decreased planktonic biomass by overstocking, displacement of native species, predation on cultured stocks, introduction and transmission of disease, introduction of nonnative bivalves, and habitat degradation and loss (Peterson et al., 2010). Excessive localized organic loading describes a benthic interaction in which the filter-feeding process of bivalves creates waste, which may alter sediment characteristics and benthic communities underneath shellfish farms (Weise et al., 2009). Decreased planktonic biomass and displacement of native species may occur because bivalve culture relies on natural sources of food, potentially reducing planktonic biomass through filter feeding and potentially displacing other animals in the marine food web by out-competing them for particulate food resources (Gibbs, 2007). Bivalve diseases, such as MSX and Dermo disease, naturally occur at low densities in wild populations, but may spread quickly in mariculture since animals live in high densities, allowing for easier disease transfer (Peterson et al., 2010). Nonnative bivalve species have been purposely introduced in bivalve mariculture if a nonnative species exhibits a faster growth rate or is more resistant to predators, and this introduction of nonnative species can directly and indirectly influence local ecosystems and can unintentionally import other nonnative species ("hitchhikers") (Peterson et al., 
2010). Habitat for some species can be degraded or lost with the introduction of some bivalve mariculture gear, especially off- and on- bottom mariculture gear (Peterson $e t$ al., 2010). Environmental changes caused by shellfish aquaculture can be minimized by using appropriate culture techniques (Kaiser et al., 1998).

Shellfish aquaculture provides a number of ecosystem services including turbidity reduction through filtration, fertilization of benthic habitats through biodeposition, denitrification, stabilization of habitats and shorelines, and habitat production for other marine organisms (Peterson et al., 2010). Bivalves gain nourishment by feeding on suspended particles from the water column, and this filtering reduces turbidity and can allow greater penetration of light, which can help production of some benthic vegetation (Peterson et al., 2010). Biodeposition was described above as a potential negative impact of bivalve aquaculture, but depending on scale, can be a positive effect when the nutrients from the biodeposits and/or excreted nitrogen enhance growth of submerged aquatic vegetation (Peterson et al., 2010). The structures bivalves are raised on and the shells of the bivalves add hard substrate and habitat complexity to ecosystems, increasing species diversity and stabilizing the shoreline (Peterson et al., 2010). With shellfish aquaculture, there is rarely consensus on the most important environmental effects because different stakeholders value impacts differently (Hargreaves, 2011). For this reason, there are often tradeoffs among different environmental impacts.

Although Peterson et al. (2010)'s definition of carrying capacity primarily focuses on environmental attributes, social tolerance is also acknowledged. Recent studies that have gathered public perceptions of shellfish aquaculture may be used to 
determine social carrying capacity (Decanay, 2010). There are both positive and negative social impacts of shellfish aquaculture. Resource use conflict is considered a negative social impact of bivalve aquaculture. Shellfish aquaculture takes place in coastal waters where there are many other uses, such as fishing, recreation, shipping, navigation, and aesthetic enjoyment (Goldburg et al., 2001). In the US, about half of the population lives near coastal and estuarine shores, causing high concentrations of people to use the areas that bivalve mariculture requires (Olin, 2002). This concentration often results in conflicts over coastal resources, which can cause delays or cancellation of proposed projects or force aquaculture sites into areas that may not be the best sites for ecological considerations. Bivalve aquaculture also generates positive social impacts, such as producing fresh food products domestically and providing employment opportunities (Olin, 2002).

Although historically bivalve aquaculture has not been criticized to the extent that finfish or shrimp aquaculture has, some believe this view is changing due to conflicts over competing uses (Dewey et al., 2011). The rapid growth of intensive, feedlot-type aquaculture of carnivorous fish has raised a number of concerns about the sustainability of aquaculture (Costa-Pierce, 2003) and attracted negative media attention. Most well publicized problems of aquaculture address shrimp and salmon aquaculture, whereas shellfish, grazing and omnivorous fish, and marine-plant cultures are addressed less frequently (Costa-Pierce, 2002). Critics of aquaculture often do not address finfish and shellfish aquaculture separately, which tends to promote overall negative attitudes toward the entire aquaculture industry (Shumway et al., 2003; Hargreaves, 2011). Certification programs may reduce criticism toward shellfish 
aquaculture by reducing negative environmental impacts and enhancing the positive ecosystem services it provides.

\subsection{Bivalve Mollusk Aquaculture in Rhode Island}

Rhode Island is a state located in New England (Figure 2). The Coastal Resources Management Council (RI CRMC), the lead agency regulating aquaculture in Rhode Island, releases a bi-annual report on the state of aquaculture in RI. As of 2011, with the exception of one marine ornamental fish operation, all aquaculture operations in Rhode Island raise bivalve shellfish (Beutel, 2011). The American oyster, Crassostrea virginica, is the most dominant species in RI aquaculture, with over 4 million pieces sold in 2011, followed by hard clams, Mercenaria mercenaria, with 58,400 pieces sold in 2011 (Beutel, 2011). Although some farmers culture other animals like hard clams, the American oyster accounts for 99 percent of total animals sold and dollar value of RI harvest (Alves, 2007). By quantity, oyster production in RI is increasing substantially, while clam production has declined to negligible amounts and since remained relatively stable over the past decade (Beutel, 2011) (Figure 3).

Figure 2: Location of Rhode Island in United States (Source: USGS, 2003).

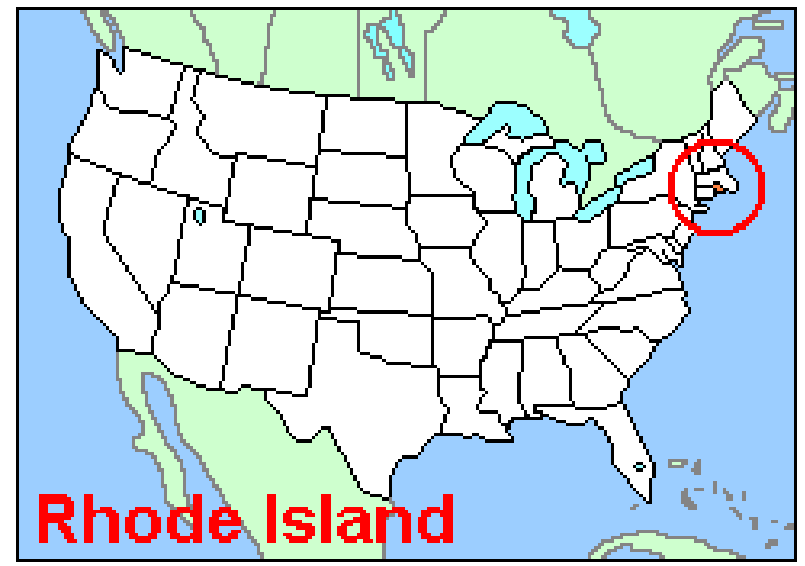




\section{Figure 3: RI Shellfish aquaculture production (pieces sold v. years) (Source: Beutel, 2011).}

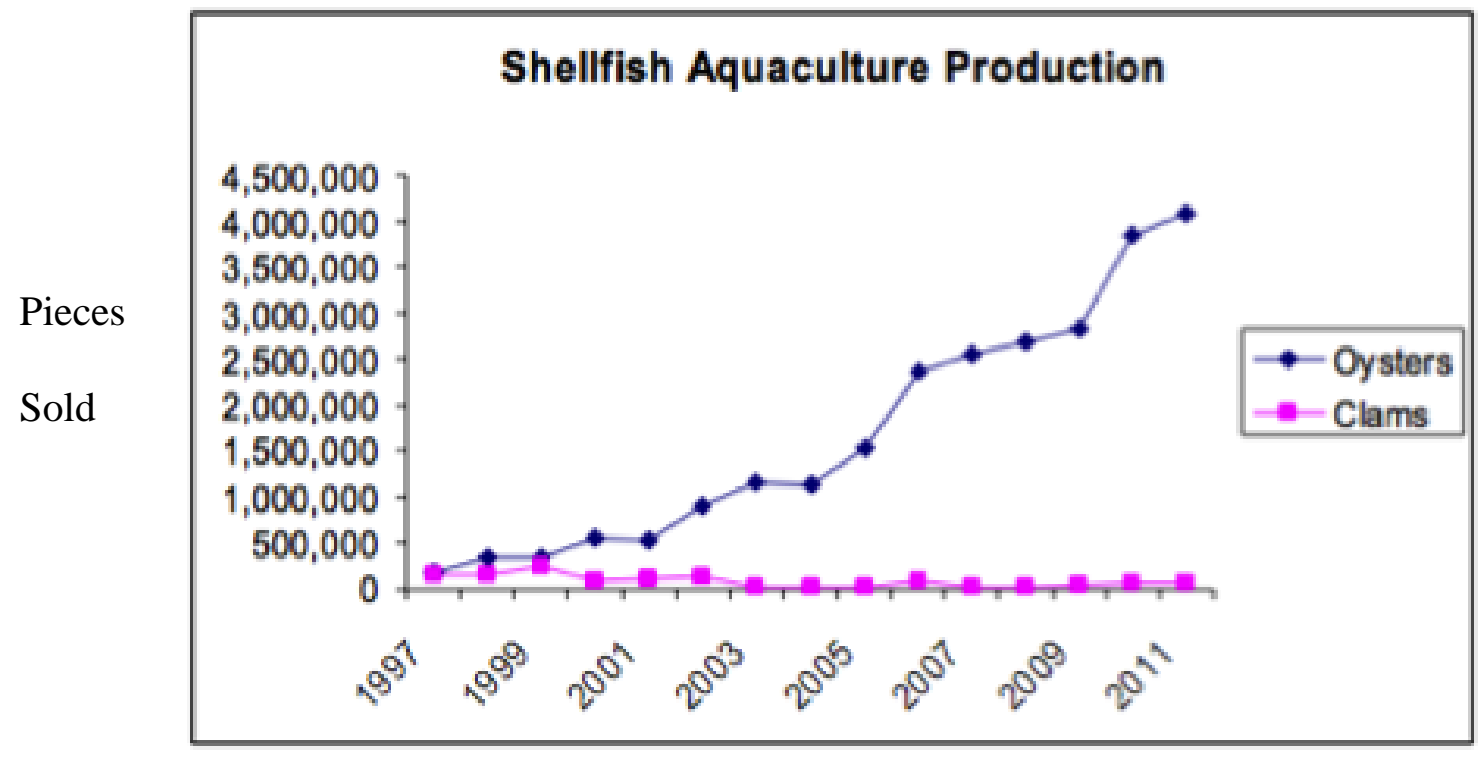

\section{Years}

RI's aquaculture is mostly limited to shellfish production, and is small in comparison to the industries of neighboring Connecticut and Massachusetts (Rhode Island Aquaculture Initiative, 2004). According to agricultural census data, Rhode Island has fewer aquaculture farms than Massachusetts, Maine, Connecticut, New York, and New Jersey (USDA and NASS, 2006). Although other states have larger coastlines than Rhode Island, there are other factors that may also contribute to the lower number of aquaculture farms in Rhode Island. For instance, Rhode Island has "high tax rates, energy costs, land costs, labor costs, costly bureaucracy, and a weakening infrastructure" which makes RI a less desirable place for firms to invest in aquaculture (p. 39, Anderson, 1998).

Similarly, Rhode Island has more persons per square mile than the US average and is the country's second most densely populated state (US Census, 2010). High 
population density in RI may lead to more user conflicts than other coastal states with aquaculture. High population density also causes the market value of land and buildings on farms in Rhode Island to be among the highest in the country (USDA, 2007). High land value makes the purchase of land and buildings for aquaculture operations expensive in RI (Anderson, 1998). These factors may contribute to Rhode Island ranking near the bottom of the 50 states in aquaculture production (Rhode Island Aquaculture Initiative, 2004).

\subsubsection{Rhode Island Aquaculture Farms}

RI CRMC reports that the number of aquaculture farms, total acreage under cultivation, and farm gate values of aquaculture products for consumption have all increased in recent years (Beutel, 2011). As of 2011, there are 43 farms in RI and RI aquaculture production occurs in Narragansett Bay, off of Block Island, and in RI's south shore salt ponds (Beutel, 2011). Aquaculture farms cover 160.3 acres in Rhode Island waters, with farms in Narragansett Bay and off of Block Island covering 85.1 acres and other south coastal ponds covering 75.2 acres (Beutel, 2011). The relevant south coastal ponds that have aquaculture farms are Ninigret Pond, Potters Pond, Point Judith Pond, and Winnapaug Pond (Beutel, 2011) (Figure 4). Shapes and sizes of aquaculture lease sites vary in RI (Figure 5). Productivity in the south shore salt ponds allows for successful shellfish growth (Rhode Island Aquaculture Initiative, 2004). Water quality is particularly important for raising shellfish, as they require ample amounts of food to filter. The water quality in Rhode Island sounds, Narragansett Bay, 
and Block Island contribute to quality shellfish products in RI (Rhode Island Aquaculture Initiative, 2004).

Figure 4: Map of RI south shore watersheds (Source: Rhode Island Sea Grant, 2012).

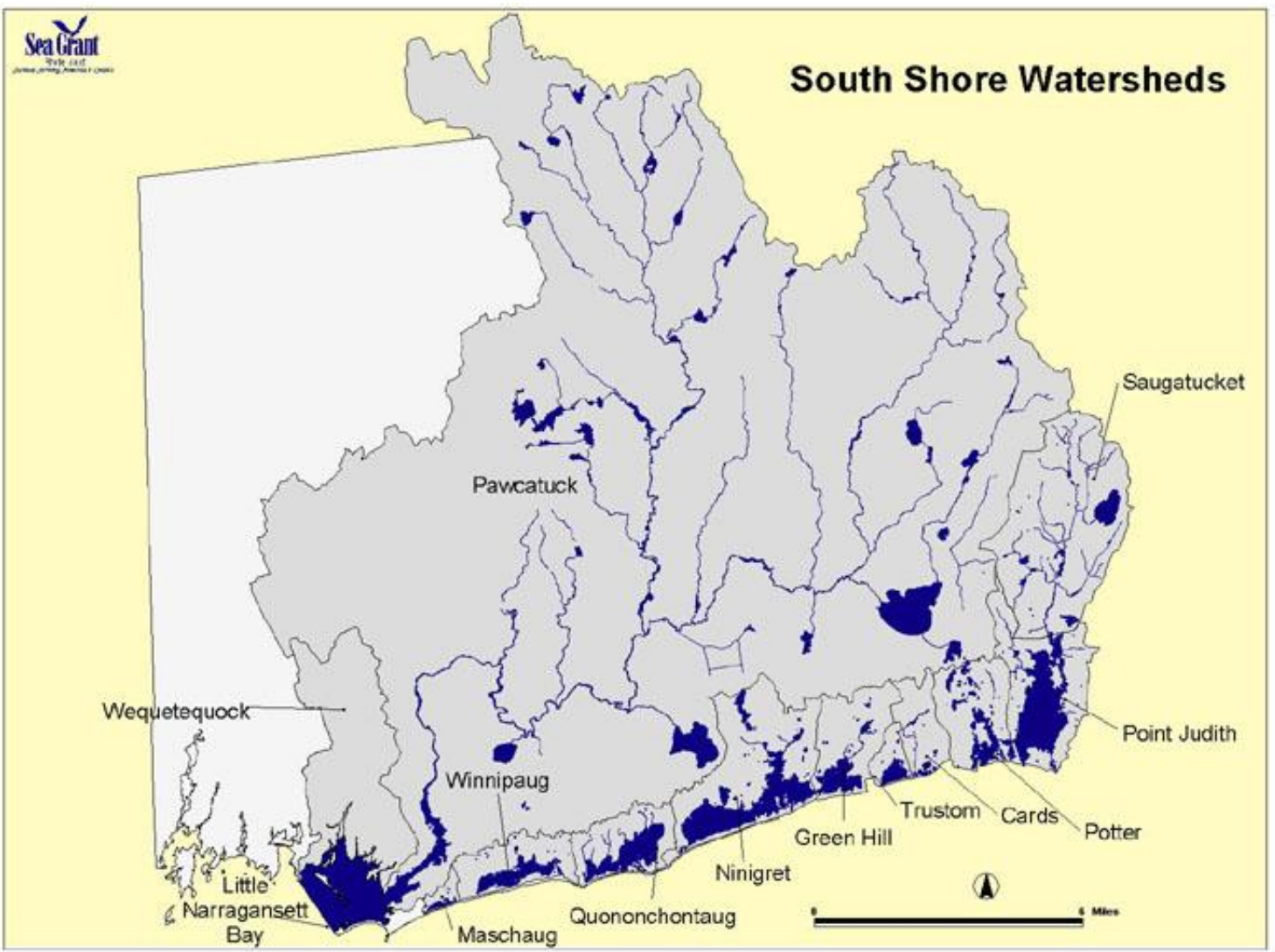


Figure 5: Aquaculture lease sites in Ninigret Pond, RI (Source: Sparks, 2012)

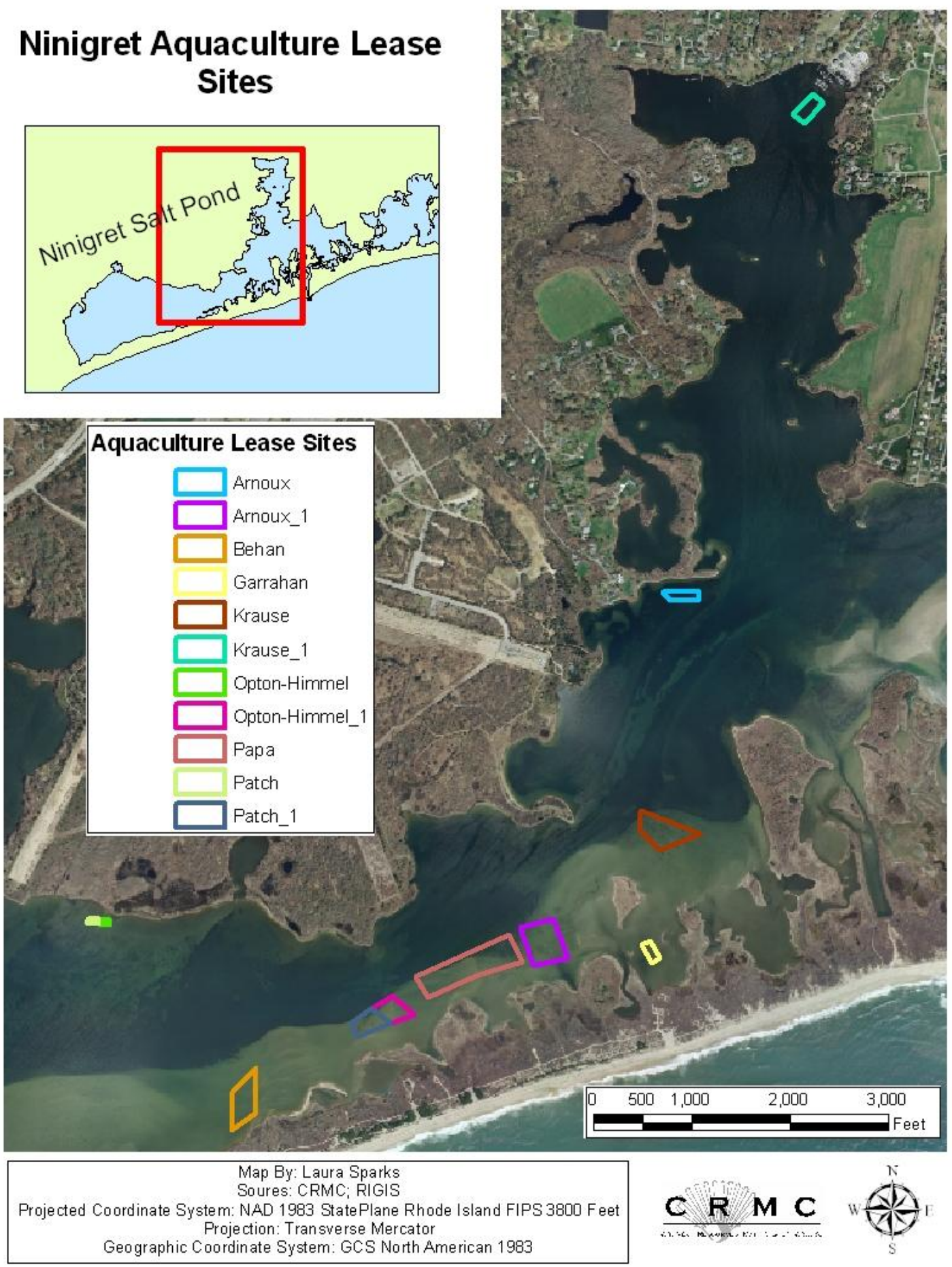


The 2011 percentages of acreage of aquaculture leases in the RI coastal ponds is: $1.01 \%$ of Ninigret Pond, $1.69 \%$ of Winnipaug Pond, $1.91 \%$ of Potters Pond, and $2.86 \%$ of Point Judith Pond (Beutel, 2011). Given that the maximum limit for aquaculture leases in RI coastal ponds is $5 \%$ of the area of each pond (RI CRMC, 2010), RI is not producing its maximum allowable amount of aquaculture products and there is great potential for continued growth. In fact, a recent study found cultured oyster biomass could be increased 625 times in Narragansett Bay without exceeding

ecological carrying capacity (Byron et al., 2011). Having acknowledged the need for and value of further aquaculture industry growth, the Rhode Island Aquaculture Initiative created a mandate for growth to assist in the growth, expansion, and diversification of aquaculture in RI (Rhode Island Aquaculture Initiative, 2004). NOAA also recently reinforced the need to expand aquaculture nationally in its 2011 Marine Aquaculture Policy, with one main goal to "encourage and foster sustainable aquaculture development" (p. 1, NOAA, 2011). As bivalve aquaculture is likely to continue to expand in Rhode Island, different mechanisms to ensure that growth is sustainable are worth exploring. Such mechanisms include mandatory government regulation, market approaches like eco-labeling, and industry-created best management practices.

\subsubsection{Regulation of Bivalve Aquaculture in Rhode Island}

Bivalve mariculture in the United States is governed by a complex set of laws, regulations, and policies, with "at least 120 federal laws and more than 1,200 state statutes across 32 states, plus local regulations," affecting mariculture (p. 13, Peterson 
et al., 2010). Bivalve mariculture is typically regulated at the state, county, or town level because estuarine and nearshore coastal waters, which are best suited for bivalve mariculture, are typically controlled by the state (Peterson et al., 2010). State and federal governments impose regulatory standards and compliance with these standards is typically required by law as a condition of the aquaculture permit (Peterson et al, 2010). The management of bivalve mariculture in Rhode Island involves a combination of efforts by federal and state actors.

The Coastal Resources Management Council (RI CRMC) is the primary state body responsible for permitting and regulating aquaculture in Rhode Island waters, as it issues aquaculture permits (RI CRMC, 2010). The RI Department of Environmental Management (RI DEM) and the RI Department of Health (RI DOH) are also involved in the regulation of aquaculture. RI DEM classifies which RI waters are approved for growing shellfish for human consumption and monitors water quality around the farms (RI DEM, 2002). RI DOH, along with RI DEM, monitors aspects of handling and temperature control to ensure shellfish is safe for human consumption (RI DEM, 2002). Federal agencies involved in aquaculture include NOAA, National Marine Fisheries Service, Army Corps of Engineers, Fish and Wildlife Service, Department of Agriculture, Food and Drug Administration, Environmental Protection Agency, and Department of Health and Human Services (AFSIC, 2013).

The first step in the aquaculture permitting process is to choose an appropriate site with suitable water quality, sufficient access to the site, and appropriate bottom type so the intended crop will grow well (RI CRMC, 2012). A suitable aquaculture site will also have minimal conflict with other uses, such as recreational boating or 
harbor activities, and will not be in an area where other fishery activities take place (RI CRMC, 2012). Once a proposed aquaculture site is selected, the grower can either apply for an aquaculture lease and permit or go through a commercial viability process first, in which a prospective grower can conduct a limited study of the proposed site to test if it is suitable for commercial purposes and then apply for a permit (RI CRMC, 2012). The application process begins with a preliminary determination, in which relevant government agencies and the prospective grower meet to discuss the initial proposal and suggestions are given (RI CRMC, 2012). After the preliminary determination, a full application is submitted, a 30-day public comment period begins, and RI CRMC may decide to call a public hearing (RI CRMC, 2012). RI CRMC then votes to approve, deny, or modify the application (RI CRMC, 2012). RI CRMC considers the compatibility with other existing and potential uses of the area, the degree of exclusivity required for the aquacultural activities, the safety and security of the equipment, projected per unit area yield of the product, cumulative impact of the aquaculture activity, the capability of the applicant to carry out the proposed activities, and scenic impacts (RI CRMC, 2010). In order to conduct aquaculture in RI, RI DEM must also determine that the proposed aquaculture activity will not adversely affect adjacent marine life, water quality, or the vitality of wild fisheries in order to grant the grower a required RI DEM Aquaculture License (CRI RMC, 2010).

\subsection{Seafood Eco-labeling and Marketing Campaigns}

Seafood certification programs have emerged due to a perception that regulatory frameworks are not meeting objectives in aquaculture and wild fisheries 
(FAO, 2011b). As such, nongovernmental international organizations, like the Marine Stewardship Council (MSC), have developed certification standards to assess the sustainability of wild fisheries. MSC, the leading seafood eco-label, is limited to wild caught fish and its label cannot be used to certify farmed fish products. One wellknown eco-label was developed in 1990 after consumers became aware that the harvest of tuna caused incidental mortality of dolphins and the "dolphin-safe" tuna label communicates to consumers that dolphins were not killed in the harvest of the tuna product (Teisl et al., 2002). Another well-known eco-label is "turtle-safe" shrimp (Gulbrandsen, 2005) for shrimp fishers that use turtle excluder devices, allowing sea turtles to escape from shrimp nets.

Third-party organizations have launched other types of seafood marketing campaigns that would not necessarily be considered eco-labeling, as they generally advocate for certain species of fish based on the general sustainability of their capture or rearing, rather than certifying a specific harvester or producer. For example, the Blue Ocean Institute publishes a consumer guide for environmentally friendly seafood, including recommendations for both wild and farmed seafood (Blue Ocean Institute, 2012). The Monterey Bay Aquarium launched its Seafood Watch program in 2001 (Sutton and Wimpee, 2008). It includes recommendations for both wild and farmed seafood (Monterey Bay Aquarium, 2012). Since the availability of certified, ecolabeled products is still relatively low, recommendation lists fill an important niche in the market by directing consumers' purchasing of uncertified and unlabeled products (Parkes et al., 2010). 
Buyers of seafood products have developed purchasing policies to support ecolabeled products and have developed their own type of eco-labels. Wegmans Food Markets, a supermarket chain in the northeastern United States, claims to exclusively purchase eco-labeled farmed seafood and Whole Foods Markets, an international supermarket chain, has developed its own standard and label for cultured seafood. Wegmans Food Markets worked with the Environmental Defense Fund, a national environmental advocacy organization, to develop a stringent purchasing policy for farmed seafood (EDF, 2007). On its website, Wegmans reports that it buys fresh tilapia, frozen shrimp (from Thailand), and E.U. organic shrimp (from Ecuador), all three of which are certified with the Global Aquaculture Alliance (Wegmans, 2013). Its website does not list the source(s) of the cultured bivalve products it sells (Wegmans, 2013). Whole Foods Market created its own standard and consumers can only find farmed products that bear its "Whole Foods Market Responsibly Farmed" logo in its stores (Whole Foods Market, 2013). Whole Foods requires their farmed seafood suppliers to pass annual independent third-party audits to ensure the Whole Foods Standards are being met (Whole Foods Market, 2013). On its website, Whole Foods only lists standards for some finfish and shrimp, but does not list standards for bivalves (Whole Foods Market, 2013).

Government agencies have become involved in seafood advocacy, by launching their own educational programs for seafood consumers. NOAA Fisheries maintains a program called FishWatch, which helps educate consumers about various seafood choices by providing seafood profiles for important commercial species (NOAA, 2013c). Some bivalve species like Atlantic sea scallops, Atlantic surfclams, 
and hard clams are included in FishWatch's seafood profiles, while oysters and mussels are not included (NOAA, 2013b). Although the FishWatch website does include a section on farmed seafood that explains basic principles of aquaculture (NOAA, 2013a), the seafood profiles FishWatch provides for various species include information about wild population status, fishing rates, the habitat impacts of fishing for that species, and bycatch associated with the fishery, but does not include information about the culture of those species (NOAA, 2013b). Currently, FishWatch does not advocate between different types of cultured shellfish, since not all major shellfish species have profiles and all of the information in the species profiles refers to wild fishing criteria.

\subsection{Bivalve Mollusk Aquaculture Eco-labels}

Since the Untied States imports far more aquaculture products than it produces, US aquaculture regulations would have a negligible impact on global aquaculture production (Connolly, 2005). For this reason and because domestic regulations would not be able to affect aquaculture practices of other countries, voluntary eco-labeling programs may be preferable to mandatory domestic regulations (Connolly, 2005). Since reaching an international environmental agreement to regulate aquaculture would be difficult, eco-labeling is a strategy that can involve producers from many countries (Connolly, 2005) and provide standardized criteria that can be used internationally (FAO, 2012).

Aquaculture eco-labels include Aquaculture Stewardship Council (ASC), AquaGAP, Food Alliance, Friend of the Sea (FOS), Global Aquaculture Alliance 
(GAA), and GlobalG.A.P. (Table 2). In these programs, an external, independent third-party auditor verifies that the aquaculture farm is in compliance with the certifier's set of standards. Many programs have been established in recent years (Table 1). Each program has a different set of standards and criteria that producers must meet in order to obtain certification and permission to use the eco-label on their products (Appendix B). These standards include compliance with relevant legal requirements, disease and pest management, energy and water efficiency, appropriate site selection, safe and fair working conditions for employees, minimal impacts on biodiversity and habitats, traceability, and minimal impacts on other marine uses like navigation (Appendix B).

Most, if not all, eco-labeling certification programs for aquaculture require producers to pay fees for the certification process. For example, Aquaculture Stewardship Council reports that certification costs will include investment costs, referring to the costs an aquaculturist might incur to make changes to come into compliance with the ASC standards, and audit costs, referring to the fees paid to the auditor for time spent conducting the annual audit and the auditor's travel and accommodation expenses (ASC, 2013b). ASC reports that profits resulting from certification may include quality improvements, higher productivity, cost reductions, added value, and access to new markets that will outweigh the costs of certification (ASC, 2013b). Food Alliance, Friend of the Sea, and GlobalG.A.P. all report that producers are charged costs associated with certification and auditing (Food Alliance, 2013; GlobalG.A.P. 2011; FOS, 2013b). 
Table 1: Characteristics of selected aquaculture eco-labeling programs

\begin{tabular}{|c|c|c|c|c|c|}
\hline Organization & $\begin{array}{c}\text { Year } \\
\text { Founded }\end{array}$ & $\begin{array}{c}\text { Type of Aquaculture } \\
\text { Products Certified }\end{array}$ & $\begin{array}{c}\text { Exclusively Certifies } \\
\text { Aquaculture } \\
\end{array}$ & $\begin{array}{c}\text { Consumer } \\
\text { Label }\end{array}$ & $\begin{array}{l}\text { Aquaculture Farms } \\
\text { Certified in the US }\end{array}$ \\
\hline $\begin{array}{l}\text { Aquaculture Stewardship } \\
\text { Council (ASC) }\end{array}$ & 2009 & $\begin{array}{l}\text { Abalone, bivalves, } \\
\text { cobia, freshwater trout, } \\
\text { pangasius, salmon, } \\
\text { seriola, shrimp, tilapia }\end{array}$ & Yes & Yes & 0 \\
\hline $\begin{array}{c}\text { AquaGAP (Good } \\
\text { Aquaculture Practice) }\end{array}$ & $2009^{1}$ & All & Yes & Yes & 0 \\
\hline Food Alliance & 1997 & Shellfish & $\mathrm{No}^{2}$ & Yes & 4 bivalve farms ${ }^{3}$ \\
\hline Friend of the Sea (FOS) & 2006 & $\begin{array}{c}\text { Finfish, molluscs, } \\
\text { crustaceans }\end{array}$ & $\mathrm{No}^{4}$ & Yes & $2^{5}$ \\
\hline $\begin{array}{c}\text { Global Aquaculture } \\
\text { Alliance (GAA)/ } \\
\text { Aquaculture Certification } \\
\text { Council (ACC) }\end{array}$ & 1997 & $\begin{array}{l}\text { Shrimp, salmon, tilapia, } \\
\text { channel catfish, } \\
\text { pangasius }\end{array}$ & Yes & Yes & 1 finfish farm ${ }^{6}$ \\
\hline $\begin{array}{c}\text { GlobalG.A.P. (Global } \\
\text { Good Aquaculture } \\
\text { Practice) } \\
\end{array}$ & $2007^{7}$ & $\begin{array}{l}\text { Finfish, molluscs, } \\
\text { crustaceans }\end{array}$ & $\mathrm{No}^{8}$ & No & $0^{9}$ \\
\hline
\end{tabular}

Note: This information was compiled from the websites of these organizations

\footnotetext{
${ }^{1}$ AquaGAP was developed by the Institute for Marketecology (IMO) and is owned by the non-profit Swiss Bio-Foundation.

${ }^{2}$ Food Alliance certifies meats, eggs, dairy, mushrooms, grains, legumes, fruits, vegetables, and prepared products with these ingredients.

${ }^{3}$ Food Alliance certified Coast Seafoods Company in Bellevue, WA for oysters and clams, Hog Island Oyster Co. in Marshall, CA for oysters and clams, and Taylor Shellfish Farms in Sheldon, WA for mussels.

${ }^{4}$ Friend of the Sea certifies both wild and farmed seafood.

${ }^{5}$ FOS has certified two aquaculture products in the US, red drum and scallops, from the same producer, Panapesca, in Massachusetts.

${ }^{6}$ Harvest Select Catfish Group has a two-star certification from GAA.

${ }^{7}$ GlobalGAP, formerly known as EUREGAP, officially began in 2007. EUREGAP started in 1997, but the organization changed its name and focus, becoming an international organization in 2007.

${ }^{8}$ GlobalGAP certifies fruits, vegetables, coffee, tea, flowers, and livestock.

${ }^{9}$ GlobalGAP has not certified any aquaculture producers, but has certified producers in the US for fruit and vegetables.
} 
Table 2: Consumer labels of selected aquaculture eco-labeling programs

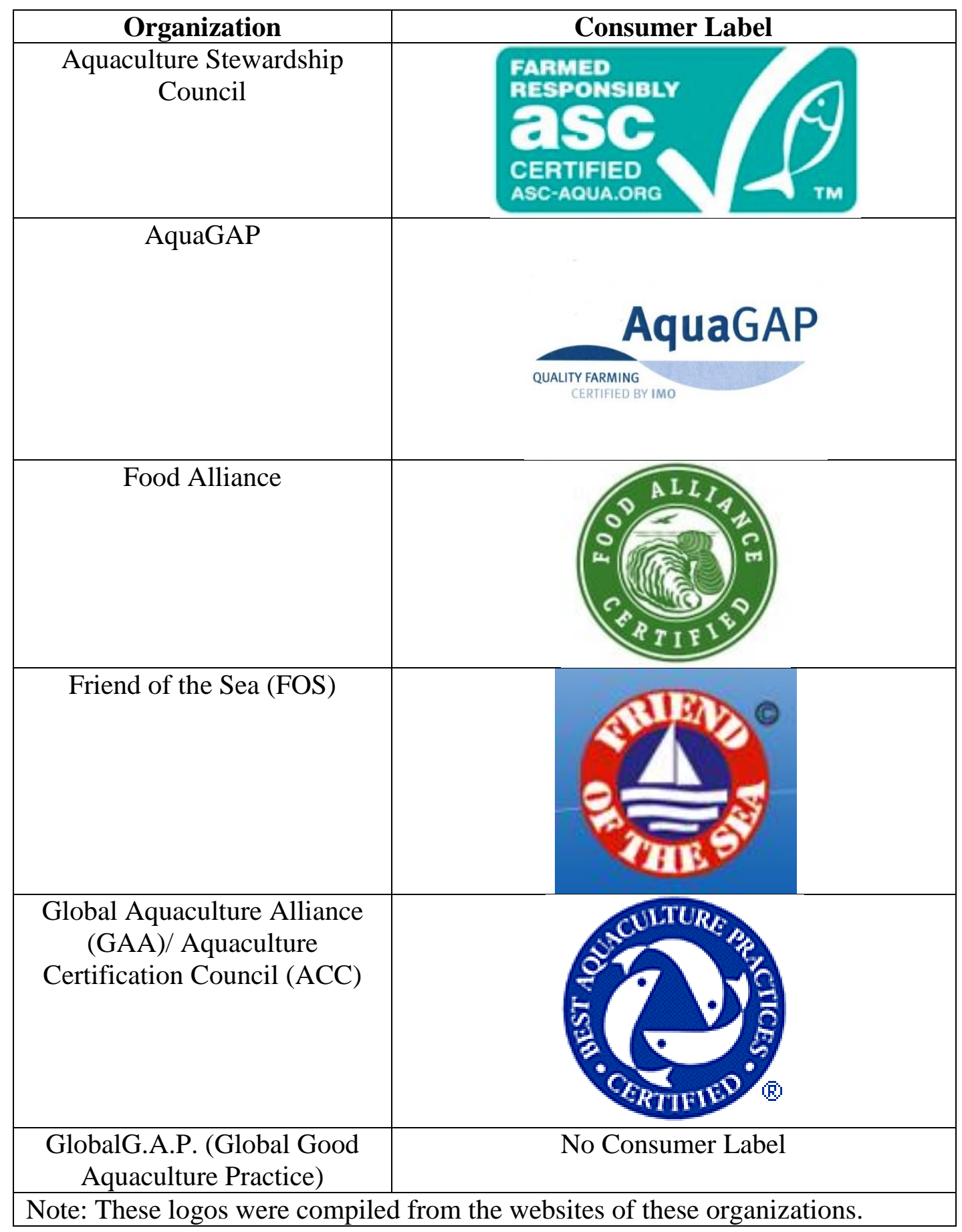


Some of these programs, like ASC and GAA, certify aquaculture products exclusively, while others like Food Alliance also certify other products like meats, fruits, and vegetables (Table 1). There are other certifications, such as the International Organization for Standardization's (ISO) standards for environmental management, which are used to certify products from a wide range of industries that may be applied to aquaculture (ISO, 2009). The ISO 14000 family of environmental management standards can be used in any type of organization, whether private or public, for environmental certification (ISO, 2009). Since standards like ISO are able to certify all types of products, they may be more widely recognized than programs that only certify aquaculture, but may not provide detailed standards that are particular to aquaculture.

Of these eco-labeling programs that certify bivalve aquaculture, Food Alliance has certified four bivalve farms in the United States: Chelsea Farms LLC in Olympia, WA, Coast Seafoods Company in Bellevue, WA, Hog Island Oyster Co. in Marshall, CA, and Taylor Shellfish Farms in Sheldon, WA (Food Alliance, 2012b). Friend of the Sea has certified two aquaculture products in the United States: red drum and scallops, from the same producer, Panapesca, in Massachusetts (FOS, 2013a). This suggests that the use of eco-labeling certification for bivalve shellfish aquaculture is limited in the United States at this time.

It is unclear which of these eco-label standards, if any, would be most useful to shellfish aquaculturists in Rhode Island at this time, since some aquaculture eco-labels do not certify bivalve mollusk aquaculture and most are not yet widely used in the United States. For example, Global Aquaculture Alliance (GAA) is one of the leading international organizations dedicated to advancing environmentally and socially 
responsible aquaculture through Best Aquaculture Practices certification

(Ramachandran, 2010), but it does not currently certify bivalve farms (GAA, 2011).

Another program, AquaGAP, does certify shellfish aquaculture operations (AquaGAP, 2010) but has not certified any operations in the United States at this time (AquaGAP, 2012). GlobalG.A.P. and Aquaculture Stewardship Council (ASC) have specific bivalve standards (GlobalG.A.P., 2012a; ASC, 2011) but also have not yet certified any bivalve aquaculture operations in the United States (GlobalG.A.P., 2012b; ASC, 2013a). Although none of these eco-labeling standards have been adopted yet by aquaculturists in Rhode Island, RI aquaculturists may seek certification in the future.

\subsubsection{Organic Eco-labels}

Organic eco-labels are the most common type of eco-labels used in the US, but organic aquaculture is not recognized by the US government at this time. The US Department of Agriculture oversees the National Organic Program, which sets the standards that must be verified by a USDA-accredited certifying agent before products can be labeled as USDA organic (USDA, 2012a). The legal status for using organic labels in the United States for aquatic species and for developing USDA certification standards for organic aquaculture products and aquatic species are currently under review (USDA, 2012b). Although the US Department of Agriculture cannot certify aquaculture products at this time, it is useful to note USDA's definition of "organic" for reference if USDA organic standards are developed for aquaculture in the future:

"a labeling term that indicates that the food or other agricultural product has been produced through approved methods that integrate cultural, biological, and mechanical practices that foster cycles of resources, promote ecological balance, and conserve biodiversity" (USDA, 2012a). 
Internationally, organic aquaculture only accounts for about 1 percent of overall aquaculture production (FAO, 2011a). There are 20-25 certifying bodies for organic aquaculture products internationally, such as Naturland, which is based in Germany but operates internationally, Bio Suisse in Switzerland, KRAV in Sweden, and the Soil Association in the United Kingdom (FAO, 2011a). These labels are not yet officially recognized in the United States as organic by the USDA, but this may change pending legal review (USDA, 2012b). Although not officially recognized as organic, Naturland has been said to be widely accepted in the United States and Europe (FAO, 2011a).

\subsection{Bivalve Mollusk Industry Best Management Practices}

For some aquaculturists, participation in third-party eco-labeling may not be desirable. Shellfish aquaculturists who still wish to engage in environmentally friendly practices or ensure their operations are sustainable, may choose to assess their practices against industry created guidelines. These guidelines are often voluntary and free to use. In many cases, shellfish growers tend to be fervent advocates for environmental quality because they own or lease the land on which they farm (Dewey et al., 2011). Unlike fishing that can takes place in open-access or poorly enforced waters, stock ownership and farm sites are clearly defined in aquaculture, providing farmers with an incentive to invest in the long-term viability of the operation (Lee, 2008). Even some federal programs acknowledge shellfish growers as environmental stewards. For example, the National Sanitation Shellfish Program encourages shellfish growers to become advocates for water quality, since the quality of their product depends on good 
water quality (Dewey et al., 2011). This commitment to stewardship causes industry groups to form best management practices and perform self-regulation.

The shellfish mariculture industry in the United States has been extremely active in self-regulation through the use of industry created best management practices (BMP), also called codes of practices or performance standards. Best management practices are protocols or procedures that provide guidance and instructions for a range of construction, operation, and management practices in aquaculture (Hargreaves, 2011). The use of best management practices (BMPs) can help to relieve perceived and real negative impacts of shellfish aquaculture.

The manuals and codes created by industry can consist of either management standards or performance standards, or a combination of the two. Management standards specify the methods producers must use to achieve a given standard, while performance standards specify the goals (Hargreaves, 2011). For example, a management practice would command that an operation have a particular technology in place to improve water quality, while a performance standard would set a level for water quality and allow the producers to use whatever technology necessary to meet that standard. Performance standards tend to encourage innovation because they allow the producer to meet a standard whatever way they wish. However, best management standards may be easier to verify from an enforcement perspective. For example, it is easier to verify that an operation uses a particular technology but it is more expensive and time consuming to actually test the water quality. 


\subsubsection{East Coast Shellfish Growers' Best Management Practices}

The East Coast Shellfish Growers Association (ECSGA) is an industry-formed association for growers along the US east coast, whose purpose is to "promote responsible commercial shellfish aquaculture through market research and promotion, active involvement in public education, [and] participation in policy formation" (ECSGA, 2010). Benefits of membership include listing on ECSGA's website for growers, dealers, and hatcheries, advertising for suppliers in ESCGA's newsletters, representation to federal agencies, and immediate response to press inquiries and shellfish illness reports (ESCGA, 2011). In June 2010, ECSGA created a set of Best Management Practices. The ECSGA does not report on its website if any growers have tried to meet or use the BMP yet (ESCGA, 2011). ECSGA members pay annual membership dues, based on their annual gross sales (ECSGA, 2011). Members are permitted and encouraged to adopt the BMPs in the manual with no additional costs for using the manual. This manual is also available online so other growers not in ECSGA could also potentially use these guidelines. Since there are Rhode Island growers in the ECSGA (ECSGA, 2011), it is important to consider that RI growers may use or begin to use these BMPs.

The ECSGA Best Management Practices Manual instructs the farm to create their own farm-specific BMP based on the suggested BMP statements in the document, instructs the farm to incorporate whatever elements they choose to include, and gives the farm freedom to modify the BMPs as they wish (Flimlin et al., 2010). The ECSGA Code of Conduct for Molluscan Shellfish Culture in the Eastern US is composed of common sense principles that most shellfish growers would instinctively 
follow as environmental stewards (Flimlin et al., 2010). This code of conduct is meant to be incorporated into the farm's BMP. The main elements of the BMP manual include the permitting process, site selection, a good neighbor policy, sourcing of seed, operational/ maintenance issues, the handling and reporting of disease, considerations of protected species and habitat, shellfish sanitation and its relevance to protection of human health, and record keeping (Flimlin et al., 2010). The BMP manual includes a blank farm-level BMP template that members of the ECSGA can modify and fill out based on their goals and specifics about their farm. The ECSGA program does not require that a third-party auditor ensures that the guidelines are met, but just recommends how aquaculturists should conduct their practices.

Industry standards are sometimes criticized for not being impartial and for allowing industry to include standards that are simple or inexpensive to meet. The Food and Agriculture Organization of the United Nations (FAO) created standards for creating aquaculture certification programs to ensure credibility of aquaculture standards. In these guidelines, FAO requires that "the accreditation body or entity should be independent and impartial... [by being] independent from vested interests [and] be free from any commercial, financial, and other pressures that might influence the results of the accreditation process" (p. 21, FAO, 2010). FAO also requires that the certification body not have any conflict of interest and should not have any interest in the aquaculture operation other than for its certification services (FAO, 2010). For this reason of impartiality, third-party certifiers, such as Aquaculture Stewardship Council or Food Alliance, may be preferable to industry set standards. 


\subsection{Local Labels and Direct-Farm Sales}

Changes in atmospheric concentrations of greenhouse gases (GHG) have been identified as drivers of climate change (IPCC, 2007). Between 1970 and 2004, energy supply, transport, and industry have caused the largest growth in GHG emissions compared to other GHG contributors (IPCC, 2007). Increasing awareness of climate change has caused an interest in local food consumption to reduce food miles and energy associated with the transportation of goods (Blake et al., 2010). Although there is no generally accepted definition of "local" food, the 2008 Farm Act defines that an agricultural food product can be considered "locally" or "regionally" produced if it is transported less than a total of 400 miles from its origin or within the state in which it was produced (Martinez et al., 2010). Since local food may provide environmental benefits, such as reduced waste from packaging and reduced GHG emissions from transportation, local labels may be considered a type of eco-label.

Motivations and goals of the local food movement include: a demand for fresh, high quality food without chemical inputs or preservatives, a reduced environmental footprint, and allowing farmers to save money they would otherwise spend on processing, transportation, packaging, and marketing (Johnson and Endres, 2011). Since there is great variation among local food markets, there is disagreement across empirical studies whether or not local food systems are more energy and emission efficient (Martinez et al., 2010). Regardless, a recent study found that in the fruit and vegetable industry, 52 percent of consumers report that it is more important to them to buy local produce than organic produce (Mintel GNPD and Mintel Oxygen Reports, 2012). 
Direct-farm, also known as direct-to-consumer, sales are one component of the local food movement, such as selling products directly from the farm or at farmers' markets. Although local food markets may account for a small share of total US agricultural sales, this share is growing (Martinez et al., 2010). Direct-to-consumer agricultural sales accounted for 0.4 percent of total agricultural sales in 2007, increasing from 0.3 percent in 1997 (Martinez et al., 2010). The number of farmers' markets in the United States increased to 5,247 in 2009 from 1,755 in 1994 (Martinez et al., 2010). Some growers are moving to direct-farm sales for increased financial returns and to regain more control over the top-down, corporate-driven, modern supply chain system (Johnson and Endres, 2011). Johnson and Endres (2011) comment:

"In an industrialized food production system, food just exists- whether in a restaurant or in a supermarket- and most consumers buy it without stopping to think about who made it, how it was made, or how it got to them. This lack of personal connection is remarkable" (p. 55).

This lack of personal connection caused by the rise of the industrial food system has led some consumers and food producers to push for local food systems, which may allow better communication between the producer and consumer and provide more control to the producer (Johnson and Endres, 2011).

One local program used in Rhode Island comes from a not-for-profit organization called Farm Fresh Rhode Island, "a local food system that values the environment, health, and quality of life of RI farmers and eaters" (Farm Fresh Rhode Island, 2012). Farm Fresh RI started a campaign in 2009 called "Get Fresh. Buy Local" and this campaign is supported by a grant from the United States Department of Agriculture (Farm Fresh Rhode Island, 2012). Aquaculturists in RI sell farm-raised 
shellfish locally through this program (Farm Fresh Rhode Island, 2013). This program does not certify the environmental sustainability of each aquaculture operation in the program like other eco-labeling programs, but selling aquaculture products with this program does communicate to consumers that the product is locally grown and sold in RI.

Even without participating in the Farm Fresh Rhode Island program, aquaculturists may communicate to consumers that their products are local in other ways, such as through the branding and name of their products. Since some aquaculturists brand their product by the location in which it is raised, this also communicates to consumers that their product has the benefits of local food production.

\subsection{First-Party Labels and Marketing}

Aquaculturists may market environmental and social attributes of their products and production without seeking third-party certification. As noted above, eco-labels may rely on first-party verification, in which producers promote environmental or social attributes of their own products. Marketing one's own sustainability through advertising is likely simpler and less expensive than seeking third-party certification for the producer, without the benefits of credibility and impartiality that a third-party certification may provide. For example, the Ocean State Shellfish Cooperative (OSSC) is an association of six different oyster farms in Rhode Island and the member farms are located in different water bodies throughout Rhode Island. The OSSC website indicates its oysters are "delicious, nutritious, sustainable" 
(OSSC, 2012a). The OSSC indicates its mission is, among other things, "to support the preservation of Rhode Island's coastal ecosystems, to promote the benefits of sustainable aquaculture and farm-fresh locally grown food" (OSSC, 2012b). In this manner, OSSC is conveying to potential buyers of its product and other interested parties that the shellfish that its members raise are "sustainable," although they have not necessarily been formally assessed against any specific sustainability criteria.

\subsubsection{Greenwashing}

The term "sustainable" is often used in consumer products without any verifiable reference point, and different usages of the term "sustainability" have led to charges of misuse of the word (Collin and Collin, 2010). "Greenwashing" is the term that describes ads or labels that do not deliver the environmental benefits they promise (Dahl, 2010). Greenwashing can occur in various ways, including using poorly or broadly defined environmental claims, using claims that cannot be substantiated with easily accessible information, making a claim based on a narrow set of attributes without addressing other relevant environmental issues, making simply false claims, and using fake third-party endorsed labels (Terrachoice, 2010). Although legitimate eco-labeling certifications can help prevent greenwashing by providing easily accessible proof of environmental and social attributes, false eco-labeling is increasing (Terrachoice, 2010).

To help combat greenwashing, the Federal Trade Commission (FTC) issued revised "Green Guides" in 2012 to address environmental claims in labels, advertising, and marketing (Code of Federal Regulations, title 16, sec 260.1-2). While Section 5 of 
the FTC Act has the force of law to prohibit unfair and deceptive acts in commerce, the "Green Guides" themselves are not enforceable under law and simply provide guidelines to how Section 5 of the FTC Act applies to environmental advertising so producers can legally abide by Section 5 in respect to environmental claims (Code of Federal Regulations, title 16, sec 260.1-2). The "Green Guides" explain different environmental claims, such as "environmentally safe," "eco-friendly," "biodegradable," "compostable," and "recyclable," and provide examples for each claim to demonstrate cases in which the claim would be deceptive or properly used (Code of Federal Regulations, title 16, sec 260.7). This guide may be useful for any producer, specifically aquaculturists, who wish to make environmental claims about their product without necessarily going through a third-party certification process.

\subsection{Summary}

As the aquaculture industry grows worldwide and in Rhode Island, increasing attention will likely be paid to the environmental and social impacts of aquaculture operations. Federal, state, and local governments play a role by regulating aquaculture activities. Eco-labeling may become a method used by aquaculturists in RI to convey environmental and social attributes of their products to consumers. Third-party ecolabeling certification, which may require standards stricter than government regulation, provides the benefits of impartiality and credibility, while potentially burdening producers with certification and auditing costs. Aquaculturists may choose to communicate environmental and social attributes through direct communication with consumers and self-promotion through marketing. Since eco-labeling 
certification programs are voluntary, RI aquaculturists will only seek certification with an eco-labeling program if they expect benefits from those programs. This study will investigate RI aquaculturists' perceptions of eco-labeling certification programs to help determine how and if eco-labeling programs may be utilized in RI aquaculture. 


\section{CHAPTER THREE}

\section{METHODOLOGY}

This chapter describes the methodology used in this study. It describes the study area, methods of data collection, interview techniques, the New Ecological Paradigm, and data analysis.

\subsection{Study Area}

Rhode Island (RI) is used as a case study for investigating aquaculturists' perceptions of eco-labeling certification programs for bivalve aquaculture. Participation in the study was limited to individuals who currently have an aquaculture lease in Rhode Island, US, for commercial purposes. Aquaculturists are defined in RI law as an "individual, firm, partnership, association, academic institution, municipality, or corporation conducting commercial, experimental, or restoration aquaculture in Rhode Island" (RI DEM, 2002). Since this study is concerned with ecolabeling, a marketing method, those conducting aquaculture for experimental or restorative purposes were excluded, as their products are not sold, and only those aquaculturists who raise shellfish for commercial purposes were included.

Located in the northeast United States, Rhode Island is the smallest and second most densely populated state (U.S. Census Bureau, 2010). Due to this high population density, there is limited space available for aquaculture. As noted in Chapter 2, Rhode Island ranks low in aquaculture production compared with other states. Although 
individual farms vary in size and production value, Rhode Island is a state with less aquaculture production and fewer farms than nearby states (USDA and NASS, 2006).

Since the RI aquaculture industry is homogenous in terms of product, dominated by shellfish, particularly oysters, Rhode Island provides a useful case study for examining perceptions of bivalve aquaculturists. By limiting this study to Rhode Island aquaculturists, this study only includes those who raise bivalve shellfish. Since some eco-labeling programs only certify aquaculture operations that raise certain species of animals or have different sets of standards for different types of animals, this study provides insight into opinions of shellfish farmers and implications for the shellfish eco-labeling programs.

This study focuses on views of RI aquaculturists because few studies, if any, have examined what producers think about eco-labels for shellfish aquaculture. There is already a wealth of literature that addresses consumer preferences for certified seafood products (e.g., Wessells et al., 1999; Johnston et al., 2001; Teisl et al., 2002; Brecard et al., 2009). Since eco-labeling certification programs are voluntary at this time, they will only be used if aquaculturists find utility in them. This study will investigate RI aquaculturists' perceptions of eco-labeling certification programs to help determine how and if eco-labeling programs would be utilized in RI aquaculture. The opinions of RI aquaculturists are being examined in this study, but their opinions may not represent the opinions of aquaculturists in other areas. 


\subsection{Data Collection}

I obtained a list of current RI aquaculturists, as of March 2012, from Mr. Dave Beutel, Director of Aquaculture of the RI Coastal Resources Management Council (RI CRMC). There are 30 aquaculturists on this list, responsible for all 43 farms in Rhode Island (Beutel, 2011). I contacted the entire list of participants by mail for inclusion in the study, as the population size is small. Potential participants were sent a letter explaining the study and asking for their voluntary participation (Appendix C).

A follow-up reminder postcard was sent a month after the initial letter to attempt to get more participants (Appendix D). The text of the postcard followed Dillman et al.'s (2009) method by informing participants that they should have received an initial letter about the study, thanking those who have participated, asking for a response with urgency from those who have not yet participated, explaining again the purpose of the study and why their help is needed, and finally providing contact information so the participants could schedule an interview. Since I was receiving responses from the initial prenotice letter for about a month, I sent the follow-up postcard after I stopped receiving responses. Dillman et al. (2009) recommend using a postcard format over a letter to contrast with the prenotice letter that was already sent because "new stimuli have greater effect than repeated stimuli" (p. 250) and the combination of a prenotice letter and a postcard has been shown to increase participation rates. Since postcards can be quickly read, the postcard followup is meant to jog the memories of participants and rearrange their priorities (Dillman et al., 2009). 


\subsection{Interview}

I conducted five pilot interviews. I did not select a subset of the population for pilot interviews because the population size is small and I did not want to reduce the number of interviews I could conduct. Instead, I conducted five pilot interviews on two aquaculture regulators (one state regulator and one federal regulator), two academics who research aquaculture, and a former RI aquaculturist. I explained the study to these pre-testers, asked the interview questions, and welcomed suggestions for other questions that could be pertinent to the study. Based on this feedback, some questions were omitted or modified for clarity and relevance.

Twelve interviews were conducted. Ten were conducted in person and two interviews were conducted by telephone. Interviews were conducted on the telephone only if participants requested a telephone interview for convenience. Both face-to-face interviews and telephone interviews used the structured interview method. In a structured interview, each participant is exposed to the same set of stimuli (Bernard, 2002). In this study, the stimulus used was the same set of questions. In structured interviewing, the researcher "controls the input that triggers people's responses so that their output can be reliably compared" (p. 240, Bernard, 2002). I chose to use the inperson interview method rather than using a self-administered questionnaire so I could control the order in which respondents answered the questions. I wanted the interviews to start with general questions about aquaculture then become more specific with questions of eco-labeling, without participants being able to know what questions I would ask later. 
Throughout the interview, I collected continuous data (such as age of the farmer or size of farm), nominal data (such as types of products raised), and interval data (where the researcher utilized the Likert scale) (Appendix E). The interview questions seek to answer my main research questions:

1. What are basic characteristics of RI aquaculture producers, farms, and products?

2. Do RI aquaculturists participate or plan to participate in eco-labeling certification programs, and what are their perceptions of eco-labeling?

3. What are the perceived incentives and disincentives to RI aquaculturists for participation in eco-labeling certification programs?

4. How do RI aquaculturists feel about government regulations of aquaculture?

Interviews lasted between 45 minutes and 2 hours. Interviews had 80 questions focusing on: 1.) personal characteristics, such as motivations for becoming involved with aquaculture, number of years experience, and participation in industry-related organizations, their farm, such as the size of the farm and number of employees, and products raised, such as types of animals raised and seed purchased annually; 2.) attitudes toward eco-labeling certification programs; 3.) perceived incentives and disincentives of eco-labeling certification; and 4.) perceptions of government regulations of aquaculture. The first set of interview questions was included because while this type of information is collected by RI CRMC, it is not publicly available. The second and third sets of interview questions help gain a sense of aquaculturists' beliefs and perceptions of eco-labeling programs. The final set of interview questions asks about government regulation, since some of the requirements and criteria of ecolabeling programs likely overlap with government regulation. This final set of questions asked participants if they felt selected government objectives were being sufficiently met with existing management. I selected these particular objectives to see 
if government is meeting them because some are cited in the literature as potential objectives of eco-labeling programs. If government is already meeting the same objectives that eco-labels claim to support, it would be interesting to consider ecolabeling's role or ability to supplement government regulations.

\subsection{New Ecological Paradigm}

Respondents were also asked to respond to supplemental questions on paper. For the interviews conducted over the telephone, this supplemental form was either emailed or sent by mail with a stamped return envelope. Information collected in the supplemental form gathered basic demographic information like education level, age, and gender. The supplemental form also asked subjects to answer 15 questions using the New Ecological Paradigm (NEP) scale developed by Dunlap, Van Liere, Mertig, and Jones in 2000 (Figure 6). The NEP scale (2000) is a revised and updated version of the widely used New Environmental Paradigm developed by Dunlap and Van Liere in 1978 (Dunlap et al., 2000). The items used in the NEP scale measure participants' beliefs about nature and humans' role in it and provide a measure of general environmental concern. 


\section{Figure 6: Supplemental interview form with NEP statements (Modified from}

Dunlap et al., 2000).

Please answer the following questions to the best of your ability. Remember that you may choose to not answer any question and can stop at any time.

Age: Gender:

Highest Level of Education Completed:

Listed below are statements about the relationship between humans and the environment. For each one, please indicate whether you:

STRONGLY AGREE (SA), MILDLY AGREE (MA), are UNSURE (U), MILDLY DISAGREE (MD), or STRONGLY DISAGREE (SD) with the statement.

1. We are approaching the limit of the number of people the earth can support.

2. Humans have the right to modify the natural environment to suit their needs.

3. When humans interfere with nature it often produces disastrous consequences.

4. Human ingenuity will insure that we do NOT make the earth unlivable.

5. Humans are severely abusing the environment.

6. The earth has plenty of natural resources if we just learn how to develop them.

7. Plants and animals have as much right as humans to exist.

8. The balance of nature is strong enough to cope with the impacts of modern industrial nations.

9. Despite our special abilities, humans are still subject to the laws of nature.

10. The so-called "ecological crisis" facing humankind has been greatly exaggerated.

11. The earth is like a spaceship with very limited room and resources.

12. Humans were meant to rule over the rest of nature.

13. The balance of nature is very delicate and easily upset.

14. Humans will eventually learn enough about how nature works to be able to control it.

15. If things continue on their present course, we will soon experience a major ecological catastrophe.

\begin{tabular}{|c|c|c|c|c|}
\hline $\begin{array}{l}\text { Strongly } \\
\text { Agree }\end{array}$ & $\begin{array}{l}\text { Mildly } \\
\text { Agree }\end{array}$ & Unsure & $\begin{array}{l}\text { Mildly } \\
\text { Disagree }\end{array}$ & $\begin{array}{l}\text { Strongly } \\
\text { Disagree }\end{array}$ \\
\hline SA & MA & $\mathrm{U}$ & MD & SD \\
\hline SA & MA & $\mathrm{U}$ & MD & SD \\
\hline SA & MA & $\mathrm{U}$ & MD & SD \\
\hline SA & MA & $\mathrm{U}$ & MD & SD \\
\hline SA & MA & $\mathrm{U}$ & MD & SD \\
\hline SA & MA & $\mathrm{U}$ & MD & SD \\
\hline SA & MA & $\mathrm{U}$ & MD & SD \\
\hline SA & MA & $\mathrm{U}$ & MD & SD \\
\hline SA & MA & $\mathrm{U}$ & MD & SD \\
\hline SA & MA & $\mathrm{U}$ & MD & SD \\
\hline SA & MA & $\mathrm{U}$ & MD & SD \\
\hline SA & MA & $\mathrm{U}$ & MD & SD \\
\hline SA & MA & $\mathrm{U}$ & MD & SD \\
\hline SA & MA & $\mathrm{U}$ & MD & SD \\
\hline SA & MA & $\mathrm{U}$ & MD & SD \\
\hline
\end{tabular}

The New Environmental Paradigm (1978) has been most widely used on samples of the general public (Dunlap et al., 2000), but has also been used on specific sectors, such as farmers (Albrecht et al., 1982). This study extends the New Ecological 
Paradigm to aquaculturists, farmers of the sea. Unlike Albrecht et al. (1982), which tested farmers against the general population using the 12-question New Environmental Paradigm scale (1978), the use of the updated NEP (2000) scale in this study provides a relative measure of environmental beliefs and attitudes to compare scores among aquaculturists in RI.

The NEP scale contains 15 questions based on five hypothesized facets of an ecological worldview: the reality of limits to growth (questions 1, 6, 11) antianthropocentricism (questions 2, 7, 12), the fragility of nature's balance (questions $3,8,13$ ), rejection of exemptionalism (questions 4,9 and 14) and the possibility of an eco-crisis (questions 5, 10, 15) (p. 432, Dunlap et al., 2000). The concept of limits to growth refers to the idea that we live on a planet with finite resources. Antianthropocentricism is the rejection of the idea that humans are the center of the universe or the most significant species. Accepting the fragility of nature's balance means acknowledging that nature is not always able to overcome human impacts. Since the concept of exemptionalism involves the belief that humans are exempt from the rules of nature because of special human characteristics like ingenuity, a person who holds an ecological worldview would reject the concept of exemptionalism. The possibility of an ecological crisis refers to global problems, such as climate change.

The NEP scale uses a Likert scale with five choices indicating strong disagreement, mild disagreement, uncertainty, mild agreement, or strong agreement with the given statement. NEP statements are written in such a way that agreement with the odd-numbered questions and disagreement with the even-numbered questions indicates a pro-ecological worldview or pro-NEP score. 
Although it is difficult to predict behavior, like willingness to participate in eco-labeling programs, from general attitudes and beliefs, like a certain NEP score, relationships between the NEP scale and some behavioral intentions and actual behaviors have been found in other studies (Dunlap et al., 2000). Regardless of ability to predict behavior, a pro-ecological orientation has still been shown to lead to proenvironmental beliefs and attitudes on a wide range of issues (Dunlap et al., 2000). Therefore, those with higher NEP scores or pro-ecological worldviews may have different attitudes or feelings about eco-labeling programs that are intended to highlight environmental attributes of aquaculture.

\subsection{Data Analysis}

Data collected in this study was analyzed using quantitative analyses. I used descriptive statistics such as mean, maximum, minimum, and standard deviation to summarize the continuous data collected in this study, such as the age of the farmer and number of years involved with aquaculture. I tallied the number of participants that gave particular responses in the closed-ended questions that collected nominal and interval data. These include closed-ended "Yes"/ "No" questions about perceptions in eco-labeling programs and Likert scale questions about perceived incentives and disincentives of participation in eco-labeling programs.

I used grounded theory to analyze responses to open-ended questions. Grounded theory describes "the discovery of theory from data systematically obtained from social research" (pg. 2, Glaser and Strauss, 1967). Joint coding and data analysis allows the researcher to look for categories that emerge from open-ended questions 
and then systematically quantify those categories (Glaser and Strauss, 1967). In this study, responses to open-ended questions were coded by themes that emerged, quantified, and summarized by response frequency. Such open-ended questions included how participants would select an eco-labeling program and their motivations for entering the aquaculture industry.

\subsubsection{New Ecological Paradigm Data Analysis}

Researchers that utilize the NEP scale may choose to treat the NEP scale as a singular measure or create subscales that correspond to the different facets (Dunlap, 2008). In this study, I chose to treat the NEP scale as a singular measure to provide one score of general environmental concern for each participant. In order to provide a single score for each aquaculturist for comparison purposes, a scoring system was developed for this study. Strong agreement with an odd-numbered question received a score of " 5 ", mild agreement received a score of " 4 ", unsure or neutral received a score of " 3 ", mild disagreement received a score of " 2 ", and strong disagreement received a score of " 1 ". Strong disagreement with an even- numbered question received a score of "5", mild disagreement received a score of "4", unsure received a score of "3", mild agreement received a score of "2", and strong agreement received a score of "1". Following Poortinga et al. 's (2004) method, these scores from the fifteen questions were totaled with equal weight to provide one score for each participant. Since the NEP scale is composed of 15 items, the resulting score could range from "15" (low environmental concern) to " 75 " (high environmental concern), with " 45 " as a midpoint value. 
I analyzed NEP scores with descriptive statistics, by reporting mean, maximum, minimum, and standard deviation of total NEP scores. I compared NEP scores with other factors, such as education level, years of experience in aquaculture, and intention to participate in eco-labeling programs. I also computed the mean level of environmental concern expressed by aquaculturists on each of the 15 questions and the five hypothesized facets of an ecological worldview. 


\section{CHAPTER FOUR}

\section{RESULTS}

The results chapter of this thesis is organized by the main research questions of this study:

1. What are basic characteristics of RI aquaculture producers, farms, and products?

2. Do RI aquaculturists participate or plan to participate in eco-labeling certification programs, and what are their perceptions of eco-labeling?

3. What are the perceived incentives and disincentives to RI aquaculturists for participation in eco-labeling certification programs?

4. How do RI aquaculturists feel about government regulations of aquaculture?

Results pertinent to each of these research questions are presented in this order.

\subsection{Response Rate}

Of the 30 potential participants that were contacted for inclusion in this study, I conducted interviews with 12 participants, for a response rate of $40 \%$. Since there was a $40 \%$ response rate in this study, the results presented here do not necessarily represent all of the aquaculturists in RI. Although results only represent the views of those 12 aquaculturists who participated in this study, they still provide insight into what RI aquaculturists think about eco-labeling. Unless otherwise stated, all 12 respondents answered all questions. A number in parentheses (\#) in this chapter refers to the number of participants who gave that particular response. 


\subsection{Characteristics of RI Aquaculture Producers, Products, and Farms}

In order to answer my first research question, the survey included questions about the aquaculturists, including general characteristics and their perceptions of aquaculture impacts, motivations for entering the aquaculture industry, and attitudes toward the environment (i.e. NEP scale), the aquaculture products raised, and the aquaculture farm.

\subsubsection{Respondents' Personal Characteristics}

The majority of participants reported that their field of education related to aquaculture, motivating them to enter the aquaculture industry (Table 3). Half of the participants noted that they were previous or current commercial fishermen (Table 3). These participants often mentioned that the skills they acquired as fishermen made the transition to aquaculture simpler. Some of these participants also explained that they made the transition from wild fishing to aquaculture when wild stocks declined or when wild fishing regulations became too stringent.

Table 3: Motivations for entering the aquaculture industry (in order of response frequency)

- Education in a related field (7)

- Previous or current commercial fishermen (6)

- Interest in growing a natural resource (1)

- Career change/ retirement opportunity (1)

- Interest in recreational aquaculture business (1)

- Interest in renewable energy potential from upwellers (1) 
All participants in this study were male, and most participants completed college

(Table 4). The average age of participants was 46 (Table 4). Seven participants named aquaculture as their primary occupation, while five said they had other occupations.

Table 4: Descriptive statistics of RI aquaculturists

\begin{tabular}{|c|c|c|c|c|c|}
\hline & $\mathrm{n}^{*}$ & Mean & Minimum & Maximum & $\begin{array}{c}\text { Standard } \\
\text { Deviation }\end{array}$ \\
\hline $\begin{array}{l}\text { Years Involved } \\
\text { with } \\
\text { Aquaculture }\end{array}$ & 12 & 10.4 & 1 & 30 & 7.75 \\
\hline $\begin{array}{l}\text { Primary } \\
\text { Occupation } \\
(0=\text { no, } 1=\text { yes })\end{array}$ & 12 & 0.6 & 0 & 1 & 0.51 \\
\hline Age & 9 & 45.6 & 31 & 59 & 9.74 \\
\hline $\begin{array}{l}\text { Gender }(0= \\
\text { male, } 1= \\
\text { female })\end{array}$ & 12 & 0 & 0 & 0 & 0 \\
\hline $\begin{array}{l}\text { Education } \\
\text { Level }(1=\text { high } \\
\text { school/ some } \\
\text { college, } 2= \\
\text { college, } 3= \\
\text { master's) } \\
\end{array}$ & 10 & 2.2 & 1 & 3 & 0.79 \\
\hline
\end{tabular}

$*_{\mathrm{n}}$ varies here because some respondents chose to not answer some questions.

\subsubsection{Involvement in Aquaculture Organizations}

Participants were involved most with two industry associations, the Ocean State Shellfish Growers Association and East Coast Shellfish Growers Association (Figure 7). While eight participants said they were members of the East Coast Shellfish Growers Association (Figure 7), nine respondents stated they were familiar with ECSGA’s Best Management Practices (BMP) Manual. Of these participants, most said they did not fill out the actual (BMP) template but all who were familiar with the BMP manual felt their practices met the standards. 
Figure 7: RI Aquaculturists' involvement in aquaculture organizations

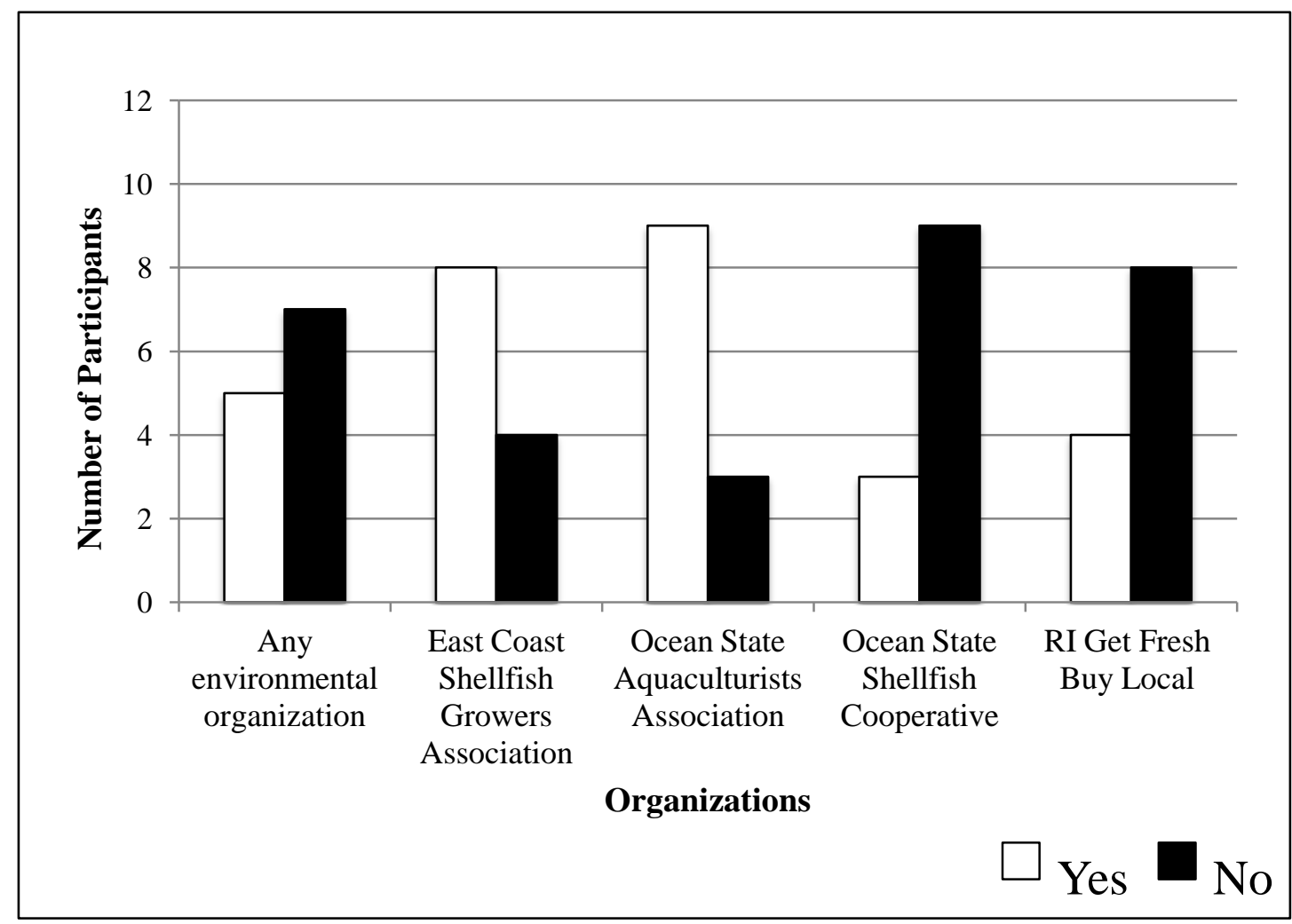

\subsubsection{New Ecological Paradigm}

As described in Chapter 3, the agreement or disagreement with the New Ecological Paradigm statements provides a relative score of environmental concern. Agreement with odd questions designates a high level of environmental concern, while agreement with even questions designates a low level of environmental concern. Since the NEP scale is composed of 15 items and each item is given a score from (1-5) designating the level of environmental concern, the resulting overall NEP score for each aquaculturist could range from 15 (low environmental concern) to 75 (high environmental concern), with 45 as a midpoint value. The mean overall NEP score of 
all participants was 56.8, which is higher than the midpoint value of possible NEP scores. In this study, the lowest NEP score was 37, and the highest NEP score was 71. For comparison purposes, I split the possible range of NEP scores into three categories with equal ranges. I considered those with NEP scores ranging from 1534.9 as having low environmental concern, those with NEP scores ranging from 3554.9 as having moderate environmental concern, and those with NEP scores ranging from 55-75 as having high environmental concern. Using these categories, no participants in this study have low environmental concern, six have moderate environmental concern, and six have high environmental concern.

Every participant gave responses with high environmental concern on statement 13 , as all 12 participants moderately or strongly agreed that "the balance of nature is very delicate and easily upset" (Table 5). Many participants showed low levels of environmental concern with statement 6 , as six participants moderately or strongly agreed that "the earth has plenty of natural resources if we just learn how to develop them" (Table 5). 
Table 5: Responses to New Ecological Paradigm statements

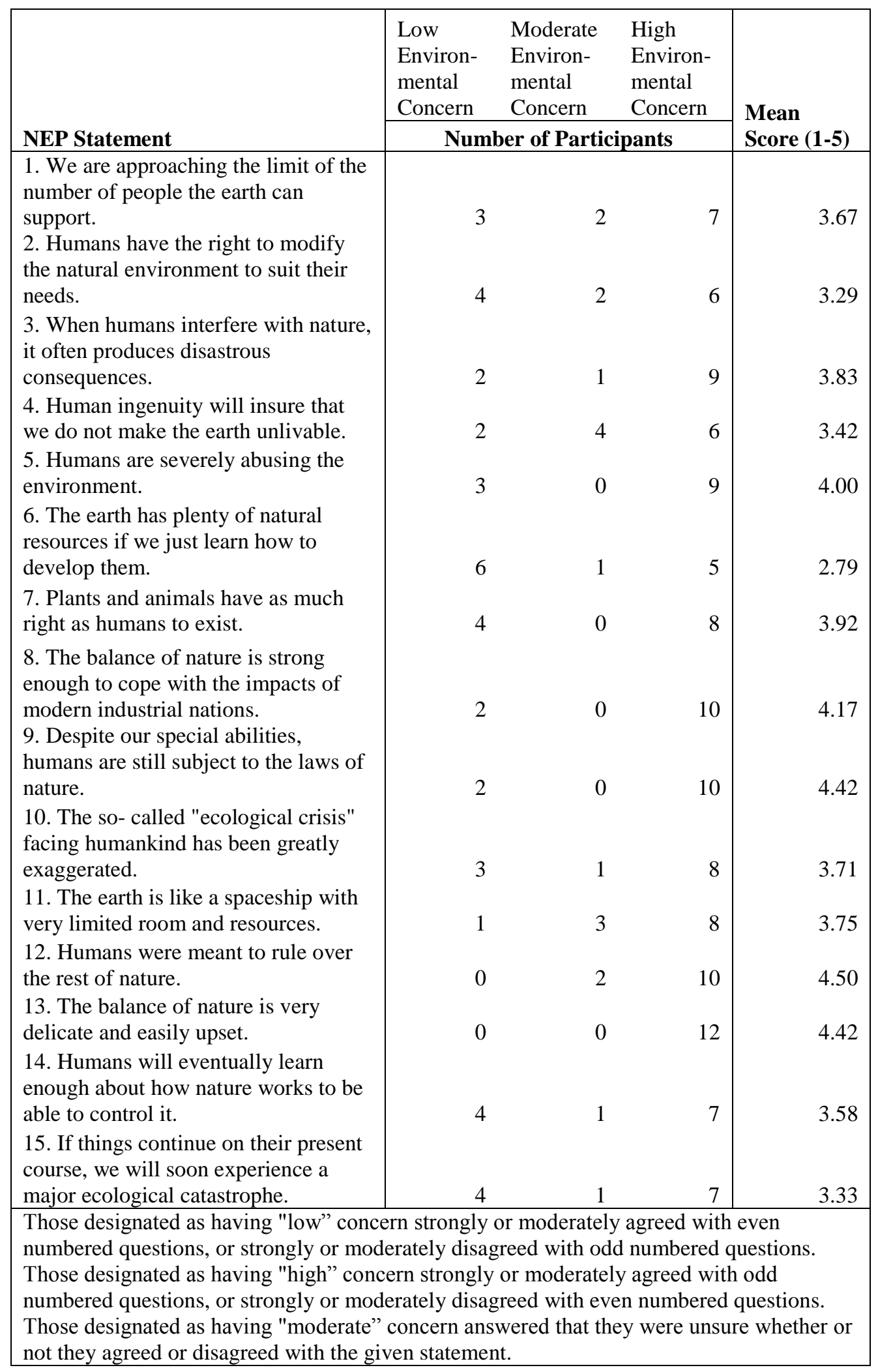


As stated in Chapter 3, the NEP scale contains 15 questions based on five hypothesized facets of an ecological worldview: the reality of limits to growth (questions 1, 6, 11) antianthropocentricism (questions 2, 7, 12), the fragility of nature's balance (questions 3, 8, 13), rejection of exemptionalism (questions 4, 9 and 14) and the possibility of an eco-crisis (questions 5, 10, 15). Relative to the other hypothesized facets of an ecological worldview, participants in this study responded to the fragility of nature's balance with the highest level of environmental concern and responded to the reality of limits to growth with the lowest environmental concern (Table 6).

Table 6: Responses to five facets of New Ecological Paradigm statements

\begin{tabular}{|l|c|}
\hline $\begin{array}{c}\text { Hypothesized Facet of an } \\
\text { Ecological Worldview }\end{array}$ & $\begin{array}{c}\text { Mean (1-5): Scale: 1= Lowest } \\
\text { Environmental Concern to 5= } \\
\text { Highest Environmental Concern }\end{array}$ \\
\hline The reality of limits to growth & 3.40 \\
\hline Antianthropocentricism & 3.90 \\
\hline The fragility of nature's balance & 4.14 \\
\hline Rejection of exemptionalism & 3.81 \\
\hline & \\
The possibility of an eco-crisis & 3.68 \\
\hline
\end{tabular}


From this study, there seems to be a relationship between education level and NEP score, as the mean NEP score is highest in the group with the highest level of education, and lowest in the group with the lowest level of education (Table 7). Since the sample sizes in this study are small and there is a lot of variance, this should be regarded as a preliminary observation that should be investigated further.

Table 7: NEP Scores by education level

\begin{tabular}{|l|c|c|c|c|c|}
\hline & \multicolumn{5}{|c|}{ NEP Scores } \\
\hline Education Level & $\mathbf{n}$ & Mean & Minimum & Maximum & $\begin{array}{c}\text { Standard } \\
\text { Deviation }\end{array}$ \\
\hline $\begin{array}{l}\text { High School and } \\
\text { Some College }\end{array}$ & 2 & 48.50 & 37 & 60 & 16.26 \\
\hline College Degree & 4 & 54.63 & 47 & 66 & 8.18 \\
\hline & 4 & 66.75 & 64 & 71 & 3.10 \\
\hline
\end{tabular}

A high NEP score does not seem to influence the participants' intent to certify their products with an eco-label, as NEP scores were lower for those who may eco-label their products in the next five and ten years than for those who did not plan to participate in an eco-labeling program in the next five and ten years (Table 8). Two of the respondents who reported that they did not plan to eco-label their products within the next 5 years reported that they may eco-label their products within the next ten years (Table 8). Those with more years of experience in aquaculture did have a higher mean NEP score than those with less experience (Table 9). 
Table 8: NEP Scores by intention to participate in eco-labeling programs

\begin{tabular}{|l|c|c|c|c|c|}
\hline & \multicolumn{5}{|c|}{ NEP Score } \\
\hline $\begin{array}{l}\text { Intention to } \\
\text { Participate in Eco- } \\
\text { labeling Programs }\end{array}$ & n & Mean & Minimum & Maximum & $\begin{array}{l}\text { Standard } \\
\text { Deviation }\end{array}$ \\
\hline $\begin{array}{l}\text { Participants who may } \\
\text { eco-label their } \\
\text { products in the next 5 } \\
\text { years }\end{array}$ & 8 & 55.9 & 37 & 67 & 10.35 \\
\hline $\begin{array}{l}\text { Participants who do } \\
\text { not plan to eco-label in } \\
\text { the next 5 years }\end{array}$ & 4 & 58.5 & 47 & 71 & 11.36 \\
\hline $\begin{array}{l}\text { Participants who may } \\
\text { eco-label their } \\
\text { products in the next 10 } \\
\text { years. }\end{array}$ & 10 & 56.7 & 37 & 71 & 10.89 \\
\hline $\begin{array}{l}\text { Participants who do } \\
\text { not plan to eco-label } \\
\text { their products in the } \\
\text { next 10 years. }\end{array}$ & 2 & 58.0 & 51 & & \\
\hline
\end{tabular}

Table 9: NEP Scores by the participant's years of experience in aquaculture

\begin{tabular}{|l|c|c|c|c|c|}
\hline & \multicolumn{5}{|c|}{ NEP Score } \\
\hline $\begin{array}{l}\text { Years } \\
\text { Experience }\end{array}$ & $\mathrm{n}$ & Mean & Minimum & Maximum & $\begin{array}{c}\text { Standard } \\
\text { Deviation }\end{array}$ \\
\hline $\begin{array}{l}\text { Under 10 } \\
\text { Years }\end{array}$ & 6 & 55.4 & 47 & 67 & \\
\hline $\begin{array}{l}\text { Over and } \\
\text { Including } \\
\text { 10 Years }\end{array}$ & 6 & 58.2 & 37 & 71 & \\
\hline
\end{tabular}




\subsubsection{RI Aquaculture Farms and Products}

The average aquaculture farm of respondents in this study has been in operation for 7.8 years (Table 10). The average farm owner visits their farm four times per week (Table 10). In this study, the greatest number of leases any one aquaculturist owns is four, while the average aquaculturist owns 1.3 leases (Table 10). The average size of a respondent's aquaculture farms is 5.3 acres (Table 10). All aquaculturists who purchased less than 250,000 oyster seed annually (4) reported that aquaculture was not their primary occupation.

Table 10: Descriptive statistics of respondents' aquaculture farms

\begin{tabular}{|c|c|c|c|c|c|}
\hline & $\mathrm{n}$ & Mean & Minimum & Maximum & $\begin{array}{c}\text { Std. } \\
\text { Deviation }\end{array}$ \\
\hline $\begin{array}{l}\text { Total Size of } \\
\text { All Farms } \\
\text { (Acres) }\end{array}$ & 12 & 5.3 & 1 & 20 & 6.17 \\
\hline $\begin{array}{l}\text { Number of } \\
\text { Leases }\end{array}$ & 12 & 1.3 & 1 & 4 & 0.89 \\
\hline $\begin{array}{l}\text { Years in } \\
\text { Operation of } \\
\text { Oldest } \\
\text { Lease }\end{array}$ & 12 & 7.8 & 1 & 14 & 4.62 \\
\hline $\begin{array}{l}\text { Oyster Seed } \\
\text { Purchased } \\
\text { Annually (\# } \\
\text { seeds) }\end{array}$ & 12 & $1,181,250$ & 75,000 & $3,500,000$ & 1197209.11 \\
\hline $\begin{array}{l}\text { Number of } \\
\text { Times at } \\
\text { Farm/ Week }\end{array}$ & 12 & 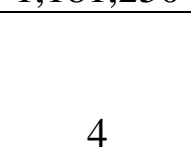 & 1 & , & 1.65 \\
\hline
\end{tabular}

All of the participants in this study raise oysters (Figure 8). In addition to oysters, one respondent also raises bay scallops and one other respondent also raises mussels (Figure 8). No respondents currently raise clams. 
Five of the twelve respondents sell their cultured products only in Rhode Island and two sell only in other states (Figure 8). Five respondents sell their products both in RI and out of state (Figure 8). Cultured products are sold to a variety of buyers, including wholesalers, restaurants, and directly to customers at farmers' markets (Figure 8). Many aquaculturists sell to more than one type of buyer. Ten respondents sell to restaurants, six respondents sell to wholesalers, and three sell products directly to consumers at farmers' markets (Figure 8).

Because characteristics of my sample were similar to those of the aquaculture industry in RI where half of all aquaculturists are previous or current commercial fishermen (Beutel, pers. comm.., 2013), $20 \%$ of all RI farmers are members of the Ocean State Shellfish Cooperative (OSSC, 2012a), and the average years in operation of all RI aquaculture farms is 8.2 (Beutel, pers. comm.., 2013), my results can be considered representative of aquaculturists in RI. 
Figure 8: Characteristics of cultured products in RI

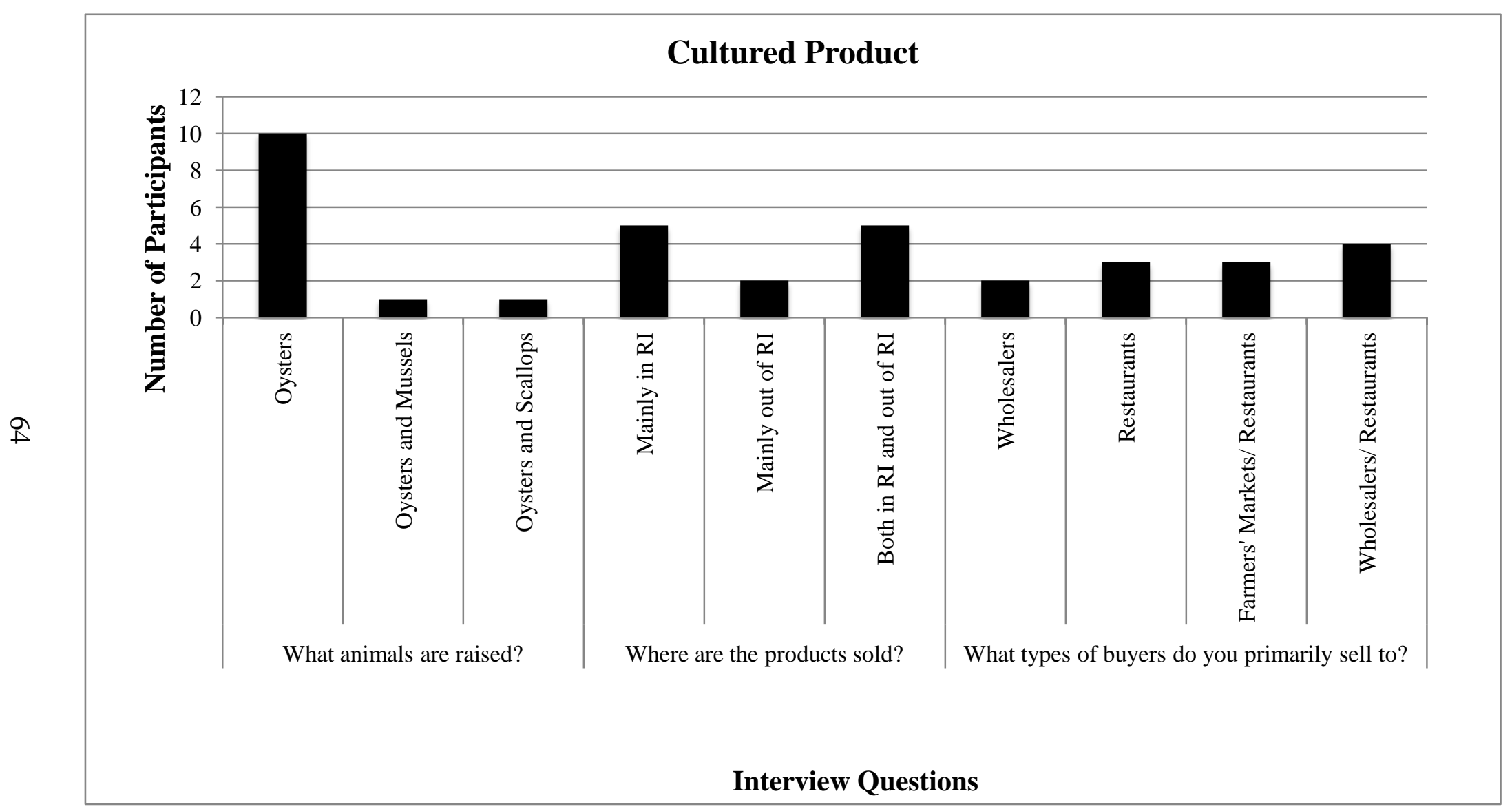




\subsubsection{Communication with Buyers and End Users}

Many respondents said they speak directly to the buyers and end users of their products. Two of the three respondents who are members of the Ocean State Shellfish Cooperative responded that they do not regularly speak directly to the buyers of their products because there is a director of sales for the cooperative that communicates with buyers. All three respondents who sold at farmers' markets reported they had direct communication with the end-user, while those who sold to restaurants communicated most directly with chefs, and those who sold to wholesalers reported that they rarely, if ever, spoke directly to the end-user.

Half of the respondents reported that they speak directly to buyers about the methods used to raise the products (Table 11). Three of these respondents said they regularly communicate with the buyers about environmental attributes of production and the sustainability of the product, and four reported they have had buyers come visit their operation (Table 11).

Table 11: Aquaculturists' interactions with buyers (in order of response frequency)

- Discuss methods/ procedures of how the product is grown (6)

- Discuss taste of product (5)

- Emphasize that the product is local (5)

- Have buyers visit the operation (4)

- Discuss environmental benefits/ sustainability (3) 


\subsubsection{Product Marketing}

In terms of marketing of the product, eight respondents have a trademarked brand name, while four respondents report they use a name, but do not have a trademark yet. One aquaculturist commented that the trademarking process takes a long time. Five respondents said their primary marketing method was word of mouth, while others mentioned using websites, business cards, and marketing pamphlets. Participants use a variety of packaging for their products, including bags, boxes, and coolers. A few participants said they are not involved in the final packaging of their product, either because they sell directly to consumers from a cooler or bag, or because they sell to a wholesaler who takes care of the packing, depending on the buyer.

\subsubsection{Methods of Aquaculture Production}

Seven participants said they partake in both nursery and grow-out stages of production, while five participants said they were only involved in grow-out. Respondents report they use a variety of methods for the grow-out phase, including rack/cage and bag methods on the bottom or raised off the bottom (9), direct planting on the seafloor (4), suspended culture (2), and floating bags (1). Four respondents use multiple methods of production. Despite the variety of methods used, the majority of respondents (9) answered that other shellfish farms in RI had a similar environmental impact to their own farms. The number of oyster seed purchased annually provides insight into the size of the operation, but only accounts for oyster seed purchased 
annually from a hatchery and does not include natural spat that is often collected by producers.

\subsubsection{Perceived Aquaculture Impacts}

All respondents mentioned that the improvement of water quality was a benefit of shellfish aquaculture (Table 12). Many reported that as filter feeders, shellfish remove suspended solids and nitrogen from the water, improving water quality. This nutrient removal allows sunlight to penetrate further down into the water column.

Table 12: Positive impacts of shellfish aquaculture (in order of response frequency)

- Improves water quality (12)

- Economic development (7)

- Job creation (6)

- Habitat creation for marine life (4)

- Tourism benefits (2)

- Diversifies waterfront (2)

- Cultured spawning supports wild shellfish populations (2)

- Produces food for humans (2)

- Renewable energy from nursery upwellers (1)

- Local oysters reduce carbon footprint (1)

- Sustains wetlands (1)

NOTE: Respondents could provide more than one positive impact.

Many participants acknowledged economic development and job creation as positive impacts of shellfish aquaculture (Table 12). Economic benefits mentioned included buying local gear and supplies, generating taxable revenues for Rhode Island, and paying dockage fees at local marinas. Four respondents identified habitat creation 
for marine life as a benefit of shellfish aquaculture (Table 12), noting the structure of aquaculture gear creates artificial habitat for other marine life and attracts other animals.

\section{Table 13: Negative impacts of shellfish aquaculture (in order of response frequency)}

- Use conflicts/ Takes away from other uses (4)

- Storms can cause lost gear (2)

- Some local wild shellfishermen dislike it (2)

- Changes benthos composition underneath due to waste (2)

- Aesthetic impacts (2)

- Direct planting causes bottom to become sharp, hard for people to walk (1)

- Dredging operations increase water turbidity (1)

NOTE: Respondents could provide more than one negative impact.

Although use conflict was the primary negative impact of shellfish aquaculture mentioned by participants (Table 13), some who mentioned it also noted that this was often more of a perceived negative impact than an actual negative impact. Those who felt use conflict was more of a perceived negative impact noted that the lease process in Rhode Island reduces use conflicts by bringing stakeholders together during the leasing process and granting aquaculture leases in areas that do not have wild shellfish or other uses.

Lost gear was also noted as a negative impact of shellfish aquaculture (Table 13). Participants noted that they try to quickly retrieve gear after storms and that providing a bond for clean-up purposes in the case of abandonment or gear loss is now a requirement of an aquaculture lease in RI. Those who mentioned that wild shellfishermen dislike shellfish aquaculture noted that local shellfishermen do not 
seem to understand aquaculture, fear the competition in the market, or feel areas that could be used for wild shellfishing are being taken away by aquaculture. Of the two participants who mentioned aesthetic impact (Table 13), one expressed that this was a tactic used by those who do not embrace aquaculture to block it since his farm is underwater and not able to be seen, while the other did feel floating aquaculture has an aesthetic impact. This participant did mention that while floating aquaculture could have a negative aesthetic impact to some, it also has a positive impact with tourists coming to view the floating site.

\subsection{RI Aquaculturists' Participation in and Perceptions of Eco-labeling Programs}

In order to answer my second research question, the survey included questions about RI aquaculturists' current and potential participation in eco-labeling certification programs, as well as their perceptions of eco-labeling programs. While only one of twelve participants has considered eco-labeling his products, nearly all participants said they supported eco-labeling programs (Figure 9). All twelve participants felt there is a market for eco-labeled products in general (Figure 10). While only one participant had considered eco-labeling his products before this study, the majority of participants said they might eco-label their products in the future (Figure 9). 
Figure 9: Summary of questions pertaining to participation in eco-labeling programs

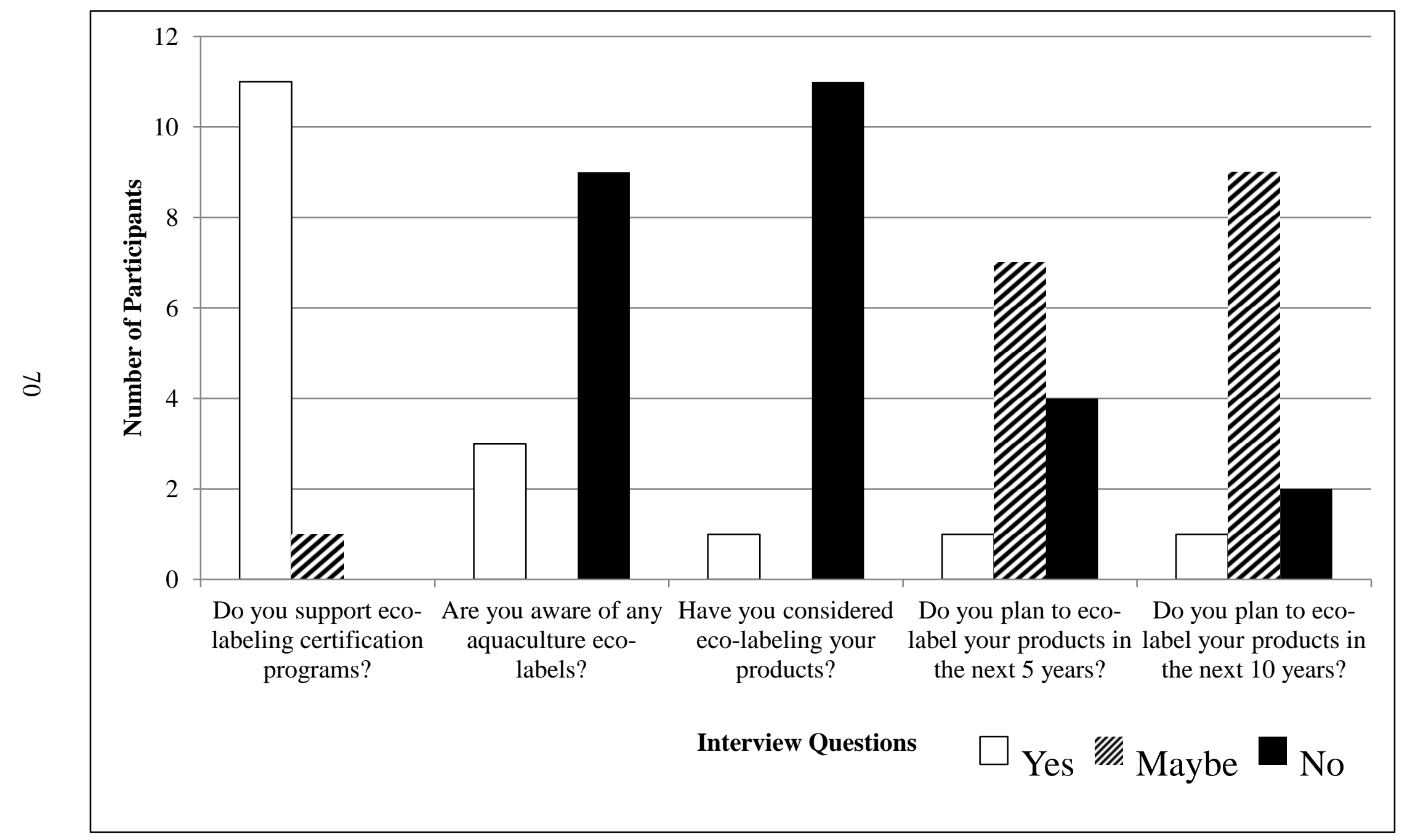


Figure 10: Summary of questions pertaining to perceptions of eco-labeling programs

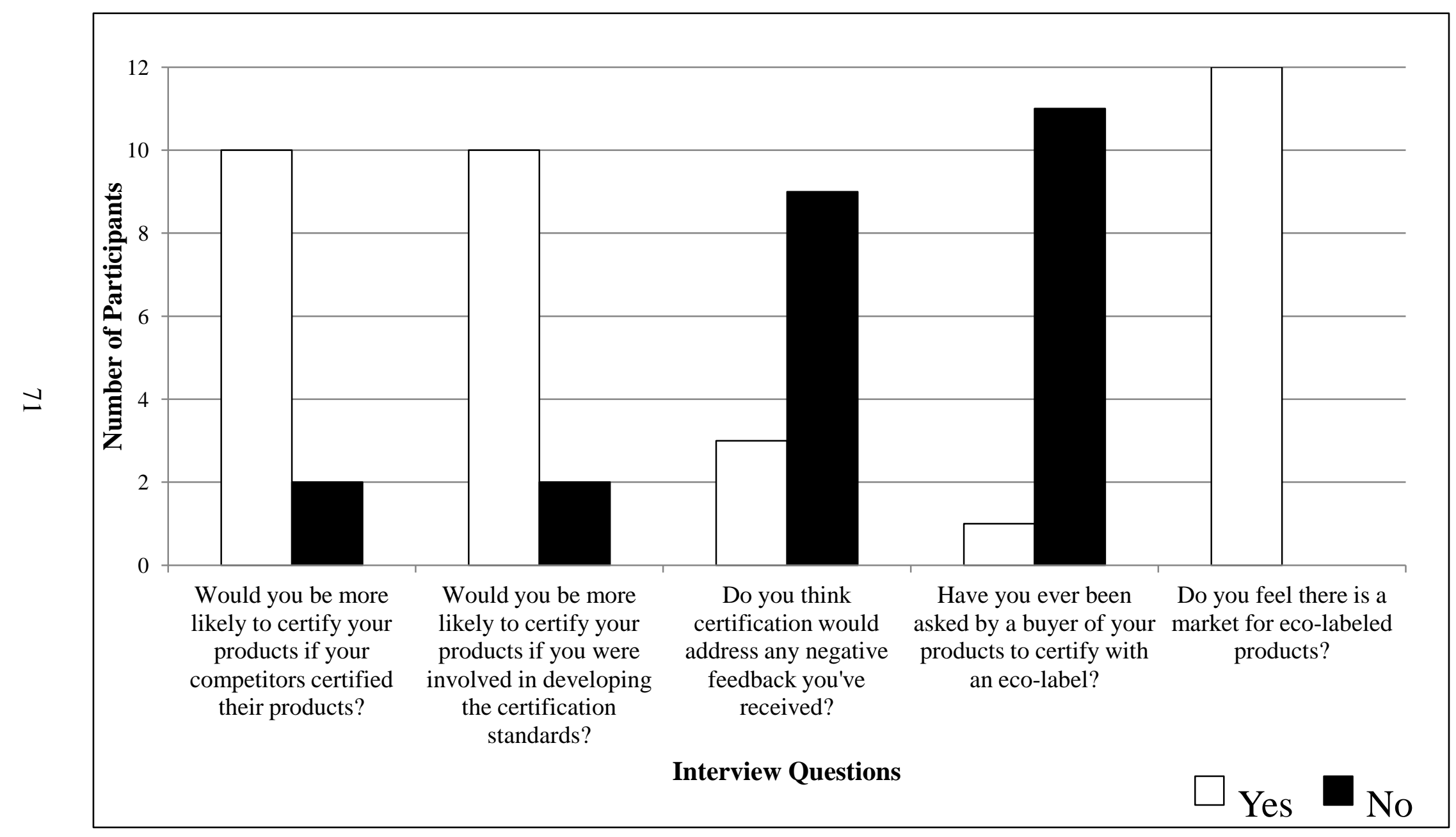


A majority of participants said they would be more likely to certify their products with an eco-label if they were involved in developing the certification standards (Figure 10) and eleven respondents said they would hypothetically be willing to serve on a committee to develop certification standards. When asked who should be responsible for developing certification criteria and standards, most agreed standards should be created by collaborations of relevant parties. Relevant parties mentioned by participants included industry groups, federal government, state government, commercial fishermen, academia, scientists, and independent third parties. While two participants felt eco-labeling criteria should exclusively be decided upon by industry associations and growers, three participants mentioned that industry groups would need to collaborate with other groups and not lead or spearhead standard setting to reduce biases.

Nearly all participants agreed they would be more likely to certify their products with an eco-label if their competitors certified their products (Figure 10). This reactive tendency suggests that once some RI producers certify their products, others may be likely to follow, resulting in a sort of certification snowball effect. Since no producers have certified their products yet with an eco-label, this reactive phenomenon is yet to be realized in practice.

Only three participants could name eco-labels for aquaculture (Figure 9). Of these three, two participants named recommendation lists like Monterey Bay Aquarium, and only one named an eco-labeling certification program like Global Aquaculture Alliance. Only one participant has been asked by a buyer to certify his products with an eco-label (Figure 10). Since most participants are not well aware of 
different eco-labeling program options for aquaculture, it is not surprising that most participants have not considered eco-labeling their products. Similarly, it is not surprising that most participants were unsure of how they would choose which ecolabeling program to use to certify their products (Table 14). Regardless of being unfamiliar with existing eco-labeling programs, participants mention that the cost of certification, time required to obtain certification, clear criteria, and a well recognized label were important qualities for eco-labeling programs they may choose (Table 14).

Table 14: Important criteria for selection for an eco-labeling program (in order of response frequency)

- Unsure how they would choose (7)

- Cost of certification (4)

- Time to obtain certification (2)

- Easily understandable criteria with clear, concise requirements (2)

- Widespread and well- recognized by the public (2)

- Clear benefits (1)

- A program that certified both wild and farmed seafood (1)

NOTE: Respondents could provide more than one criterion.

\subsubsection{Basic Characteristics and Intention to Participate in Eco-labeling Programs}

There may be certain characteristics about an aquaculturist, his farm, or his products that makes him more or less interested in eco-labeling certification. Although this study found that aquaculturists in RI are relatively homogenous in the types of products raised in that they all raise oysters primarily, the scale of farms did vary. Amount of oyster seed purchased can be used as a measure of the scale of farm. This is not an exact measure of how many oysters are sold annually, as some aquaculturists may also rely on natural spat for seed and farms may have different survival rates for seed, depending both on the size of seed purchased and other factors like disease, 
predators, or water flow that may affect the farm. In this study, the scale of the farm by annual oyster seed purchased does not appear to affect the participant's plan to participate in an eco-labeling certification program in the next five years (Table 15).

Table 15: Intention to participate in eco-labeling programs in the next five years by annual oyster seed amount

\begin{tabular}{|l|c|c|c|}
\hline & \multicolumn{3}{|c|}{ Plan to eco-label products in the next 5 years } \\
\hline $\begin{array}{l}\text { Oyster seed } \\
\text { purchased annually } \\
\text { \# seeds) }\end{array}$ & Yes & Maybe & No \\
\hline $0-750,000$ & 0 & 5 & 1 \\
\hline 750,001 and up & 1 & 2 & 3 \\
\hline
\end{tabular}

Smaller producers (less than 750,000 oyster seed purchased annually) seem most unsure about their plans to participate in eco-labeling programs in the near future, as most of them replied that they may participate in the next five years, while larger producers (greater than 750,000 oyster seed purchased annually) had mixed response of whether or not they planned to eco-label their products in the next five years (Table 15). Note that those aquaculturists who purchased smaller amounts of seed also tended to report that aquaculture was not their primary occupation.

Table 16: Intention to participate in eco-labeling programs in the next five years by type of buyer

\begin{tabular}{|l|c|c|c|}
\hline & \multicolumn{3}{|c|}{ Plan to eco-label products in the next 5 years } \\
\hline $\begin{array}{l}\text { Types of Buyer(s) } \\
\text { Aquaculturist Primarily } \\
\text { Sells to }\end{array}$ & Yes & Maybe & No \\
\hline Wholesalers & 0 & 1 & 1 \\
\hline Restaurants & 0 & 2 & 1 \\
\hline Restaurants/Farmers Markets & 0 & 2 & 1 \\
\hline Restaurants/ Wholesalers & 1 & 2 & 1 \\
\hline
\end{tabular}


Aquaculturists in this study also differed in the types of buyers they primarily sell to. In this study, the types of buyers that aquaculturists sell to does not seem to affect the participant's plans to participate in an eco-labeling program in the next five years (Table 16). Those producers who may eco-label their products in the next five years and those producers who do not plan to eco-label their products sell to all types of buyers (Table 16).

\subsection{Perceived Incentives and Disincentives of Eco-labeling Programs}

In order to answer my third research question, the survey included questions about what participants perceived to be incentives and disincentives for influencing their decision to become certified. The majority of participants felt obtaining a price premium (10), access to new markets (9), and recognition of sustainable practices (9) were strong incentives for seeking certification from an eco-label (Figure 11). Half of the respondents felt differentiation from competitors was a strong incentive to certify with an eco-label (Figure 11).

The majority of participants felt that pressure from environmental groups, the town or neighbors, and other growers were not factors that would influence their decision to become certified with an eco-label. When asked what they felt the public opinion of shellfish aquaculture is in Rhode Island, most respondents replied that in general, public opinion is positive. A few respondents did note that there is a strong, vocal minority comprised of other users, like landowners and fishermen, who have vested interests and are sometimes able to stop good aquaculture projects by protesting at public hearings or through public comments during the permit application process. 
Figure 11: Summary of perceived incentives for participation in eco-labeling programs

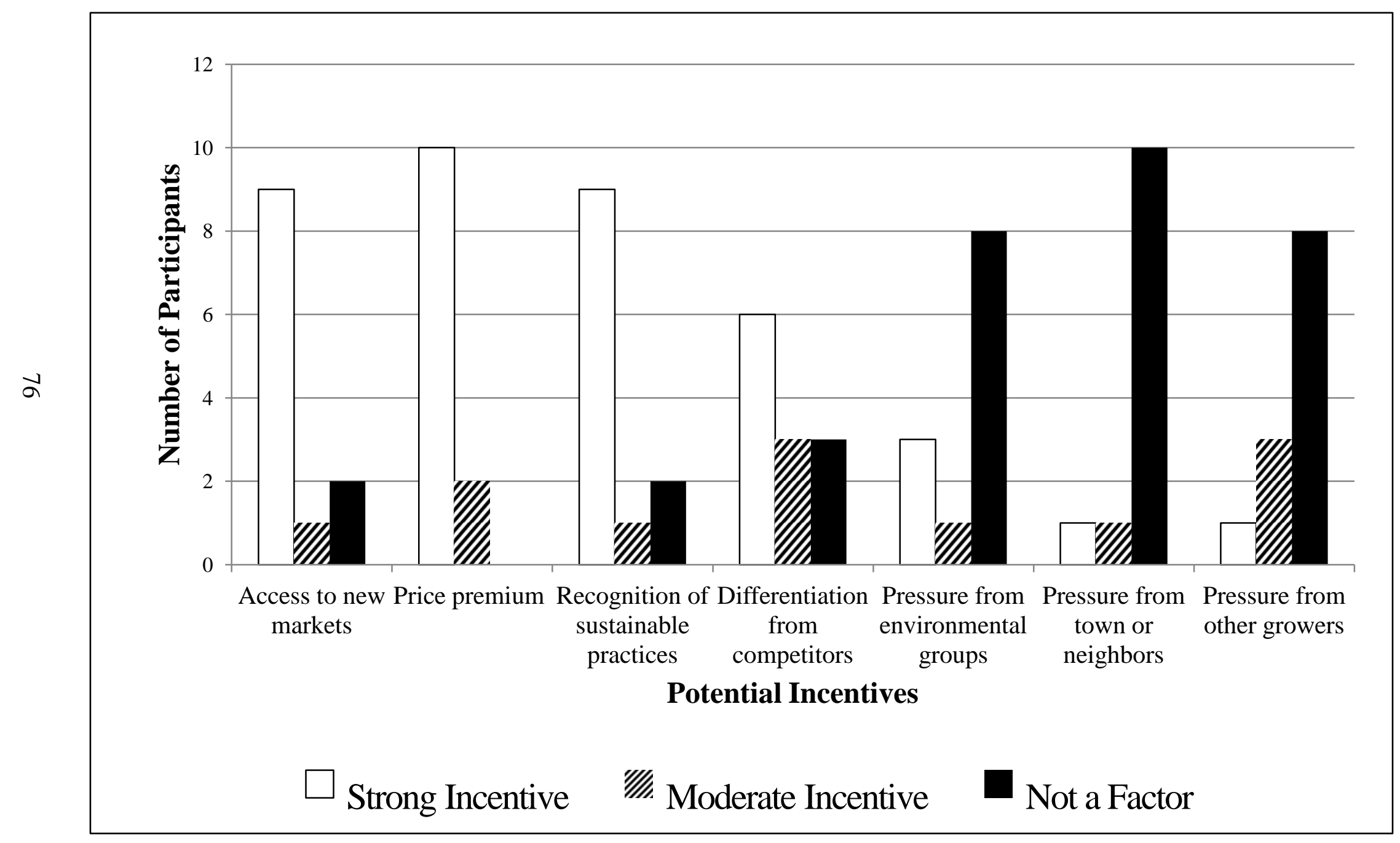


A few respondents mentioned that outreach and education are needed to help with the negative opinions that do exist and help those who do not know what aquaculture is.

Although growers did not report they felt pressure to become certified by anyone, producers still reported that being recognized as being sustainable was important to them. A few of the respondents who agreed that price premium would be an incentive mentioned that they were unsure that they would actually be able to ask buyers for more money since they said they already charged more than their competitors because of the quality of their product and would not want to price themselves out of the market. A few of the respondents who felt access to new markets could be an incentive did mention that they were unsure if they would be able to produce enough to supply any more customers, as they feel demand already exceeds the supply.

There was less agreement among participants about the primary disincentives of becoming certified with an eco-label. For instance, six participants felt the cost of certification and recordkeeping required for certification were strong disincentives, while four felt the cost of certification and recordkeeping were not factors influencing their decisions to become certified (Figure 12). Some of the participants who felt the cost of certification, recordkeeping and time required were not important factors expressed that these things are involved in every day business relations and if worth it, would not be disincentives. 
Figure 12: Summary of perceived disincentives for participation in eco-labeling programs

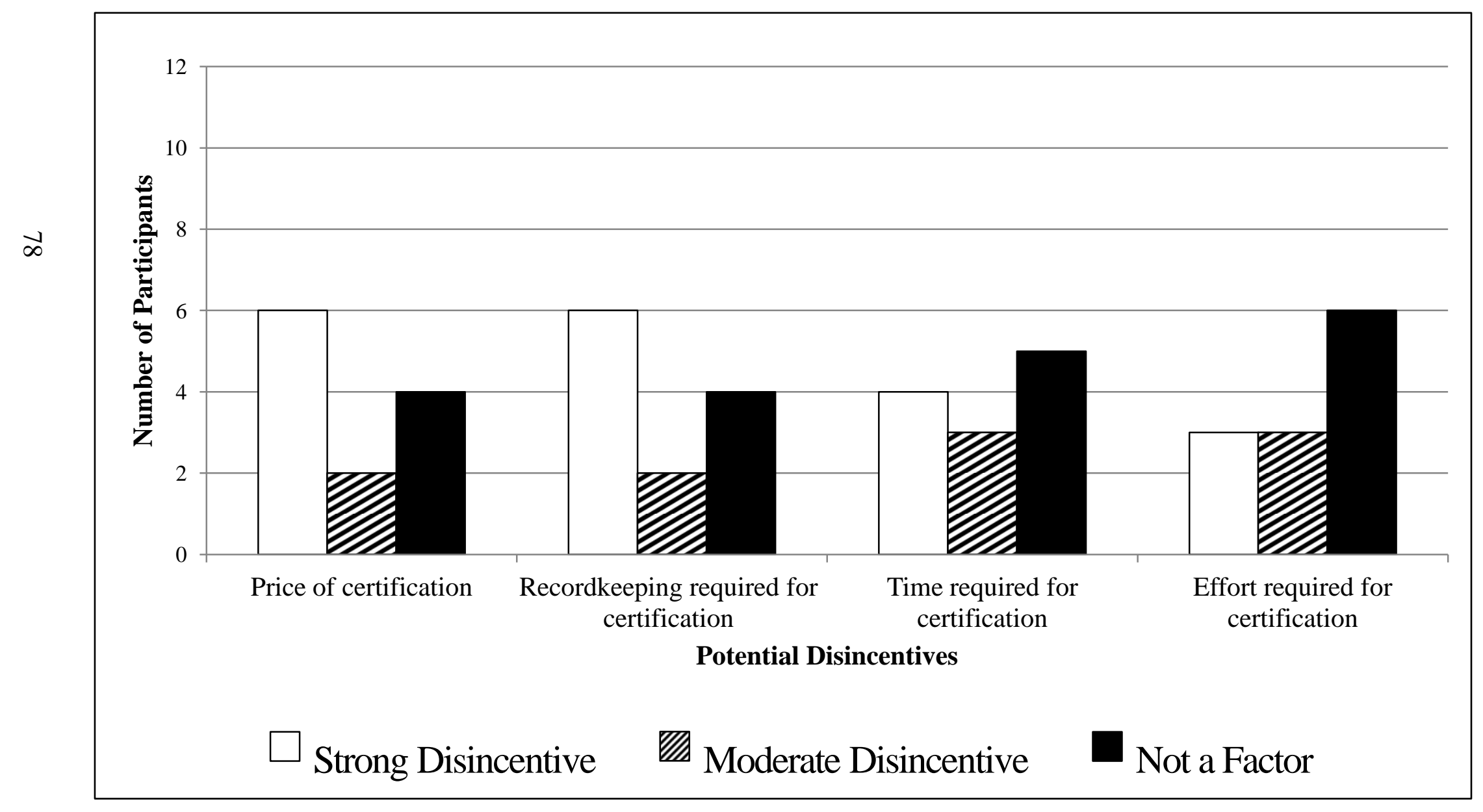


Participants were asked to express their willingness to participate in ecolabeling programs (unsure, not at all, low, moderate, high), given different certification costs (Table 17). No respondent commented that their willingness to participate in eco-labeling programs was high, given any of the certification costs. Multiple participants commented that this hypothetical set of questions was difficult to answer, without knowing how great of a price premium they could receive, as they would only participate if it made financial sense to do so.

Table 17: Participants' willingness to participate in eco-labeling certification programs with varying costs

\begin{tabular}{|l|c|c|c|c|c|c|}
\hline & & \multicolumn{6}{|c|}{$\begin{array}{c}\text { Number of Participants' Willingness to Participate } \\
\text { in Eco-Labeling Programs with Varying Cost }\end{array}$} \\
\hline $\begin{array}{l}\text { Certification } \\
\text { Cost }\end{array}$ & $\mathrm{n}$ & Unsure & Not at all & Low & Moderate & High \\
\hline$\$ 2,500$ & 12 & 1 & 5 & 4 & 2 & 0 \\
\hline$\$ 5,000$ & 12 & 1 & 7 & 3 & 1 & 0 \\
\hline$\$ 7,500$ & 12 & 2 & 8 & 2 & 0 & 0 \\
\hline$\$ 10,000$ & 12 & 2 & 8 & 2 & 0 & 0 \\
\hline
\end{tabular}

\subsection{RI Aquaculturists' Opinions of Government Regulations of Aquaculture}

Eleven participants agreed that certification programs could promote environmental quality beyond the scope of government regulation, while one was unsure. Various participants mentioned that eco-labels could help educate the public and the consumer about aquaculture, expose the benefits of shellfish aquaculture to the public, and potentially provide outreach benefits that government cannot. Some participants mentioned that government regulators do not have sufficient funds for outreach and eco-labels could help show benefits of aquaculture to the public. 
The majority of participants felt government aquaculture regulations meet objectives of promoting environmental quality in aquaculture operations (11), ensuring cultured shellfish is safe for human consumption (11), reducing user conflicts from aquaculture (10), and encouraging producer responsibility in aquaculture (10) (Figure 13). Two participants mentioned that if you follow RI CRMC regulations, you will not interfere with environmental quality, especially since shellfish farms naturally have low environmental impact. When asked about regulations ensuring that shellfish is safe for human consumption, participants said there are many safeguards in place like a biosecurity board, shellfish sanitation regulations, and health requirements. In response to this question, participants also said there was a significant amount of selfpolicing in terms of ensuring shellfish safety since there is sufficient traceability and you would be put out of business if you sold shellfish that made a consumer sick. Participants said that by only harvesting when water temperature is below a certain point, the threat of disease is minimized. Participants mentioned that the permitting process reduces user conflict by allowing the public to give input and by placing aquaculture leases in areas with the least impact on other user groups. Aquaculturists stated that the state encourages producer responsibility by requiring aquaculturists to have a performance bond to ensure aquaculture plots are not abandoned. 
Figure 13: RI Aquaculturists' opinions of government regulations of aquaculture

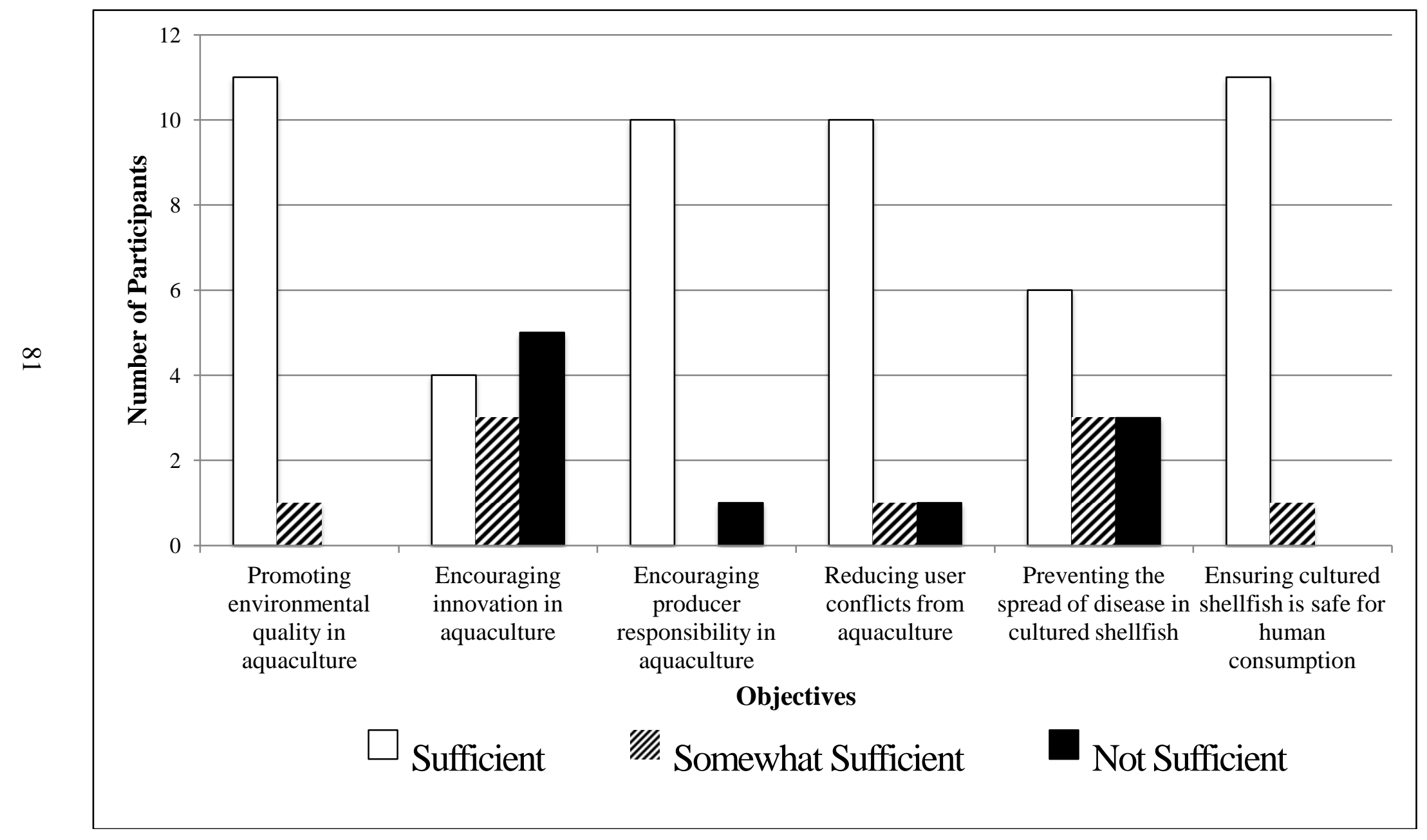


Only four participants responded that government regulations sufficiently encourage innovation in the aquaculture industry (Figure 13). One respondent commented that RI DEM and RI CRMC have opposing ideas about innovation, making it difficult to be innovative. One participant mentioned that gear restrictions tend to limit innovation. A couple participants mentioned that there is some federal funding available for projects, but not necessarily state funds. One aquaculturist commented that his colleagues have been able to take advantage of small grants to build innovative technology like solar powered upwellers. Only half of the participants feel that government regulations sufficiently prevent the spread of disease in shellfish aquaculture (Figure 13). Many of those who responded that government regulations were only somewhat sufficient or not sufficient at preventing the spread of disease expressed that they responded that way because there are not really effective ways to prevent the spread of disease in the water. This may explain why many more participants (11) said that government sufficiently ensures cultured shellfish is safe for human consumption (Figure 13). Although some said that the spread of disease in the water was not preventable, most participants expressed that once the shellfish are brought to market, regulations ensure that the shellfish are safe for human consumption and free from disease.

Although not directly asked about the roles of RI CRMC and RI DEM in aquaculture management, some participants discussed this relationship in response to other survey questions. A few participants mentioned that these state agencies have different, sometimes opposing interests in aquaculture. A couple participants felt RI DEM does not support aquaculture growth, whereas CRMC tries to expand 
aquaculture. These participants noted that DEM is primarily concerned with protecting the wild fishing industry, sometimes at the expense of aquaculture. A couple participants mentioned that these opposing interests have led to a power struggle between these two agencies and an uncertain regulatory regime, in which some aquaculturists noted they fear additional, unnecessary regulations will be imposed upon them. For instance, one participant mentioned that he does not use an upweller because of confusing rules from RI DEM and fear that RI DEM will eventually put out rules that would make him shut down the upweller. Some participants mentioned throughout the interview that there are too many regulations that apply to aquaculture that are unnecessary, such as applying regulations meant for wild harvest, like size limits, to aquaculture. 


\section{CHAPTER FIVE}

\section{DISCUSSION}

This chapter discusses important selected findings, provides suggestions for future studies, and concludes with recommendations for eco-labeling certification programs, aquaculturists, government regulators, and academics.

\subsection{Relationship of Producer, Farm, and Product and Intention to Participate in Eco-labeling}

In this study, Rhode Island aquaculturists were relatively homogenous in that they were all male and primarily raise oysters. At least half of the aquaculturists completed college, were educated in a field related to aquaculture, were previously commercial fishermen, and currently work in aquaculture as their primary occupation.

Since there was little variation among responses to questions about characteristics of the producer, farm, and product, it was difficult to compare characteristics of aquaculturists and opinions of eco-labeling certification programs. There were two variables in which RI aquaculturists had a range of responses: scale of farm, measured by amount of oyster seed purchased annually, and type of buyer to which the aquaculturist primarily sells, so I examined how these characteristics relate to the aquaculturist's intention to participate in eco-labeling programs in the next five years. In this study, there did not appear to be a relationship between the scale of the

farm or the type of buyer and the aquaculturist's plan to eco-label. There likely is not a 
relationship because there are many other factors that influence intention to participate in eco-labeling certification. For example, this study found there was limited awareness of eco-labeling certification programs in general, which likely reduces intention to participate. Since eco-labeling certification is a new concept to these aquaculturists, basic characteristics might become more important in influencing an aquaculturist's decision to become certified in the future if eco-labels gain popularity in Rhode Island and worldwide. Small sample size, which was unavoidable due to the small number of participants in the RI aquaculture industry, was a major limitation of this study, and could have contributed to the lack of relationship between characteristics and intention to participate in eco-labeling. Future studies could expand this type of analysis of basic characteristics and intention to participate in eco-labeling to other states and aquaculturists who raise different products to not only obtain a larger sample size, but also to attempt to find greater variations in the types of characteristics explored in this study. For instance, future studies could investigate if finfish aquaculturists have different opinions about eco-labeling certification than shellfish aquaculturists, or if there is a difference of opinion across aquaculturists in different states or countries.

\subsection{Relationship of environmental concern with stakeholder characteristics and} attitudes

Eco-labeling certification programs have the potential to improve the environment and social conditions if producers change aspects of their operations to comply with certification standards. In this respect, eco-labeling certification is not 
just a business strategy or marketing tool but can also be seen as a measure producers can take to improve the environment by choosing to meet stricter environmental standards than may be required by law.

Stern (2000) defines environmentally significant behavior in two ways, with an impact-oriented definition that focuses on the actual impact of a behavior on the environment, and with an intent-oriented definition, defined as "behavior that is undertaken with the intention to change (normally, to benefit) the environment" (p. 408). Environmental self-reported behaviors and behavioral intentions can be predicted by a pattern of attitudinal factors, including norms, beliefs (like the belief of an ecological worldview demonstrated by the NEP score), and values (Stern, 2000). In addition to attitudinal factors, other causal variables of environmentally significant behavior are contextual forces, including community expectations and government regulations, personal capabilities, including knowledge and skills required for particular actions, and habit, referring to routines that would need to be broken for a new behavior (Stern, 2000).

In this study, I found an ecological worldview demonstrated by a high NEP score did not seem to influence existing or intended behavior of participating in ecolabeling programs. In fact, my findings suggest that lower NEP scores are related to intentions to participate in eco-labeling programs. Since an ecological worldview is just one belief that can influence the decision to become certified with an eco-label, it is not surprising that there was a slightly negative relationship between the NEP score and interest in eco-labeling certification. In fact, environmentally significant behavior is so complex that Stern (2000) warns that studies that only examine attitudinal factors 
will likely only find effects inconsistently. Dunlap (2008) also recommends that to predict environmental behaviors, the NEP scale should be used with other variables. Other portions of this study examined other variables such as contextual forces, like pressure from the local community and opinions of government regulations, and personal capabilities, like knowledge of eco-labeling certification programs. Market forces may also be more important to aquaculturists than environmental concern with respect to opinions about eco-labeling. This study provided insight into some of the potential variables that could influence an aquaculturist to seek eco-labeling certification. Future studies could investigate other types of variables, in addition to the NEP score, that may influence the behavior of seeking eco-labeling certification.

The value of understanding aquaculturists' general environmental concern is not limited to predicting environmentally significant behavior, like eco-label certification. Since aquaculturists work in the marine environment and directly impact that environment, their opinions of human interaction with the environment are important. For example, an aquaculturist that underestimates how humans affect an ecosystem or overestimates the availability of resources may conduct his business differently from an aquaculturist with an ecological worldview. In this study, the total NEP score for each aquaculturist gives a relative measure of his environmental concern. As noted in Chapter 4, RI aquaculturists in this study demonstrated moderate to high levels of environmental concern. Since shellfish aquaculturists have been praised as being advocates for environmental quality and environmental stewards (Lee, 2008; Dewey et al., 2011), results of this study confirm that most of these 
aquaculturists do have an ecological worldview, demonstrated by moderate to high NEP scores.

Mental models describe the way individuals organize their beliefs and values, and models that are shared within a culture or social group are called cultural models (Kempton et al., 1995). It is possible that aquaculturists in RI share a cultural model that influences their individual levels of environmental concern. One study suggested that infrequent contact with nature may be related to a lack of environmental concern (Kempton et al, 1995). Since it is an aquaculturist's profession to work in nature, it is possible that this frequent contact with nature influences their level of environmental concern.

In this study, there seems to be a relationship between formal education and NEP score, as the mean NEP score was highest in the group of aquaculturists with the highest level of formal education, and lowest in the group with the lowest level of formal education. Although formal education does seem to facilitate environmental concern, it is important to note that aquaculturists in this study demonstrated moderate to high levels of environmental concern overall.

Since RI aquaculturists already seem to have moderate to high levels of environmental concern, regulators and other individuals or organizations who wish to conduct informal environmental education or outreach programs for aquaculturists would not necessarily need to focus their programs on changing environmental attitudes of aquaculturists. If the goal of the outreach program is to encourage aquaculturists to participate in eco-labeling, these programs could target other 
knowledge or attitudinal factors that may affect willingness to participate in ecolabeling programs.

\subsection{Communication with Buyers and the Local Food Movement}

This study found that RI aquaculturists use different methods of communication with various types of buyers, some who are direct consumers of their product and others who move the product along various stages of the supply chain. For instance, those aquaculturists who sell at farmers' markets reported that they have the most direct contact with the end-user (actual person who consumed the product), and those who sell to wholesalers are the most removed from the end user, as many reported that they did not regularly communicate with the end-user. Since many producers who sell to restaurants speak directly to chefs, there is likely only one "middle-man" between the producer and the direct consumer.

One important function eco-labels serve is communicating the environmental and social attributes of a product from producer to consumer. Eco-labels are said to provide a quality assurance role by communicating product information on environmental impacts (Bratt et al., 2011), allowing consumers to make informed choices and producers to share information about environmental and social impacts of the product with consumers.

Since producers in this study have varying levels of contact and methods of communication with the final consumers of their product, it is possible that producers may have different needs for an eco-label. Since some of the producers who sell at farmers' markets and to restaurants report that they already communicate with the 
final consumers of their products by speaking to them directly, they might have a different need for an eco-label than those producers who do not have an opportunity to discuss environmental and social attributes of their products directly with consumers. Those producers who already are able to interact with their consumers might seek ecolabels for reasons other than communication, like ensuring their products meet a high standard of sustainability.

This study did not find that aquaculturists who sell to particular types of buyers were more or less likely to have been asked by a buyer to certify their products with an eco-label. Since only one producer was asked to certify their products by a buyer, I could not make any claims about certain types of buyers being more or less likely to request that an aquaculturist seek certification. Future studies could further investigate this link by asking a greater number of aquaculturists how they communicate with their buyers about environmental and social impacts of their products, and comparing if varying levels of communication affect an aquaculturists' intent to certify their products with an eco-label.

Since local food systems have been said to facilitate communication between producer and consumer (Johnson and Endres, 2011), it is possible that those producers who sell locally can also more easily communicate directly with their buyers and may not need to use eco-labels to communicate information about their product. Only two of the participants in this study said they sold their products mainly out of state, so most aquaculturists do sell at least a portion of their products in RI. Four respondents said they participate in the "Get Fresh Buy Local" program. In addition to those in the "Get Fresh Buy Local" program, other participants also mentioned that they 
emphasize that their product is local to buyers. Many of the producers said that the location where the product is raised is included on the label or brand name they use. It should also be noted that participants were not explicitly asked in survey questions their thoughts or opinions on the local food movement, or whether or not they emphasize that their product is local to consumers or buyers. Participants brought up that they market their product as local in response to questions asking about how they market their product and communicate with their buyers. While the local food movement was not a topic I intended to explore in this study, it does appear to influence RI aquaculturists. Since many of the aquaculturists use the location of where their product is raised as part of its name or brand and participate in local food programs, they are communicating that their product is local to RI consumers. Currently, it appears the local food movement is more important to RI aquaculturists than eco-labeling certification programs, as evidenced by their participation in local food programs and their emphasis of location in product branding and advertising, compared to their lack of participation in eco-labeling programs.

For other products, such as produce, more than half of consumers in the United States report that purchasing local produce is more important to them than purchasing organic produce (Mintel GNPD and Mintel Oxygen Reports, 2012). As the local food movement progresses and eco-labels gain popularity, it will be important to see how they interact and influence each other. For instance, there have been calls for seafood eco-labels to take on a more holistic approach to sustainability by considering impacts that occur after seafood products are harvested or landed, such as processing and 
transport (Thrane et al., 2009). These are some of the impacts that the local food movement aims to minimize.

As noted in Chapter 2, few eco-labeling programs for shellfish aquaculture have certified producers in America. Therefore, buyers in the United States that wish to purchase or sell eco-labeled aquaculture products would likely seek certified aquaculture products from other countries. For instance, Wegmans, a grocery store chain in the northeastern United States, sells seafood products certified with the Global Aquaculture Alliance from Ecuador and Thailand (Wegmans, 2013). If buyers of shellfish aquaculture products intend to purchase products that have minimal negative environmental impacts, they must weigh the potential benefits of local food production and consumption, such as reduced waste from packaging and reduced greenhouse gas emission from transportation, against the potential benefits of various eco-labeling certification programs.

\subsection{Lack of Awareness of Eco-labeling Programs}

Since eco-labeling certification programs for aquaculture are voluntary at this time, aquaculturists need to be aware of the programs that are available to them in order to seek certification. In this study, only three of the participants could name ecolabels for aquaculture and seven said they were unsure how they would choose between certification programs. Of the three participants who were aware of ecolabels for aquaculture, two named recommendation lists, like Monterey Bay, and only one named an eco-labeling certification program, like Global Aquaculture Alliance. 
Recommendation lists, like those produced by Monterey Bay Aquarium's Seafood Watch Program, do not require any action from the producer but just provide consumers with grades or ratings of various types of seafood based on the methods and location of the product. For example, Monterey Bay reports that they research current science on a species, evaluate this information against their standards, and then provide their recommendation of "Best Choice," "Good Alternatives," or "Avoid" (Monterey Bay Aquarium, 2007). Monterey Bay Aquarium’s Seafood Watch program gives farmed oysters a "Best Choice” rating (Monterey Bay Aquarium, 2013).

Therefore, these recommendations do not provide distinctions between various oyster aquaculturists, but just distinguish farmed oysters from other seafood choices.

Given the different methods that can be used to raise shellfish and the varying scales of aquaculture production, eco-labels help distinguish between different shellfish aquaculture operations on the basis of their particular environmental and social impacts. However, since recommendation lists do not require that any individual farm be inspected, producers could receive some of the benefits of being recognized as a "best choice" for sustainability, without the cost or time required for an eco-labeling certification.

Only one producer in my study had been asked by a buyer to certify his products with an eco-label and that same producer is the only one who said he had considered eco-labeling before the interview. Despite the lack of knowledge about existing eco-labeling programs, nearly all the aquaculturists in this study said they supported eco-labeling programs and some said they might consider eco-labeling their 
products in the future. Aquaculturists in this study would likely need to invest time into learning more about eco-labeling programs before they seek certification.

When asked how they might choose between eco-labeling programs, two aquaculturists replied that they would seek a widespread eco-label that is well recognized by the public. This reveals a dilemma. Eco-labels will only become well recognized by the public if enough producers choose to certify their products, yet some producers only want to certify their products with well-known labels.

Future studies could ask those aquaculturists in other areas who are already certified how they learned about eco-labeling programs and how they chose between programs, providing insights on how to effectively communicate this information with aquculturists in RI and elsewhere. Future studies could also explore how eco-labeling certification programs currently market and reach out to aquaculturists to encourage them to participate in their programs.

\subsection{Perceived Incentives and Disincentives of Eco-labeling Programs}

Respondents identified obtaining a price premium, access to new markets, recognition of sustainable practices, and differentiation from competitors as the strongest incentives for seeking eco-labeling certification programs. The majority of participants said that pressure from environmental groups, other growers, and the surrounding town or neighbors would not influence their decision to become certified. The finding that most participants did not fear pressure from any group may be because many aquaculturists expressed that public opinion of shellfish aquaculture in $\mathrm{RI}$ is generally positive. 
Eco-labels allow consumers to differentiate between goods and services by their environmental and social attributes, and this differentiation allows certified producers to charge a price premium (Blackman and Rivera, 2011). Half of the producers said that being differentiated from their competitors with an eco-label would be a strong incentive to seek eco-labeling certification. Many aquaculturists reported that they would also be more likely to certify their products with an eco-label if their competitors sought certification. However, if many members of the industry sought certification, the benefit of differentiation from competitors might be diluted. In this sense, if enough producers sought certification, having an eco-label could become a new sort of standard, rather than demonstrating a level of compliance with stricter sets of environmental and social criteria.

If eco-labels for shellfish aquaculture gain popularity, there may be negative implications for Rhode Island aquaculturists if they do not seek eco-labeling certification in the future. To a consumer or buyer of a product, the choice between one product that is certified and one that is not may imply that the certified product is sustainable and the product without certification is not. However, the two products could have similar environmental and social attributes, but one producer simply chose to seek certification and the other producer did not. Regardless, the producer who did not seek certification would not be recognized for their sustainable practices, might be perceived as less sustainable than they are, and appear less desirable to buyers concerned with sustainability. 


\subsubsection{Price Premiums and Certification Cost}

In this study, it seems that price premiums had a greater influence on an aquaculturists' willingness to participate in eco-labeling certification programs than the cost of certification. This was surprising, given that both affect a producer's overall profit. While ten respondents identified obtaining a price premium on their products as a strong incentive to participate in eco-labeling and the other two respondents identified a price premium as a moderate incentive, only six participants identified the cost of certification as a strong disincentive, two identified cost as a moderate disincentive, and four felt cost was not a factor influencing their decision. It is possible that participants had a difficult time describing incentives and disincentives because they were hypothetical. For instance, I did not provide monetary figures of how large of a price premium could be expected or obtained, how much programs cost, or how much time or effort would be required for certification. This may have impacted responses since factors like cost of certification could be offset by other factors like price premium.

I asked participants about their willingness to participate (not at all, low, moderate, high) in eco-labeling certification programs that cost $\$ 2500, \$ 5000, \$ 7500$, or $\$ 10000$ annually. None of the aquaculturists in my study were highly willing to participate in eco-labeling programs given any of these annual costs. Determining which program costs to include in my survey was a challenge, and likely affected responses to this set of questions. Some eco-labeling certification programs do not explicitly list the cost of certification on their websites (ASC, 2013b). Friend of the

Sea's website reports that its certification has a first year fee that starts at 5.000 Euros 
upwards (Friend of the Sea, 2013b), which is about \$6671 USD, using a \$1.33 US Dollar per Euro exchange rate (fx-rate.net, 2013). Food Alliance reports that its certification cost is annual, based on a percentage of gross sales of certified products (Food Alliance, 2013). Individual producers pay 0.5\% of their first $\$ 175000$ in gross sales (at least \$400) in order to be certified by Food Alliance and members in cooperatives and producer groups pay a flat fee of $\$ 810$ every three years to cover inspection costs (Food Alliance, 2013). Therefore, the questions in my study were more reflective of the types of cost likely incurred by an aquaculturist wishing to seek certification with Friend of the Sea or a large producer under Food Alliance. Based on my findings, it is unlikely that the aquaculturists in my study would seek eco-labeling certification if it cost over $\$ 2500$ annually. If future studies wish to use these types of questions, I suggest they also include lower hypothetical costs to be more reflective of what a small producer could pay under the Food Alliance program (minimum of $\$ 400$ for an individual producer annually and a minimum of $\$ 270$ annually for a producer in a cooperative).

Some certification programs' costs are reliant on the scale, complexity, and location of the farm, and some of these programs do not make information regarding the exact cost of certification easily accessible to producers. Certification programs without a fixed annual cost should provide information about how much certification has cost those producers who are already certified, so producers considering certification could find certified producers who raise similar products at a similar scale and gain a better understanding of what the certification process would likely cost. Future studies could ask certified producers if they have received many of the benefits 
from eco-labeling certification that were identified as potential incentives in this study, such as a price premium and access to new markets, or faced some of the drawbacks of eco-labeling certification that were identified as potential disincentives in this study, such as cost of certification and additional recordkeeping.

\subsection{Government Regulation of Aquaculture in Rhode Island}

Overall, aquaculturists in this study felt government regulations were sufficient for promoting environmental quality in aquaculture, encouraging producer responsibility, reducing user conflicts, and ensuring farmed shellfish is safe for human consumption. One important finding was that aquaculturists felt there is a significant amount of self-policing that occurs in a number of these areas. For example, participants said that by only harvesting shellfish when water temperatures are below a certain point, it helps to ensure the shellfish are free of disease and safe for human consumption. Given the traceability of shellfish products, the aquaculturists said they take every precaution to ensure that their products do not get anyone sick, as this type of incident would likely put an aquaculturist out of business.

Another main finding is that aquaculturists did not feel that state and federal government agencies encouraged innovation in the aquaculture industry. Some commented that gear restrictions and other regulations limit the amount of innovation that can take place. If aquaculturists are given funding and encouraged to make innovative developments in the field, they have shown they can make worthwhile contributions. For example, one aquaculturist commented that his colleagues have been able to take advantage of small government grants to build innovative technology 
like solar powered upwellers. Given the variety of ways that shellfish can be grown, encouraging innovation, providing funding for aquaculture innovation, and identifying those regulations that limit innovation should be addressed by regulators.

Another finding that emerged that was not even explicitly addressed through a survey question was a confusion and frustration about the roles and agendas of RI CRMC and RI DEM, two important agencies for RI aquaculture management. Some participants expressed their feelings that these two agencies have opposing interests in aquaculture, with CRMC encouraging aquaculture development and DEM discouraging aquaculture. One participant shared that he did not purchase an upweller because he felt unsure of future regulations that might require him to remove the upweller. Regulators should be aware that some aquaculturists are not making investments into their businesses that they would otherwise make, just out of fear of future regulation, such as the upweller example. During January 2013, a series of meetings began to discuss the creation of a new Rhode Island Shellfish Management Plan and this effort involves both RI CRMC and RI DEM (Rhode Island Sea Grant, 2013). The purpose of this plan is to "provide comprehensive policy guidance regarding state management and protection measures for shellfish resources" (Rhode Island Sea Grant, 2013). During the development of this plan, agencies should address the concerns raised by aquaculturists in my study to encourage agencies to develop a common vision for aquaculture in Rhode Island and create a regulatory environment that allows aquaculturists to safely invest in their businesses, without fear of changing regulations. 


\subsubsection{Government Regulations and Eco-labels}

Nearly all the aquaculturists in this study agreed that eco-labeling certification programs could promote environmental quality in aquaculture beyond the scope of government regulation. This was an interesting finding considering most aquaculturists did not know much about eco-labeling certification programs for aquaculture, and therefore did not know what the standards or criteria for the programs include or what environmental benefits certification programs may provide. In fact, there has been limited research to measure how certification programs affect environmental quality, especially for aquaculture. Limited analyses have been conducted to evaluate the effects of seafood eco-labeling certification on the environment (Blackman and Rivera, 2011), and most of these analyses have focused on the impacts of wild fishery certification and were not conducted in the United States (e.g., Phillips et al., 2003; Hicks and Schnier, 2008; Ward, 2008). Future studies could investigate the environmental and social effects of aquaculture certification in the United States and these could be compared with evaluations of the environmental and social effects of aquaculture laws.

The extent to which eco-labels could promote environmental quality beyond the scope of government regulation depends on how stringent the eco-labeling criteria are in comparison to the relevant aquaculture laws. Since most eco-labeling certification programs are international programs, producers may find it easier or more difficult to meet the criteria required by the certification program, depending on the aquaculture laws already required by the state or country in which the aquaculturist operates. 
Future studies could analyze the criteria and standards required by the different certification programs and compare these to regulations required by federal and state aquaculture laws in the United States. This comparison could identify areas where eco-labeling certification criteria and aquaculture laws overlap, and where they differ. This comparison could not only provide lawmakers with ideas about regulations that are regarded as promoting a high level of environmental protection, but also provide clarification for aquaculturists by identifying certification criteria that they may already meet due to their compliance with relevant aquaculture laws. This would help aquaculturists know what changes they might need to make to their operations to come into compliance with the certification criteria. More than one aquaculturist mentioned they would seek out certification programs with easily understandable criteria with clear, concise requirements. By simplifying certification programs by region to include only those requirements that are not already required by law may help simplify the certification process for producers.

\subsection{Recommendations}

This section provides recommendations that emerged from my findings for eco-labeling certification programs, aquaculturists, government regulators for aquaculture, and academics, and recommends areas for future research.

\subsubsection{Management Recommendations}

1. Regulators and other individuals or organizations that wish to conduct environmental education or outreach for aquaculturists in Rhode Island 
should consider that aquaculturists already have moderate to high levels of environmental concern, evidenced by their overall NEP scores. Resources do not need to be spent on trying to increase RI aquaculturists' environmental concern.

2. Since RI aquaculturists seem to care more about the local food movement than eco-labeling certification at this time and since the local food movement and eco-labeling certification programs share some common goals, eco-labeling programs and leaders of the local food movement should consider how their missions relate and consider coordinating their efforts.

3. To get aquaculturists to invest in eco-labeling programs, certification programs should consider conducting outreach to both producers, so they are aware of the available programs, and consumers, so that the programs are well recognized enough for producers to want to participate.

4. Eco-labeling programs should report tangible benefits and costs aquaculturists should expect from certification, using testimonials from those producers who are already certified with their programs. If prospective producers were able to see testimony from other producers who are certified about the actual benefits and costs of certification, they might be more willing to seek eco-labeling certification.

5. This study found that some aquaculturists in RI feel that state agencies responsible for aquaculture have opposing interests, which constrains aquaculture growth. Since multiple agencies regulate aquaculture in Rhode 
Island, those agencies should work together to develop a common vision for aquaculture development in the state to create a stable regulatory environment in which aquaculturists feel comfortable investing in the aquaculture industry.

\subsubsection{Recommendations for Future Studies}

1. To better understand why aquaculturists might be willing to participate in eco-labeling, future studies could expand the sample to include aquaculturists who raise different types of animals and aquaculturists in different areas.

2. To improve understanding about how the NEP score influences intent to participate and participation in eco-labeling certification programs, future studies could analyze aquaculturists' NEP scores in conjunction with other types of variables, like contextual forces or personal capabilities.

3. This study found that RI aquaculturists sell to a variety of buyers and utilize different methods of communication to share information about their products with their buyers. Since a primary purpose of eco-labeling is to facilitate communication between producer and consumer about the environmental and social impacts of aquaculture products, future studies should examine how existing methods of communication between a producer and a consumer may affect the need for an eco-label.

4. To better understand how and why aquaculturists may seek eco-labeling certification, future studies should investigate how certified aquaculturists 
in other areas learned about eco-labeling programs, how those aquaculturists chose between programs, what influenced their decisions to seek certification, and what benefits and challenges those aquaculturists experienced from certification.

5. Future studies should analyze the criteria and standards required by different eco-labeling certification programs and compare these to regulations required by federal and state aquaculture laws to identify overlaps and differences. This comparison could clarify the potential role of eco-labeling certification in improving environmental and social conditions, beyond what is already ensured by government regulation. 


\section{CHAPTER SIX}

\section{CONCLUSION}

Since wild fisheries are variable and some are overexploited, the increasing demand for fish products has led to a rise in aquaculture production worldwide (CostaPierce, 2003). As aquaculture production grows worldwide (FAO, 2012), increasing attention will be paid to the environmental and social impacts of the industry. Since mollusk aquaculture comprises a large share of worldwide and marine aquaculture production (FAO, 2012), minimizing its negative impacts is important.

Eco-labeling has been suggested as a tool for assessing and ensuring the sustainability of aquaculture by evaluating aquaculture operations against a set of environmental (and often social) criteria. Aquaculturists who meet the certification criteria are allowed to place an eco-label on their product, communicating to the buyers of their product that their operations meet that certification program's standards. In the past 25 years, over five international eco-labeling certification programs have emerged for shellfish aquaculture, most of which have been founded in the past seven years. Many organic certification programs for aquaculture and seafood recommendation lists that include aquaculture products have also gained popularity in recent years, suggesting that consumers are increasingly concerned with the sustainability of cultured seafood products and producers are increasingly encouraged to share information about the environmental and social impacts of their products. 
Since eco-labeling certification programs for aquaculture are voluntary at this time, they will only be utilized if aquaculturists find value in them. Since Rhode Island aquaculturists almost exclusively raise bivalves, interviewing RI aquaculturists provided a valuable case study for understanding aquaculturists' opinions of ecolabeling certification for shellfish aquaculture. This study found that RI aquaculturists do not currently participate in eco-labeling certification programs, and only one aquaculturist plans to eco-label his products within the next ten years. While other aquaculturists said they might consider eco-labeling their products in the future, this study found that most aquaculturists interviewed were unaware of the eco-labeling programs available for aquaculture and unsure how they would choose between certification programs. Since only one aquaculturist in this study was asked by a buyer to certify his products, most aquaculturists do not feel there is currently a consumer demand requiring them to seek eco-labeling certification.

This study found that obtaining a price premium from certification, gaining access to new markets, achieving recognition of sustainable practices, and being differentiated from competitors were the strongest incentives for participation in ecolabeling programs. The cost of certification and additional recordkeeping required for certification were identified as the strongest disincentives for participation in ecolabeling programs. Pressure from environmental groups, neighbors, and other growers, as well as the additional effort and time required for the certification process were not important factors influencing the decision to seek certification. For aquaculturists in RI to participate in eco-labeling certification, they will have to learn more about the available certification programs and be encouraged to join by incentives like price 
premiums and access to new markets. In order for RI aquaculturists to seek certification, disincentives like cost of certification and additional recordkeeping would likely need to be offset by potential benefits.

As the popularity of eco-labeling grows in other industries such as produce, timber, and wild seafood (Eilperin, 2010) and as new aquaculture eco-labeling programs gain recognition, producers of aquaculture products may become more interested in seeking eco-labeling certification in the future. Currently, aquaculturists in RI have been able to communicate sustainability efforts through other measures, like speaking directly with consumers, providing information on their websites, and giving tours of their aquaculture farms to buyers and the public. Until these measures are no longer sufficient or other market influences change their opinions, most aquaculturists in RI will not seek eco-labeling certification in the near future. 


\section{APPENDICES}

\section{Appendix A: Methods of Bivalve Culture}

Oyster Bags Set Above the Seafloor (Source: Croke, 2012)

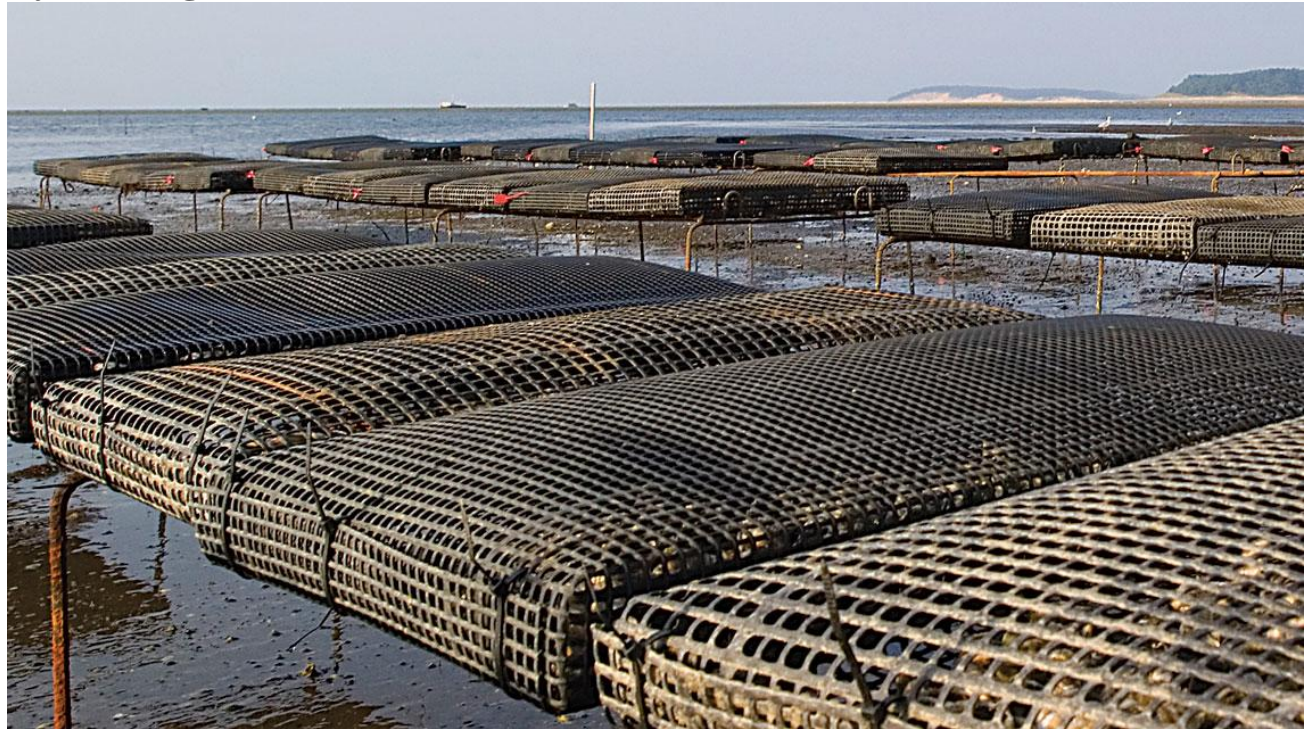

Oyster Cage Set Above the Seafloor (Source: Nealon, 2011)

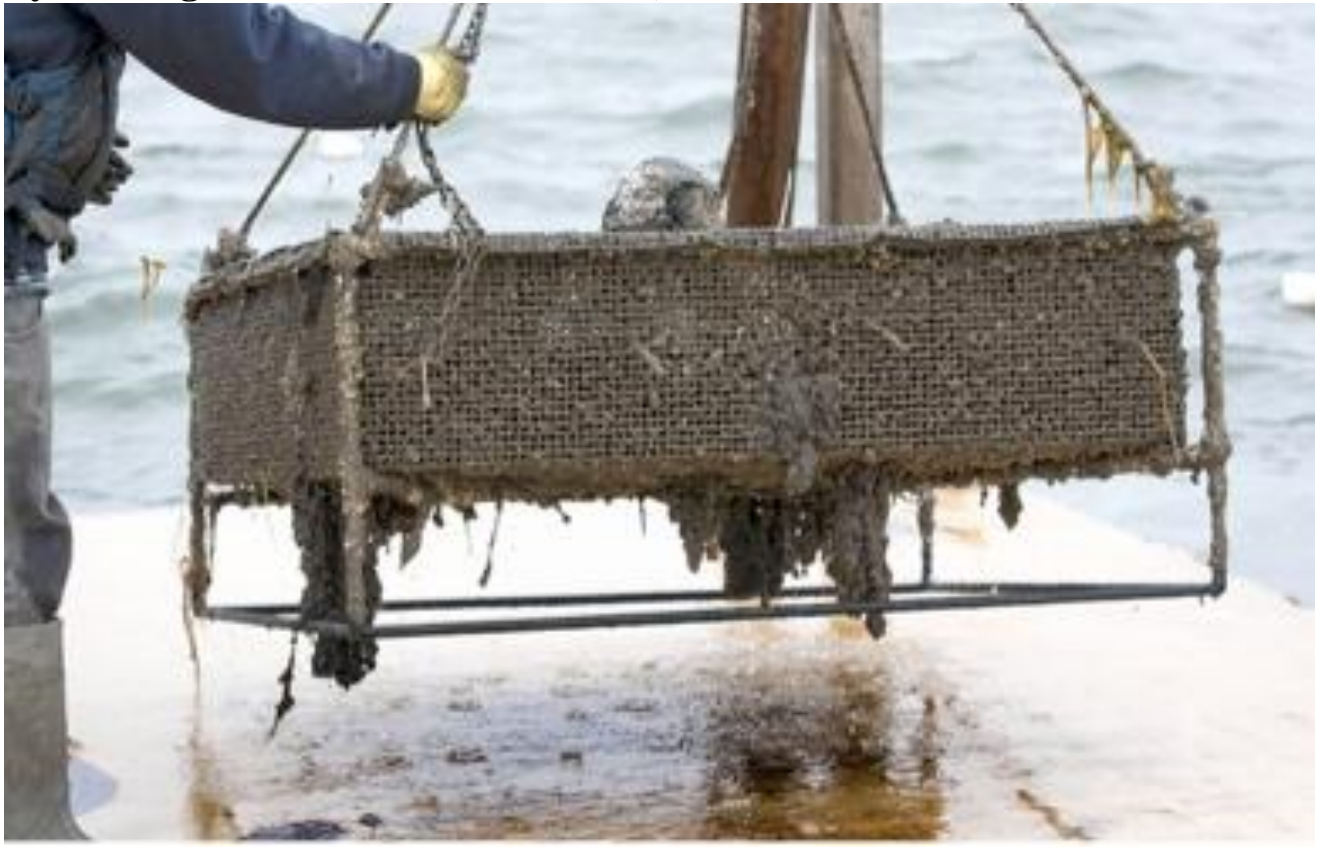


Hanging Oyster Bags (Source: NOAA Fisheries, 2013)

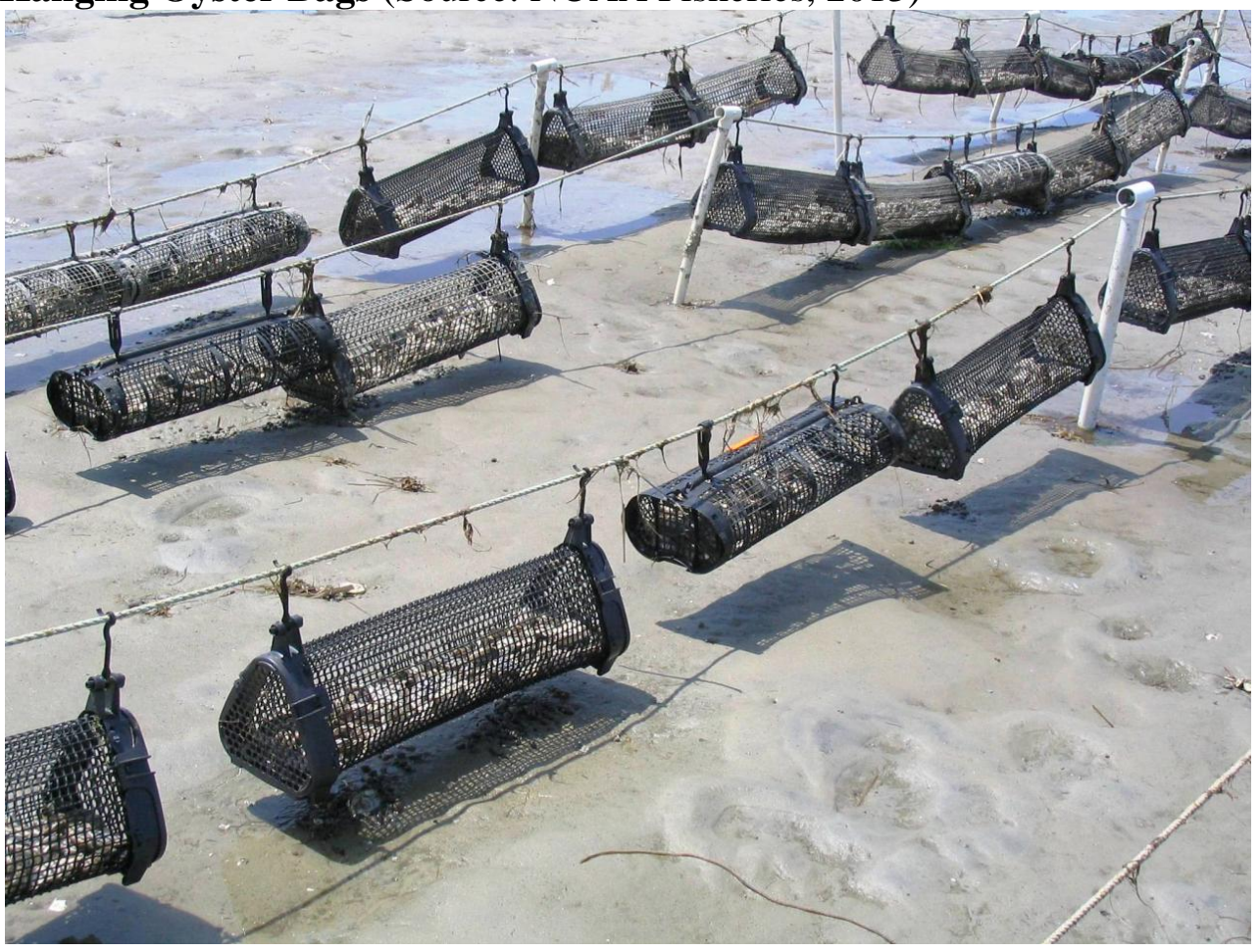

Oyster Rack (Could be placed directly on bottom or on stilts)

(Source: Kobell, 2011)

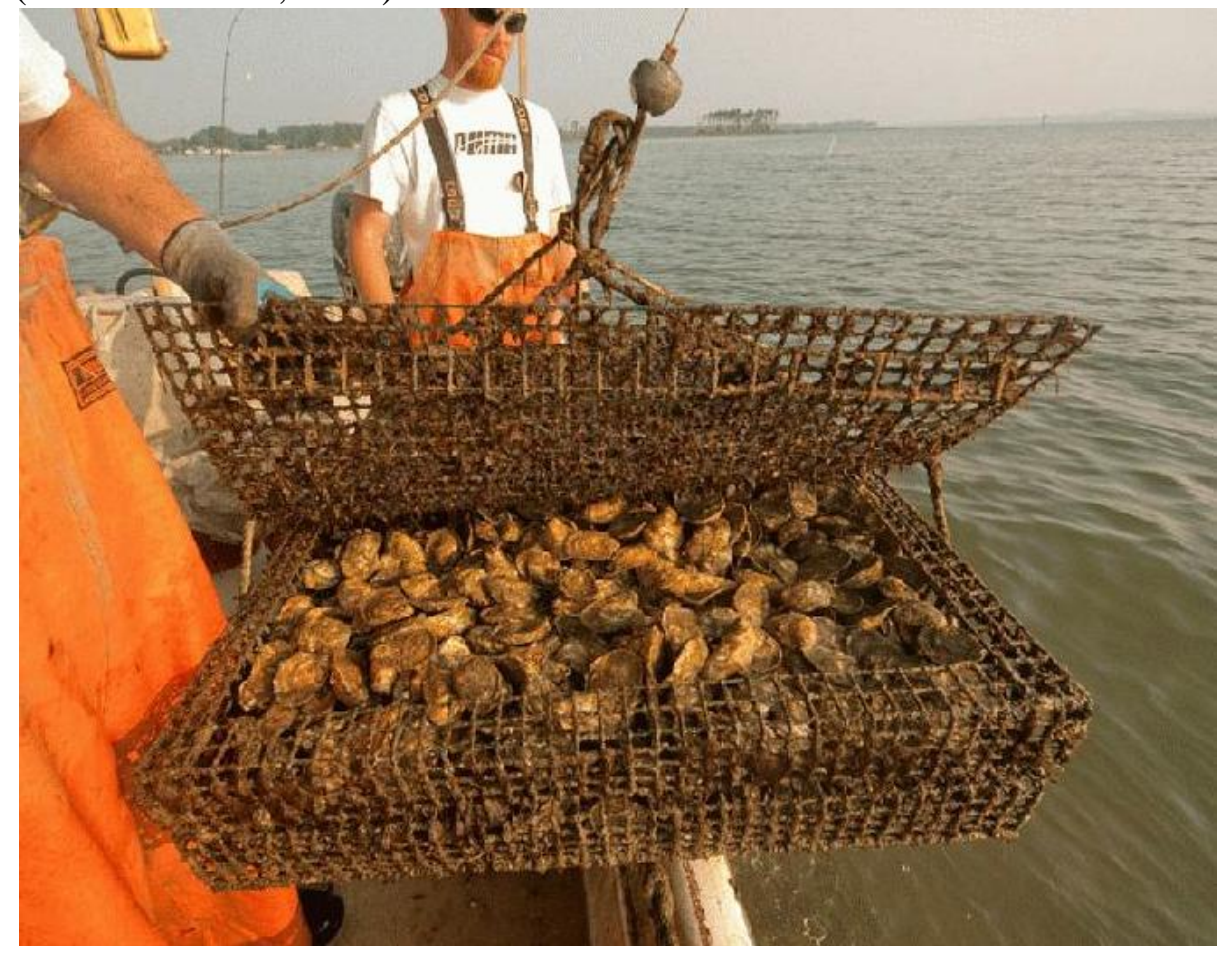

Floating Oyster Bags (Source: Cotuit Oysters, 2013) 


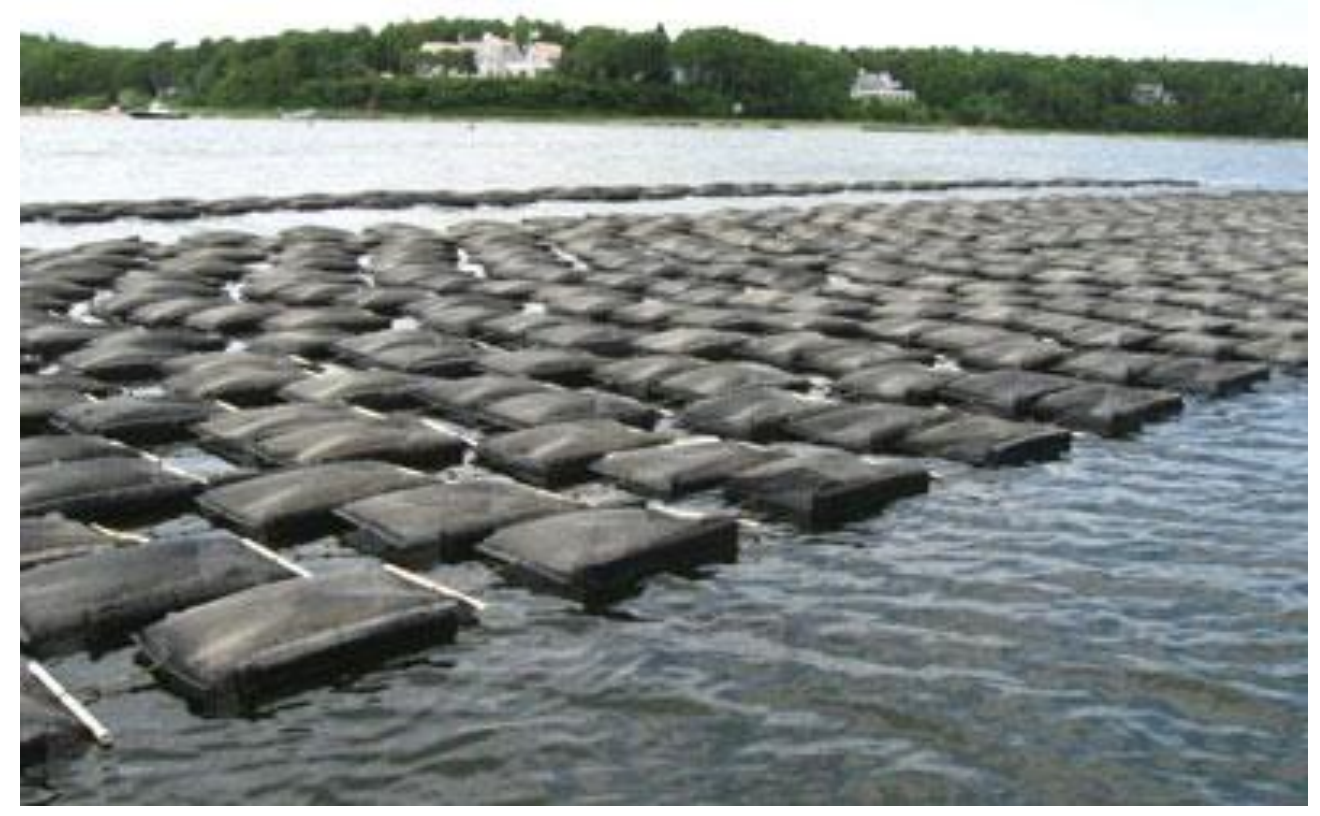

Mussel Culture Ropes (Source: Fisheries and Oceans Canada, 2011)

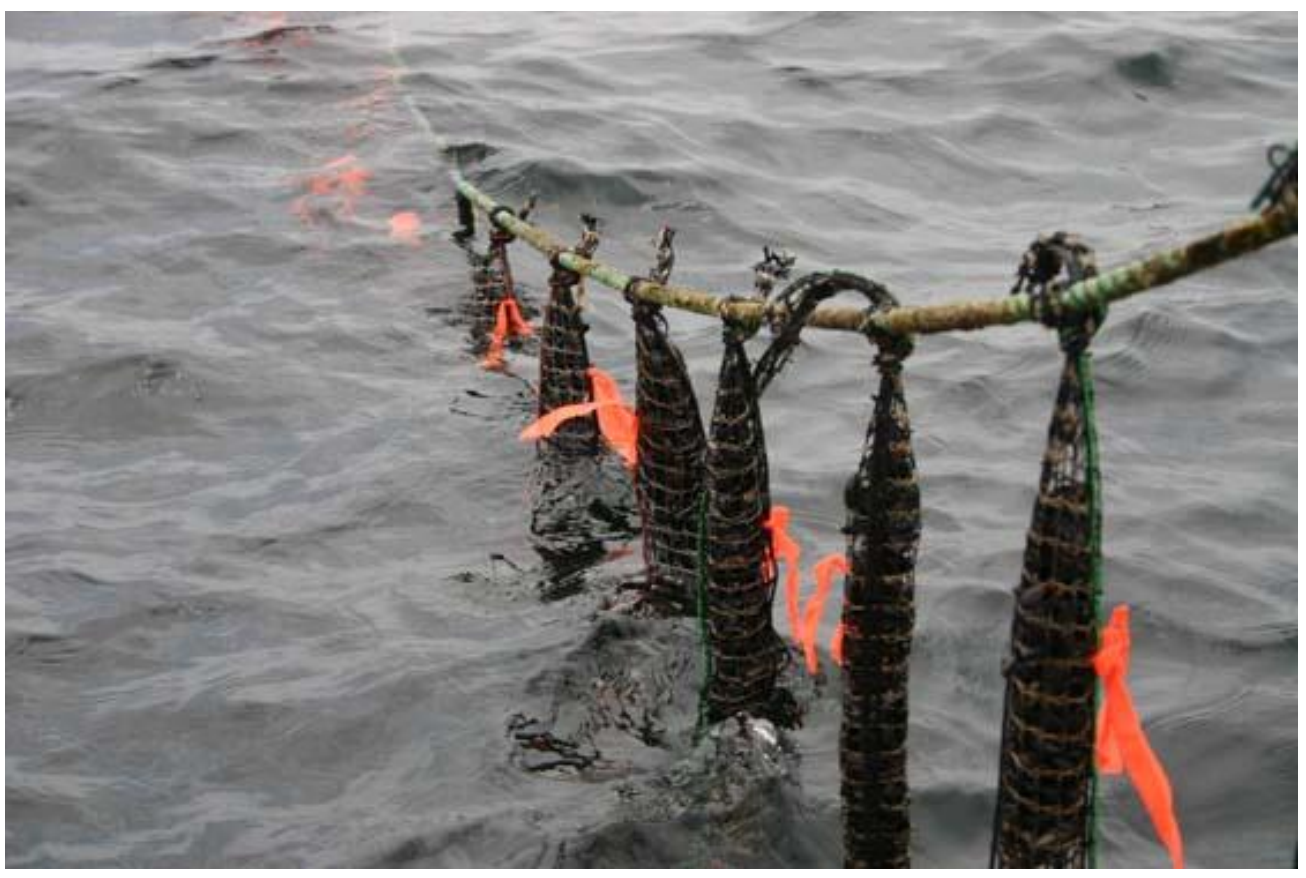




\section{Appendix B: Standards for selected aquaculture eco-labelling certification programs}

ACS Bivalve Standards (ACS, 2011)

Main Principles

- Obey the law and comply with all applicable legal requirements and regulations where farming operation is located.

- Avoid, remedy, or mitigate significant adverse effects on habitats, biodiversity, and ecological processes.

- Avoid adverse effects on the health and genetic diversity of wild populations.

- Manage disease and pests in an environmentally responsible manner.

- Use resources efficiently.

- Be a good neighbor and conscientious coastal citizen.

- Develop and operate farms in a socially and culturally responsible manner.

AquaGAP Standards (AquaGAP, 2010)

Main Principles

- Quality assurance (e.g. adherence to applicable laws, communication with stakeholders)

- Sites and facilities- management and maintenance (e.g. site selection, pest control)

- Aquaculture livestock- management and husbandry (e.g. hygiene and health, source and quality of juvenile stock)

- Environment- management and conservation (e.g. energy and water efficiency, environmental risk assessment)

- Recording system (e.g. traceability, product flow)

- Staff (e.g. occupational health and safety policy, social responsibility)

- Post harvest handling, processing, and marketing (e.g. cleaning, food safety)

- Marketing (e.g. logo use, export)

- Internal Control System (ICS)

Food Alliance Farmed Shellfish Standards (Food Alliance, 2012a)

Main Standard Areas

- Soil and water conservation, nutrient management (e.g. buffer strips/ sensitive habitats, water quality)

- Fish and wildlife habitat and biodiversity conservation (e.g. invasive species management, genetic integrity of native shellfish)

- Integrated pest, disease and weed management, and pesticide risk reduction (e.g. pesticide record keeping, predator management)

- Healthy and humane care for shell stock (e.g. disease prevention and management, carrying capacity management)

- Safe and fair working conditions (e.g. sanitation, employee benefits)

- Shared resource management (e.g. user relations, marine operations and navigation) 
Friend of the Sea (FOS, 2010)

Main Principles

- Management of a sustainable aquaculture installation (e.g. maintenance and control of infrastructure, preparation for environmental emergencies and response capability)

- Site location (e.g. EIA, access to fishing areas for coastal communities)

- Infrastructure (e.g. reduce escapes, avoid entry of other organisms)

- Fattening

- Feeding

- GMOs and growth hormones

- Disease prevention and the use of drugs

- Water and waste management

- Hazardous substances

- Energy management (e.g. energy records, calculate and reduce carbon footprints)

- Social accountability (e.g. minimum wage, child labor)

- Traceability

Global G.A.P. Aquaculture Standard (Global G.A.P., 2012a)

Main Principles

- Site management

- Reproduction

- Chemicals

- Occupational health and safety

- Fish welfare, management, and husbandry

- Harvesting

- Sampling and testing

- Feed management

- Pest control

- Environmental and biodiversity management

- Water usage and disposal

- Post-harvest- Mass balance and traceability

- Post-harvest- Operations

- Social criteria

*Global Aquaculture Alliance does not yet certify bivalves so their main certification principles were not included here. 


\section{Appendix C: Recruitment letter}

The University of Rhode Island

[Date]

Department of Marine Affairs

Kingston Coastal Institute

1 Greenhouse Road, Kingston, RI, 02881

[Participant Address]

Dear [Participant Name],

You have been selected to take part in a research project through the University of Rhode Island about aquaculture. Your name and address were obtained from Mr. Dave Beutel, Director of Aquaculture of the Coastal Resources Management Council (CRMC). Your experience with the aquaculture industry in Rhode Island will contribute a unique perspective to this research.

If you decide to take part in this study, you will be interviewed regarding your thoughts as they pertain to management strategies for shellfish aquaculture. The interview will last between 30 minutes and an hour, and will be recorded with your permission. Your participation in this study is voluntary, and you may decline to answer any question presented in the interview. If you choose to take part in the study, your participation and any information shared in the interview are confidential.

If you would like to participate in the study, please contact Nicole DeAngelis by phone at (856) 449-8104 or by email at ndeangelis89@gmail.com for more information and/or to schedule an interview. She will work with your schedule and come to meet you wherever is most convenient for you. Tracey Dalton, a University of Rhode Island professor, is advising this study.

Sincerely,

Nicole DeAngelis

Master of Marine Affairs candidate

College of the Environment and Life Sciences

University of Rhode Island

[Phone Number] [Email] 


\section{Appendix D: Follow-up postcard}

\section{RHODE ISLAND AQUACULTURE RESEARCH PROJECT REMINDER}

Dear participant,

About a month ago, you should have received a letter inviting you to take part in a study about aquaculture in Rhode Island.

If you have already had an interview, thank you for your participation. Your input has been extremely valuable in assessing current regulations and evaluating future aquaculture programs.

If you have not yet scheduled an interview, please do so as soon as possible. As an aquaculturist, your views are important and can only be considered if you participate with an interview.

If you have any questions or would like to schedule an interview, please contact me at the University of Rhode Island (856-449-8104 or ndeangelis89@ gmail.com).

Thank you,

Nicole DeAngelis 


\section{Appendix E: Interview questions}

1. Please tell me about your farm.

a. How much area does the farm cover?

b. How many leases do you own?

c. How long has the farm been in operation?

d. How many employees work on the farm? (Permanent, seasonal)

e. Do you have a hatchery, nursery, and/or grow-out?

2. What motivated you to become involved with aquaculture?

3. How long have you been involved with aquaculture?

4. Is aquaculture your primary occupation? $\mathrm{Y} \quad \mathrm{N}$

5. How far do you live from your farm? How often are you at your farm?

6. Tell me about the products raised on your farm.

a. What types of product(s) do you raise?

b. Have you always raised the same product(s)?

c. What method(s) do you use to culture your product?

d. Approximately how much seed do you get annually for each type of animal?

7.

a. A. Where are your products typically sold (in state or out of state or both)?

b. What types of buyers are you primarily selling to? (Wholesalers, markets, restaurants, directly to individual customers, etc.)

8. How is your product currently marketed?

a. What does the packaging look like?

b. Do you use any particular brand or catch phrases?

c. What methods of marketing do you use?

d. Do you talk directly to your buyers (or chefs) and give any details about the farm to try to sell your products?

e. If so, what types of qualities do you tell them about?

9. Please list any positive impacts you feel shellfish aquaculture has. Prompts: Environmental, economic, social

10. Please list any negative impacts you feel shellfish aquaculture has.

Prompts: Environmental, economic, social 
11. How do you think other shellfish farms in Rhode Island compare to yours in terms of environmental impact?

Do other farms have a: Significantly more negative environmental impact, more negative, the same, more positive, significantly more positive.

12. How do you think fishing for wild shellfish in RI compares to shellfish aquaculture in terms of environmental impact?

Does fishing for shellfish have a: Significantly more negative environmental impact, more negative, the same, more positive, significantly more positive.

13. Are you currently or have you ever been a member of any environmental organization? $\mathrm{Y} \quad \mathrm{N}$

14. Are you a member of: $\mathrm{Y} / \mathrm{N}$

a. The East Coast Shellfish Growers Association (ECSGA)

b. Ocean State Aquaculturists Association

c. A cooperative,

d. Any other groups related to shellfish aquaculture? List.

15. If YES to member of ECSGA, are you familiar with its Best Management Practices Manual? Y N

16. If YES, do you feel your operations abide by the Code of Conduct and meet the Best Management Practices listed in that manual? Y N

Read statement: For the rest of this interview, when I mention eco-labeling certification programs, I am referring to voluntary programs that certify aquaculture products or supply chains. These programs I am referring to can be developed by non-governmental organizations, public agencies, buyers, marketing groups or others, not programs developed solely by regulators or industry members. Aquaculturists who use these programs have their operations audited against specified criteria and if they meet those qualifications, can use the certification label or tell buyers they have the certification. Examples from other industries include the Marine Stewardship Council for wild fisheries and the Forestry Stewardship Council for timber.

17. Do you support these voluntary eco-labeling certification programs for aquaculture? Y N

a. Explain.

18. Are you aware of any eco-labeling certification programs for shellfish aquaculture? Y N If so, can you name any? 
19. What do you think public opinion is of aquaculture in Rhode Island?

a. What do you think public opinion is of aquaculture outside of Rhode Island?

b. What do you think public opinion is of shellfish aquaculture in particular?

20. Compared to public opinion of finfish aquaculture, is public opinion of shellfish aquaculture:

Significantly more negative, more negative, the same, more positive, or significantly more positive.

21. What feedback, if any, have you received from the local community, environmental groups, buyers, or government about your operations?

a. Do you feel these perceptions have changed at all over time (from when you first started v now)?

22. If you have received negative feedback from any of the groups, what have you done or plan to do to address their concerns?

a. Do you think certifying your products with an eco-label would help address the negative feedback?

23. Have you considered eco-labeling your products? Y N

a. Explain.

b. Do you plan to eco-label your products in the next 5 years? Y N Maybe

c. Next 10 years? Y N Maybe

24. If you were going to certify your products with an eco-label, how would you choose which label to use?

25. Do you feel there is a market for eco-labeled products? Y N

a. Explain.

26. Would you be more likely to certify your products if your competitors certified their products with an eco-label? Y N

a. Explain.

27. I'm going to state some factors that could influence your decision to become certified. For each factor, I'd like you to say whether you think it would be a disincentive to get certified or an incentive to get certified?

[Then: If participant responds: "incentive," ask further if they consider it a "strong incentive" or a " moderate incentive." If participant responds "disincentive," ask further if he/she considers it a "strong disincentive" or a "moderate disincentive"]. Have them explain.

a. Access to new markets 
b. Price premium for products

c. Recognition of sustainable practices

d. Differentiation from competitors

e. Pressure from environmental groups

f. Pressure from town or neighbors

g. Pressure from other growers

h. Price of certification

i. Recordkeeping for certification process

j. Time required for certification process

k. Effort required for certification process

1. Are there any other factors that could influence your decision that I did not mention?

28. Have you been asked by a buyer of your products to certify with an eco-label? Y $\mathrm{N}$ Explain.

a. If you are also a buyer, have you asked your producers to certify their products? $\mathrm{Y} \quad \mathrm{N}$ Explain.

29. Who do you think should be responsible for developing certification standards?

Prompt:

a. Local aquaculturists?, regulators?, scientists?, cooperatives?, NGOs? other)

30. Would you be more likely to certify your products if you were involved in developing the certification standards? Y N

31. Hypothetically, would you be willing to serve on a committee to develop standards? Y N

32. If certification costs $\$ 2,500$ annually, would you describe your willingness to participate as high moderate low or not at all?

33. If certification costs $\$ 5,000$ annually, would you describe your willingness to participate as high moderate low or not at all? 
34. If certification costs $\$ 7,500$ annually, would you describe your willingness to participate as high moderate low or not at all?

35. If certification costs $\$ 10,000$ annually, would you describe your willingness to participate as high moderate low or not at all?

36. [Recently Massachusetts aquaculturists developed a code of conduct and best management practices] How would you feel if Rhode Island decided to make adhering to Best Management Practices mandatory?

Strongly disapprove, disapprove, neutral, approve, strongly approve

37. Are you familiar with the Farm Fresh RI Program/ Get Fresh Buy Local Campaign? Y/N

a. Do you participate in that program? Y/N?

38. I'm going to ask you a list of questions about your thoughts on existing regulations in RI. Do you feel existing regulations in $\mathrm{RI}$ are sufficient for: $\mathrm{Y} \mathrm{N}$ for each

a. Promoting environmental quality

b. Encouraging innovation

c. Encouraging corporate responsibility

d. Reducing user conflicts

e. Preventing the spread of disease

39. Do you think certification programs can promote environmental quality beyond the scope of governmental regulation? $\mathrm{Y} \quad \mathrm{N}$

40. Are there other programs or alternatives that you can think of that would better encourage environmental quality in shellfish aquaculture other than using a label? 


\section{BIBLIOGRAPHY}

Albrecht, Don, Gordon Bultena, Eric Hoiberg, and Peter Nowak. "The New Environmental Paradigm Scale." The Journal of Environmental Education 13 (1982): 39- 43.

Alternative Farming Systems Information Center (AFSIC). "Federal Government Agencies." United States Department of Agriculture National Agriculture Library. (2013).

http://afsic.nal.usda.gov/aquaculture-and-soilless-farming/aquaculture/federalgovernment-agencies (accessed March 27, 2013).

Alves, David. Aquaculture in Rhode Island: 2007 Annual Status Report. Coastal Resources Management Council, Wakefield, 2007.

Anderson, James. A Strategic Plan for Rhode Island Aquaculture. Rhode Island Legislative Commission on Aquaculture (1998): 1- 170.

Aquaculture Stewardship Council (ASC). “Certified Farm.” (2013a). http://www.asc-aqua.org/index.cfm?act=tekst.item\&iid=4\&iids=204\&lng=1 (accessed January 4, 2013).

Aquaculture Stewardship Council (ASC). “Get Certified! Farms FAQs.” (2013b). http://www.ascaqua.org/index.cfm?act=tekst.item\&iid=4\&iids=256\&lng=1\#ggvxiuqykkoo (accessed January 6, 2013).

Aquaculture Stewardship Council (ASC). "ASC Bivalve Standard: Version 1.0.” (2011).

AquaG.A.P. “AquaG.A.P. Standard for Good Aquaculture Practices: Version 3.” (2010).

AquaG.A.P. "AquaG.A.P. Certified Operations: List of certified companies." AquaG.A.P. Certified Quality Sustainable Aquaculture. (2012). http://www.aquagap.net/operators.htm (accessed November 1, 2012).

Babbie, Earl. The Practice of Social Science Research. 12 ${ }^{\text {th }}$ ed. Belmont, CA: Wadsworth Cengage, 2010.

Bernard, H. Russell. Research Methods in Anthropology. $3^{\text {rd }}$ ed. Walnut Creek, CA: Altamira Press, 2002.

Beutel, David. Aquaculture in Rhode Island: 2011 Annual Status Report. Coastal Resources Management Council, Wakefield, 2011. 
Beutel, David. Personal Communication. CRMC Aquaculture Coordinator, March 2013.

Blackman, Allen, and Jorge Rivera. "Producer-Level Benefits of Sustainability Certification.” Conservation Biology 25, no. 6 (2010): 1176- 1185.

Blake, Megan, Jody Mellor, and Lucy Crane. "Buying Local Food: Shopping Practices, Place, and Consumption Networks in Defining Food as 'Local'." Annals of the Association of American Geographers 100, no. 2 (2010): 409426.

Blue Ocean Institute. "Seafood Guide." (2012). http://www.blueocean.org/seafood/seafood-guide (accessed April 10, 2012).

Boyd, Claude. "Guidelines for aquaculture effluent management at the farm-level." Aquaculture 226 (2003): 101- 112.

Bratt, Cecilia, Sophie Hallstedt, K.H. Robert, Goran Broman, and Jonas Oldmark. "Assessment of eco-labelling criteria development from a strategic sustainability perspective." Journal of Cleaner Production 19 (2011): 16311638.

Brecard, Dorothee, Boubaker Hlaimi, Sterenn Lucas, Yves Perraudeau, and Frederic Salladarre. "Determinants of demands for green products: An application to eco-label demand for fish in Europe." Ecological Economics 69 (2009): 115125.

Bundy, Alida, Ratana Chuenpagdee, Svein Jentoft, and Robin Mahon. "If Science is Not the Answer, What Is?." Frontiers in Ecology and the Environment 6, no. 3 (2008): 152-155.

Byron, Carrie, Jason Link, Barry Costa-Pierce, and David Bengtson. "Calculating ecological carrying capacity of shellfish aquaculture using mass-balance modeling: Narragansett Bay, Rhode Island.” Ecological Modeling 222 (2011): 1743- 1755.

Coastal Resources Management Council (RI CRMC). State of Rhode Island and Providence Plantations Guide to Aquaculture Lease Application. Wakefield, RI, 2012. http://www.crmc.ri.gov/applicationforms/AquaApp.pdf (accessed January 4, 2013).

Coastal Resources Management Council (RI CRMC). Rhode Island Coastal Resources Management Program. Providence, RI, 2010. http://www.crmc.ri.gov/regulations/RICRMP.pdf (accessed December 24, 2012). 
Collin, Robin, and Robert Collin. Encyclopedia of Sustainability Volume 2: Business and Economics. Santa Barbara, CA: Greenwood Press, 2010. 193-195.

Connolly, Matthew. "Thinking Globally, Acting Locally: Cleaning Up Global Aquaculture Through Eco-Labeling In the United States." Public Land and Resources Law Review 26 (2005): 121- 147.

Constance, Douglas, and Alessandro Bonanno. "Regulating the global fisheries: The World Wildlife Fund, Unilever, and the Marine Stewardship Council." Agriculture and Human Values 17 (2000): 125- 139.

Costa-Pierce, Barry. "Use of Ecosystems Science in Ecological Aquaculture.” Bulletin of the Aquaculture Association of Canada 103, no.2 (2003): 32- 40.

Costa-Pierce, Barry. “The 'Blue Revolution'- aquaculture must go green.” World Aquaculture 33 (2002).

Cotuit Oysters. "Oyster Grow-out Methods.” (2013). http://www.cotuitoystercompany.com/cotuit-oyster-grow-methods.asp (accessed February 6, 2013).

Crawford, Christine, Catriona Macleod, and Iona Mitchell. "Effects of shellfish farming on the benthic environment." Aquaculture 224 (2003): 117- 140.

Croke, Tom. Oyster Farm stock photo in "Oyster Farms Proposed to Clean Up Northport, NY.” Boating Local (2012). http://boatinglocal.com/news/oyster-farms-proposed-to-clean-up-northportny.html (accessed February 6, 2013).

Dahl, Richard. "Green Washing: Do you know what you're buying?.” Environmental Health Perspectives 118, no. 6 (2010): A246-A252.

Decanay, Kira. Public Perceptions of shellfish aquaculture in southern Rhode Island salt ponds. University of Rhode Island M.A. Thesis. 2010.

Dewey, William, Jonathan Davis, and Daniel Cheney. "Chapter 2: Shellfish Aquaculture and the Environment: An Industry Perspective." In Shellfish Aquaculture and the Environment. First ed. Oxford, UK: Wiley-Blackwell, 2011. 33- 50.

Dillman, Don, Jolene Smyth, and Leah Christian. Internet, mail, and mixed-mode survey: the tailored design method. $3^{\text {rd }}$ ed. Hoboken, NJ: John Wiley \& Sons, Inc, 2009.

Dunlap, Riley. "The New Environmental Paradigm Scale: From Marginality to Worldwide Use." Journal of Environmental Education 40, no. 1 (2008): 3-18. 
Dunlap, Riley, and Kent Van Liere. “The New Environmental Paradigm: A Proposed Measuring Instrument and Preliminary Results.” Journal of Environmental Education 9 (1978): 10- 19.

Dunlap, Riley, Kent Van Liere, Angela Mertig, and Robert Jones. "Measuring Endorsement of the New Ecological Paradigm: A Revised NEP Scale." Journal of Social Issues 56, no. 3 (2000): 425- 442.

East Coast Shellfish Growers Association (ECSGA). "By-Laws." (2010). http://www.ecsga.org/Pages/About\%20Us/bylaws2010.pdf (accessed February 1, 2012).

East Coast Shellfish Growers Association (ECSGA). "Our Members.” (2011). http://www.ecsga.org/Pages/About\%20Us/members.htm (accessed February 1, 2012).

Eilperin, Juliet. "Environmental certification becoming a battleground." Washington Post A.4 May (2010).

Enchanted Learning. "Rhode Island Map.' http://www.enchantedlearning.com/usa/states/rhodeisland/map.GIF (accessed November 7, 2012).

Environmental Defense Fund (EDF). "Wegmans Adopts New Standards for Buying Farmed Shrimp: Partnership with Environmental Defense to promote rigorous standards for nation's most popular seafood." (2007). http://apps.edf.org/pressrelease.cfm?contentID=7285 (accessed April 10, 2012).

Environmental Law Institute (ELI) and The Ocean Foundation. Gold Standard for Sustainable Aquaculture Ecolabel Design: Technical Report, 2008.

Farm Fresh Rhode Island. “About Farm Fresh Rhode Island.” (2012). http://www.farmfreshri.org/about/about.php (accessed October 31, 2012).

Farm Fresh Rhode Island. "Local Food Guide to Rhode Island: Seafood." (2013). http://www.farmfresh.org/food/foodcategory.php?foodtype=7\&zip=02909 (accessed January 4, 2013).

Fisheries and Oceans Canada. "Canadian Aquaculture R\&D Review 2011." http://www.dfo-mpo.gc.ca/science/enviro/aquaculture/rd2011/rdshellfishmollusques-eng.html (accessed February 6, 2013).

Flimlin, Gef, Sandy Macfarlane, Edwin Rhodes, and Kathleen Rhodes. "Best Management Practices for the East Coast Shellfish Aquaculture Industry." East Coast Shellfish Growers Association, 2010. 
Food Alliance. "Fees for Producer Certification." (2013).

http://foodalliance.org/certification/producer/fees (accessed January 24, 2013).

Food Alliance. "FA Sustainability Standard for Farmed Shellfish Operations." (2012a). http://foodalliance.org/shellfish/FA-SS-03-Shellfish-Final2012.pdf (accessed January 1, 2013).

Food Alliance. "Food Alliance Certified Products." (2012b). http://foodalliance.org/files/FoodAllianceCertified-Products2012.pdf (accessed April 10, 2012).

Food and Agriculture Organization of the United Nations (FAO). The State of World Fisheries and Aquaculture. Fisheries and Aquaculture Department of the United Nations, 2012. 1-46; 181- 186.

Food and Agriculture Organization of the United Nations (FAO). Private Standards and certification in fisheries and aquaculture: Current practice and emerging issues. No. 533. Rome, 2011a.

Food and Agriculture Organization of the United Nations (FAO). Technical Guidelines on Aquaculture Certification. $29^{\text {th }}$ Session of Committee on Fisheries, Rome, 2011b.

Food and Agriculture Organization of the United Nations (FAO). Revised Draft Technical Guidelines on Aquaculture Certification. 2010.

Food and Agriculture Organization of the Untied Nations (FAO). FAO Technical Guidelines for Responsible Fisheries. No. 5 Rome, 1997.

Frankic, Anamarija, and Carl Hershner. "Sustainable aquaculture: developing the promise of aquaculture." Aquaculture International 11, no. 6 (2003): 517-530.

Friend of the Sea (FOS). "Certified Products." (2013). http://www.friendofthesea.org/certified-products.asp (accessed January 4, 2013).

Friend of the Sea (FOS). "Frequently Asked Questions." (2013b). http://www.friendofthesea.org/faq.asp (accessed January 6, 2013).

Friend of the Sea (FOS). "Friend of the Sea Certification Criteria Checklist for Aquaculture Production: Marine Aquaculture.” (2010). http://www.friendofthesea.org/public/page/en\%20$\% 20$ checklist\%20fos\%20marine\%20aquaculture.pdf (accessed January 4, 2013). 
Fx-rate.net. "Euro to Dollar Conversion Table on Thu, 24 January, 2013." (2013). http://fx-rate.net/EUR/USD/ (accessed January 24, 2013).

Gibbs, Mark. "Sustainability performance indicators for suspended aquaculture activities.” Ecological Indicators 7 (2007): 94- 107.

Giovannucci, Daniele, and Stefano Ponte. "Standards as a new form of social contract? Sustainability initiatives in the coffee industry." Food Policy 30 (2005): 284- 301.

Glaser, Barney, and Anselm Strauss. The Discovery of Grounded Theory: strategies for qualitative research. 1967. Reprint, Chicago, IL: Aldine Pub. Co., 2009.

Global Aquaculture Alliance (GAA). "BAP Standards.” (2011). http://www.gaalliance.org/bap/standards.php (accessed April 10, 2012).

Global G.A.P. "Control Points and Compliance Criteria.” Integrated Farm Assurance: Aquaculture Module. Ed 4.0-1, (2012a).

Global G.A.P. "Producer/Supplier Members.” (2012b). http://www2.globalgap.org/members.html?memtype=supplier (accessed February 1, 2012).

Global G.A.P. “General Global G.A.P. North America Producer Fee Table.” (2011). http://www1.globalgap.org/north-america/upload/Fee_Tables/12-0924_Producer_Fee_Table_2011_GGNA.pdf (accessed January 6, 2013).

Goldburg, Rebecca, Matthew Elliott, and Rosamond Naylor. Marine Aquaculture in the United States: Environmental Impacts and Policy Options. Pew Oceans Commission, 2001.

Gosling, Elizabeth. Bivalve Molluscs: Biology, Ecology, and Culture. Oxford, UK: Fishing News Books (Blackwell Publishing), 2003.

"Guidelines for the Use of Environmental Marketing Claims, Final Rule," Title 16 Code of Federal Regulations, Pt. 260. 2012. http://www.gpo.gov/fdsys/pkg/CFR-2012-title16-vol1/pdf/CFR-2012-title16vol1-part260.pdf (accessed January 5, 2013).

Gulbrandsen, Lars H. "Accountability Arrangements in Non-State Standards Organizations: Instrumental Design and Imitation." Organization 15, no. 4 (2008): 563- 583.

Gulbrandsen, Lars H. "Mark of Sustainability?: Challenges for Fishery and Forestry Eco-labeling." Environment 47, no. 5 (2005): 8- 23. 
Hargreaves, John. "Chapter 3: Molluscan shellfish aquaculture and best management practices." In Shellfish Aquaculture and the Environment. First ed. Oxford, UK: Wiley-Blackwell, 2011. 51- 80.

Hicks, Robert, and Kurt Schnier. "Eco-labeling and dolphin avoidance: a dynamic model of tuna fishing in the eastern Tropical Pacific." Journal of Environmental Economics and Management 56, 2008: 103-116.

Intergovernmental Panel on Climate Change (IPCC). Climate change 2007: The AR4 Synthesis Report. [R.K. Pachauri and A. Reisinger (Eds.)]. Geneva: IPCC, 2007. http://www.iucnredlist.org/details/41712/0 (accessed December 26, 2012).

International Organization for Standardization (ISO). "Environmental management. The ISO 14000 family of International Standards." (2009). http://www.iso.org/iso/theiso14000family_2009.pdf (accessed January 8, 2013).

Interstate Shellfish Sanitation Conference (ISSC). "National Shellfish Sanitation Program: Guide for the Control of Molluscan Shellfish." U.S. Food and Drug Administration, 2007.

Johnson, Nicholas, and A. Bryan Endres. "Small Producers, Big Hurdles: Barriers Facing Producers of 'Local Foods'.” Journal of Public Law and Policy 33 (2011): 49- 122.

Johnston, Robert, Cathy Wessells, Holger Donath, and Frank Asche. "Measuring Consumer Preferences for Ecolabeled Seafood: An International Comparison." Journal of Agricultural and Resource Economics 26, no. 1 (2001): 20- 39.

Kaiser, M.J., I. Lang, S.D. Utting, and G.M. Burnell. "Environmental Impacts of Bivalve Mariculture.” Journal of Shellfish Research 17, no. 1 (1998): 59 - 66.

Kempton, Willett, James Boster, and Jennifer Hartley. Environmental Values in American Culture. Cambridge, MA: MIT Press, 1995.

Kobell, Rona. "VA, MD to reduce hurdles to oyster aquaculture." Chesapeake Bay Journal (2011).

http://www.bayjournal.com/article/va_md_working_to_reduce_hurdles_to_oys ter_aquaculture (accessed February 6, 2013).

Lee, Daniel. "Chapter 5: Aquaculture Certification." Ed. by Trevor Ward and Bruce Phillips. In Seafood Ecolabelling: Principles and Practice. Oxford, UK: Wiley- Blackwell, 2008. 106- 133. 
Martinez, Steve, Michael Hand, Michelle Da Pra, Susan Pollack, Katherine Ralston, Travis Smith, Stephen Vogel, Shellye Clark, Luanne Lohr, Sarah Low, and Constance Newman. Local Food Systems: Concepts, Impacts, and Issues, ERR 97, U.S. Department of Agriculture, Economic Research Service, 2010.

Mintel GNPD and Mintel Oxygen Reports. "Local produce edging out organic in importance among consumers.” Mintel Press Release Mar (2012).

Monterey Bay Aquarium. "Monterey Bay Aquarium Seafood Watch: Oysters." (2013). http://www.montereybayaquarium.org//cr/SeafoodWatch/web/sfw_factsheet.as px? gid=40 (accessed January 22, 2013).

Monterey Bay Aquarium. "Monterey Bay Aquarium Seafood Watch Seafood Search." (2012). http://www.montereybayaquarium.org/cr/SeafoodWatch/web/sfw_factsheet.as px (accessed April 10, 2012).

Monterey Bay Aquarium. "Seafood Watch Seafood Report: Farmed Oysters." (2007). http://www.montereybayaquarium.org/cr/cr_seafoodwatch/content/media/MB A_SeafoodWatch_FarmedOysters.pdf (accessed January 22, 2013).

National Oceanic and Atmospheric Administration (NOAA). "Farmed Seafood." FishWatch (2013a). http://www.fishwatch.gov/farmed_seafood/index.htm (accessed January 8, 2013).

National Oceanic and Atmospheric Administration (NOAA). "Seafood Profiles." FishWatch (2013b). http://www.fishwatch.gov/seafood_profiles/index.htm (accessed January 8, 2013).

National Oceanic and Atmospheric Administration (NOAA). "What is FishWatch?" FishWatch. (2013c).

http://www.fishwatch.gov/about/index.htm (accessed January 8, 2013).

National Oceanic and Atmospheric Administration (NOAA). Marine Aquaculture Policy, 2011.

http://www.nmfs.noaa.gov/aquaculture/docs/policy/noaa_aquaculture_policy_ 2011.pdf (accessed December 26, 2012).

Nealon, Cory. “Oyster aquaulture thrives, but consequences loom.” Daily Press (2011). http://articles.dailypress.com/2011-04-03/news/dp-nws-cp-aquaculture-one20110402_1_virginia-seafood-council-asian-oyster-oyster-farming (accessed February 6, 2013). 
NOAA Fisheries. "NOAA Fisheries Aquaculture Image Gallery." (2013). http://www.nmfs.noaa.gov/gallery/images/category/aquaculture.html (accessed February 6. 2013).

Ocean State Shellfish Cooperative (OSSC).“About the Cooperative.” (2012a). http://www.oceanstateoysters.com/About-the-Cooperative.html (accessed October 31, 2012).

Ocean State Shellfish Cooperative (OSSC). "Our Mission.” (2012b). http://www.oceanstateoysters.com/Mission.html (accessed October 31, 2012).

Olin, Paul; J.R. Tomasso (editor). "Chapter 7: Environmental Interactions of Bivalve Shellfish Aquaculture." In Aquaculture and the Environment in the United States. Baton Rouge, LA: US Aquaculture Society, A Chapter of the World Aquaculture Society, 2002. 141- 154.

Parkes, G., J. Young, S. Walmsley, R. Abel, J. Harman, P. Horvat, A. Lem, A. MacFarlane, M. Mens, and C. Nolan. "Behind the Signs- A Global Review of Fish Sustainability Information." Reviews in Fisheries Science 18, no. 4 (2010): 344- 356.

Pelletier, Nathan, and Peter Tyedmers. "Life Cycle Considerations for Improving Sustainability Assessments in Seafood Awareness Campaigns." Environmental Management 42 (2008): 918- 931.

Peterson, C., et al. Ecosystem Concepts for Sustainable Bivalve Mariculture. Washington D.C.: The National Academies Press, 2010.

Phillips, Bruce, Trevor Ward, and Chet Chaffee. Eco-labelling in Fisheries: What is it all about?. Oxford, UK: Wiley-Blackwell, 2003.

Poortinga, Wouter, Linda Steg, and Chares Vlek. "Values, Environmental Concern, and Environmental Behavior: A Study into Household Energy Use." Environment and Behavior 36 (2004): 70- 93.

Quayle, D.B., and G.F. Newkirk. "Farming Bivalve Molluscs: Methods for Study and Development." In Advances in World Aquaculture Volume 1. Baton Rouge, LA: The World Aquaculture Society, 1989.

Ramachandran, A. "Ecolabeling and Green Certification for Effective Fisheries Management- An Analysis." World Academy of Science, Engineering and Technology 65 (2010): 763- 775.

Rhode Island Aquaculture Initiative. Rhode Island Aquaculture Initiative: A Shared Vision for the Future. Rhode Island Sea Grant, Narragansett, RI, 2004. 
Rhode Island Department of Environmental Management (RI DEM). Aquaculture of Marine Species in Rhode Island Waters. State of Rhode Island and Providence Plantations, 2002.

http://www.dem.ri.gov/pubs/regs/regs/fishwild/aquacult.pdf (accessed October 31, 2012).

Rhode Island Sea Grant. "Rhode Island Shellfish Management Plan.” (2013). http://seagrant.gso.uri.edu/seafood/shellfish_mgmt_plan.html (accessed January 29, 2013).

Rhode Island Sea Grant. "Watersheds Map." Rhode Island South Shore Sea Grant Project. (2012).

http://seagrant.gso.uri.edu/coasts/wtrshdmap.jpg (accessed November 7, 2012).

Shumway, Sandra, Christ Davis, Robin Downey, Rick Karney, John Kraeuter, Jay Parsons, Robert Rheault, and Gary Wikfors. "Shellfish aquaculture- In praise of sustainable economies and environments." World Aquaculture 34, no. 4 (2003).

Sparks, Laura. Ninigret Aquaculture Lease Sites. CRMC, Unpublished Data. 2012.

Stern, Paul. "Toward a Coherent Theory of Environmentally Significant Behavior." Journal of Social Issues 56, no. 3 (2000): 407-424.

Sutton, Michael, and Laura Wimpee. "Chapter 20: Towards Sustainable Seafood: The Evolution of a Conservation Movement." Ed. by Trevor Ward and Bruce Phillips. In Seafood Ecolabelling: Principles and Practice. Oxford, UK: Wiley- Blackwell, 2008. 403- 415.

Teisl, Brian Roe, and Robert Hicks. "Can Eco-Labels Tune a Market? Evidence from Dolphin- Safe Labeling." Journal of Environmental Economics and Management 43 (2002): 339- 359.

Terrachoice. The Sins of Greenwashing, Home and Family Edition: A Report on Environmental Claims Made in the North American Consumer Market. 2010. http://sinsofgreenwashing.org/index35c6.pdf (accessed January 5, 2013).

Thrane, Mikkel, Friederike Ziegler, and Ulf Sonesson. "Eco-labelling of Wild-Caught Seafood Products." Journal of Cleaner Production 17 (2009): 416- 423.

United States Census Bureau (US Census). "2010 Census: Rhode Island Profile." 2010. http://www.census.gov/geo/www/guidestloc/pdf/44_RhodeIsland.pdf (accessed October 3, 2012). 
United States Department of Agriculture (USDA). "National Organic Program." USDA Agricultural Marketing Service. (2012a).

http://www.ams.usda.gov/AMSv1.0/nop (accessed November 6, 2012).

United States Department of Agriculture (USDA). "Organic Aquaculture." USDA National Agricultural Library. (2012b).

http://afsic.nal.usda.gov/aquaculture- and-soilless-farming/aquaculture/organicaquaculture. (accessed November 6, 2012).

United States Department of Agriculture (USDA). "Value of Farm Land and Buildings." 2007 Census of Agriculture, 2007. http://www.agcensus.usda.gov/Publications/2007/Online_Highlights/Fact_She ets/Economics/land_values.pdf (accessed October 30, 2012).

United States Department of Agriculture (USDA) and National Agricultural Statistics Service (NASS). "Census of Aquaculture 2005" 2002 Census of Agriculture 3, Special Studies part 2, 2006.

United States Environmental Protection Agency (US EPA). Environmental Labeling Issues, Policies, and Practices Worldwide. Office of Prevention, Pesticides, and Toxic Substances, Washington D.C., 1998. 1- 66.

United States Geological Survey (USGS). "America's Volcanic Past: Rhode Island." USGS/ Cascades Volcano Observatory, Vancouver, Washington. 2003. http://vulcan.wr.usgs.gov/LivingWith/VolcanicPast/Places/volcanic_past_rhod e_island.html (accessed December 24, 2012).

University of Florida. "Online Resource Guide for Florida Shellfish Aquaculture." UF Shellfish Extension Office, SeaGrant Florida. 2012.

http://shellfish.ifas.ufl.edu/industry.html\#Background (accessed December 24, 2012).

Ward, Trevor. "Barriers to biodiversity conservation in marine fishery certification." Fish and Fisheries 9 (2008): 169-177.

Wegmans. "Seafood Sustainability: Product Chart." http://www.wegmans.com/webapp/wcs/stores/servlet/ProductDisplay?storeId= $10052 \&$ catalogId=10002\&langId=-1\&partNumber=UNIVERSAL_17270 (Accessed January 4, 2013).

Weise, Andrea, Chris Cromey, Mryiam Callier, Philippe Archambault, Jon Chamberlain, and Chistopher McKindsey. "Shellfish-DEPOMOD: Modelling the biodeposition from suspended shellfish aquaculture and assessing benthic effects." Aquaculture 228 (2009): 239- 253. 
Wessells, Cathy, Robert Johnston, and Holger Donath. "Assessing Consumer Preferences for Ecolabeled Seafood: The Influences of Species, Certifier, and Household Attributes." American Journal of Agricultural Economics 81, no. 5 (1999): 1084- 1089.

Whole Foods Market. “Aquaculture.” (2013).

http://www.wholefoodsmarket.com/mission-values/seafoodsustainability/aquaculture (Accessed January 4, 2013).

World Commission on Environment and Development (WCED), "Our Common Future." (1987). 